\title{
Abstracts of the 6th International Academic Medical Congress of Maranhão (VI COIMAMA) 2019
}

01. PHOTOPROTECTION AND SELF-EXAMINATION OF THE SKIN: USE OF SMARTPHONE AS AN EDUCATION TOOL

Ana Beatriz Costa Brito; Brenna Carolina Sousa Braga; Ricardo Tadeu Villa.

Universidade Federal do Maranhão (UFMA)

INTRODUCTION: "mobile health" or "mHealth" can be defined as a rapid transfer of information about health, using smartphones or other devices. This concept was applied to observe its impacts on the habits of photoprotection and self-examination of the skin. METHODOLOGY: experimental study, carried out in a basic health unit of São Luis, Maranhão. 300 users were interviewed during 4 weeks in July 2018. In the first moment, SEPI (Sun Exposure and Protection Index) and SSEAS (Self Skin Examination Attitudes Scale) questionnaires were used to evaluate the habits of photoprotection and self-examination and it was also performed an oral presentation, supported by image, about the subject. After randomization, 150 users received 2 WhatsApp educational messages weekly for a period of 8 weeks. At the end, all 300 users received links, via WhatsApp, to the same questionnaires. RESULTS: SEPI 1, SEPI 2 and SSEAS final scores improved in both groups $(p<0.05)$ compared to initial ones. As for photoprotection, inicially, $39.66 \%$ of customers said they used sunscreen always or frequently. In intervention group, this habit ascended to $47.91 \%$ and no change was observed in control group. With regard to selfexamination, $92.33 \%$ considered it was important since the beginning of the research and this number remained stable. However, inicially, only $48.67 \%$ considered self-examination a priority and this percentage increased to $73.91 \%$ in the control group and $69.8 \%$ in the intervention group, without difference between groups. CONCLUSION: initially, less than half of the sample used photoprotection always or frequently and, even after an improvement at the end of 8 weeks, this habit remained below ideal. As for self-examination of the skin, after 8 weeks, it has turned into a priority for two-thirds of users. Nonetheless, it was not possible to stablish that the results were superior in the group that received educational messages via Whatsapp.

TREATMENT OF PATIENTS WITH CARPAL TUNNEL SYNDROME IN THE HUUFMA PAIN AMBULATORY

José Estevam Ribeiro Júnior: Vinicius Conçalves Melo; Daniel Victor Viana Rodrigues Nunes; Luiza Sousa Soares; João Batista Santos Garcia; Thiago Alves Rodrigues; Rayanne Luiza Tajra Mualem de Araujo

Universidade Federal do Maranhão - UFMA

INTRODUCTION: Carpal tunnel syndrome (CTS) is the most common involvement among peripheral nerve compressions, whose management involves multiple drugs, such as gabapentinoides and tricyclic antidepressants (TCA), in addition to non-pharmacological interventions. This study aims to describe how a reference center in pain in São Luís-MA conducts CTS treatment and patients' response to prescribed therapy. METHODS: We evaluated 32 medical records of patients diagnosed with CTS, attended at the Chronic Pain Outpatient Clinic of the University HospitalUFMA, between January 2012 and March 2019. The variables collected were: pain location and intensity, associated symptoms, pharmacological and non-pharmacological treatment, drug response and adherence to the therapy instituted. RESULTS: The rate of adherence to pharmacological treatment was $59.37 \%$, while non-pharmacological treatment was $65.65 \%$, with financial conditions (50\%) and side effects $(50 \%)$ being the main causes of non-adherence. In the last consultations, gabapentinoides, weak opioids and NSAIDs were the most prescribed. CONCLUSION: Gabapentinoides were the most commonly prescribed medications in the initial treatment, associated or not with other drugs. Most patients reported improvement with the proposed treatment. However, better adherence rates to pharmacological treatment and rehabilitation therapies could reflect better pain control.

03. EPIDEMIOLOGICAL PROFILE OF VIRAL MENINGITIS IN THE STATE OF MARANHÃO IN THE LAST 10 YEARS

Nathacha adriela lima carvalho; Amanda de carvalho Nogueira Thiara Araújo Fernandes Ribeiro; Angela Falcai Centro Universitário do Maranhão (CEUMA)

INTRODUCTION: Viral meningitis is caused by an inflammatory process that affects the meninges, especially the subarachnoid space, which can affect both cranial and spinal cord follow-up. The main etiological agent is enterovirus ( $80 \%$ ). OBJECTIVE: To analyze the epidemiological profile of viral meningitis in Maranhão from January 2008 to June 2019. METHODS: This is a descriptive epidemiological study with a quantitative approach based on data from the DATA-SUS / TABNET database. of SUS hospital morbidity by place of residence of the state of Maranhão, from January 2008 to June 2019. Statistical data analyzes were performed using GraphPad Prism 7.0 software. RESULTS: During this period, a total of 11,992 cases of viral meningitis were reported in Brazil. In the state of Maranhão, 983 cases were registered, with the most prevalent cities: Timon with 216 cases, Caxias 119 cases and Codó 60 cases. The age group with the largest number of cases was 5 to 9 years with 185, with the highest incidence of notifications in 2009 with 232 cases. On the other hand, of this total, 45 deaths were reported. CONCLUSION: Over the past 10 years the number of cases of viral meningitis has declined. Thus, it demonstrates the relevance of continuing education through public policies related to health education aiming at the prevention and awareness of the population about the risks and forms of contagion.

04 .

\section{NEUROPATHIC PAIN IN PATIENT WITH NEUROFIBROMATOSIS DIAGNOSIS} 1- CASE REPORT

Vanessa Vieira Pinheiro; Beatriz Morais Costa; Vinícius Conçalves Melo; William Sousa Moura; João Batista Santos Garcia; Thiago Alves Rodrigues; Rayanne Luiza Tajra Mualem De Araujo UNIVERSIDADE FEDERAL DO MARANHÃO (UFMA)

BACKGROUND: Neurofibromatosis 1, also called von Recklinghausen's disease, is a genetic and multisystem disorder that can be characterized by multiple café au lait spots, freckled nerve and skin tumours (neurofibromas) in the axillary or inguinal region, and nodules Lisch. The objective of this study was to describe the condition of a patient with a previous diagnosis of Neurofibromatosis 1 who was admitted to an emergency department, referring neuropathic abdominal pain, in addition to a concomitant infectious condition. CASE DESCRIPTION: Male patient, 10 years old, previous diagnosis of neurofibromatosis 1; referred to the Chronic Pain service Clinic of the University Hospital of the Federal University of Maranhão (HUUFMA), by another service where he was hospitalized for 20 days with acute, continuous, severe pain, with burning in left hemothorax and abdomen, associated with fever and respiratory symptoms. On physical examination, she presented deep palpation pain in the hypogastric region and on the left flank. No visceromegaly. He was on treatment for bronchopneumonia, with improvement, but still with pain in the abdomen. The hypothesis of the 
acute inflammatory abdomen was raised, however, computed tomography of the abdomen presented only nodules in the spinal roots of the thoracolumbar and lumbosacral region, suggesting neurofibroma. As a treatment, treatment with nortriptyline $10 \mathrm{mg}$ at night, with acetaminophen and tramadol was started in case of severe pain. Two months after the beginning of treatment, the patient returned to the HUUFMA pain service clinic, reporting complete remission of abdominal pain. CONCLUSION: In patients diagnosed with Neurofibromatosis 1, investigating the presence of neurofibromas is essential for early elucidation of the pain cause. Treatment with tricyclic antidepressants, considering the neuropathic component of pain, was satisfactory and with good response.

\section{COMPARATIVE ANALYSIS OF QUALITY OF LIFE BETWEEN ELDERLY} SEDENTARY AND ASSETS

Vanessa Alves de Sousa; Áthila Gabriele Ferreira da Silva; Diego de Sousa Silva; Rossana Vanessa Dantas de Almeida Marques; Cecilma Miranda de Sousa Teixeira

Universidade Federal do Maranhão - UFMA

INTRODUCTION: Aging is a natural process that makes the individual susceptible to physical and psychosocial problems. Therefore, the practice of physical activity is recommended because it provides the elderly with a good Quality of Life (QOL). Thus, the objective was to analyze the impact of physical activity on the quality of life of the elderly. METHODS: The research used the quantitative method, descriptive, observational, field and transverse, whose sampling was non-probabilistic for convenience. A biosocial characterization questionnaire and Whogol-bref questionnaire were used to conduct the interviews. 80 interviews were conducted with elderly people at the Nova Imperatriz Basic Health Unit of the city of Imperatriz - MA who agreed to participate in the study by signing the Informed Consent Form. Then, the data were analyzed using the Statistical Package for Social Sciences Software. RESULTS: It was observed that $55 \%$ of participants were female and the average age was 67.9 years $( \pm 5.9)$. Health was classified as "good" by most active elderly (43.1\%) and "poor" by sedentary $(58.3 \%), 55 \%$ of the elderly were active, and of these, $54.5 \%$ had QOL "Very good", while $41.7 \%$ of sedentary people had "good" QoL (chisquare: $\mathrm{p}<0.01$ ). In the Whoqol-bref questionnaire, the domain that most compromised the QOL of the elderly was "Social Relations" with an average score of 4.1. The domain that most compromised QOL of sedentary elderly was "Physical" with an average score of 3.5. CONCLUSION: It was noticed that the QOL of sedentary and active elderly was classified as "good" and "very good", respectively. However, it was analyzed that the active elderly obtained a higher score on the Whogol-bref questionnaire, thus having a better QoL compared to sedentary elderly.

\section{ROUTE LARGE PARIETAL ENCEFALOCELE IN NEWBORN WITH} MICROCEPHALY: A REPORT

Gabriela Coutinho Amorim Carneiro; Cláudio Avila Duailibe Mendonça; Gabriel Costa Ferreira Andrade; Gloria Maria Grangeiro Ferreira; Amanda Angelo Pinheiro; Maria Eduarda Andrade e Andrade; Benedito Sabbak Thome Junior

Centro de Ensino Universitário do Maranhao (CEUMA)

INTRODUCTION: Encephalocele, a malformation that affects $1 / 10,000$ individuals, is a defect in neural tube closure characterized by herniation of the brain and meninges by openings found in the skull as an embryo. Its main symptoms include seizures, delayed mental development and cerebrospinal fluid accumulation in the brain. Its main cause or prophylaxis is not yet known, but it is believed that this disease is related to the use of teratogenic substances, besides low socioeconomic development. The only way to stop symptoms is the surgical approach, which should be performed during childhood, being the treatment of choice, both due to the improvement of deficits and the low risk of injury. It is worth remembering that the biggest aggravating factor is the lack of information, being the role of health professionals to inform the population about the ideal behaviors in pregnancy and their advantages. CASE DESCRIPTION: Newborn (RN) hypocolored and with respiratory distress, is admitted, severe, in a neonatal intensive care unit (ICU). Presents encephalocele associated with microcephaly. After clinical diagnosis, the hospitalization process was initiated and, immediately after, a magnetic resonance imaging of the skull was requested to identify the degree of the lesion. Until surgery, his condition remained severe, despite the stabilization of vital signs and the use of antibiotic therapy. CONCLUSION: Corrective surgery was performed and there was a progressive evolution and improvement of clinical condition, without complications, except for slight respiratory distress, treated during hospitalization with nebulization and respiratory physiotherapy. The patient recovered well and was discharged within 40 days. Thus, we can see that surgical correction must be performed and is of utmost importance, both for the patient's well-being and quality of life, since its correct management is of equal importance for the neuropsychomotor development of the affected patient.

\section{FATAL VICTIMS OF FIREARMS IN A PUBLIC HOSPITAL BETWEEN THE} YEARS OF 2015 AND 2018

Daniel Ewerton Herculano; Santiago Cirilo Noguera Servin; Ricardo José Guimarães de Sousa Mourão; Rodrigo Matheus Santos Alves; José Maria Honório de Carvalho Neto; Thiago Sousa Dourado Liga Acadêmica do Trauma e Emergência do Maranhão, Universidade Federal do Maranhão

INTRODUCTION: According to the Atlas da violência 2018, published by the Instituto de Pesquisa Econômica e Aplicada (Ipea) and the Fórum Brasileiro de Segurança Pública (FBSP), between 1980 and 2016, the percentage of deaths in Brazil caused by projectiles of firearms (PAF) increased from $40 \%$ to $71 \%$. However, it is believed that many deaths of this nature are not reported. This study aims to present the epidemiological profile of deaths by PAF registered at the Municipal Hospi-tal Djalma Marques (HMDM) in São Luís (MA) between the years 2015 and 2018. METHODOLOGY: This is a retrospective study involving research of deaths from PAF between 2015 years and 2018, through the consultation of medical records of the HMDM. The data was stored in the Microsoft Excel program. The following variables were analyzed: provenance, age, gender and length of stay. RESULTS: Between 2015 and 2018, 348 deaths were recorded by PAF in HMDM. In 2015, 100 deaths oc-curred (28.73\%); In 2016, 88 deaths (25.28\%); in 2017. 88 deaths $(25.28 \%)$; and 2018,72 deaths $(20.68 \%)$. The provenance of the victims was higher in the state capital $(81.03 \%)$. The age group from 21 to 30 years was the most affected, corresponding to $41.09 \%$ of the cases. There was a clear predominance of males, totalizing $95.11 \%$ of the cases. Most of the victims (77.59\%) had up to 1 day of the length of stay. CONCLUSION: During the study period, the number of PAF's deaths recorded in the HMDM remained practi-cally stable. The discrepancy between the provenance of the capital and other cities of the state points to the violence installed in the first. The prevalence in young male adults reflects the behavioral factor of this group. It is noteworthy the brevity of the length of hospitalization, indicating the severity of the cases. We conclude that campaigns are needed to prevent vio-lence, reinforce the supervision of arms possession and punishment of offenders.

\section{TECHNIQUE AND OUTCOMES OF LAPAROSCOPIC DISTAL} PANCREATECTOMY: CLOCKWISE APPROACH

ROMARIO ALBUQUERQUE; LIA GABRIELA LUCIANO GONÇALVES; Clara da Cunha Ferreira Santos; DANIELLE SANTOS BRITTO; Ozimo Pereira Gama Filho

Centro Universitário do Maranhão (CEUMA)

INTRODUCTION: Laparoscopic distal pancreatectomy (LDP) has proven advantages over its open counterpart and is becoming more frequently performed around the world. It still remains a difficult operation due to the retroperitoneal location of the pancreas and limited experience and training with the procedure. In addition, complications such as bleeding of postoperative pancreatic fistula (POPF) remain a problem. A standardized approach to LDP CLOCKWISE APPROACH has been utilized at a single center, and we sought to describe the technique and determine the outcomes. METHODS: A review of all patients undergoing LDP by a clockwise approach including the graded compression technique from January 2011 to December, 2018was performed. RESULTS: Overall, 17 patients with a benign pancreatic cystic neoplasm, mean age and a BMI of 43 and 26 , respectively, underwent LDP using this technique. Mean operative time and blood loss were $267 \mathrm{~min}$ and $395 \mathrm{~mL}$, respectively. Hand-assisted method and conversion to open were both $20 \%$.

\section{DEATHS IN PUBLIC HOSPITALS IN SÃO LUÍS BY CHAPTER OF ICD-10} BETWEEN 2010 AND 2018

Carlos Augusto Cavalcante Filho; Joelmistokles Luís da Silva de Macedo Vale; Samantha Cunha Vieira; Mariana Cutrim Pers; Raphael Erick Lima Pereira; Gabriel de Sousa Macedo Centro Universitário do Maranhão (CEUMA) 
INTRODUCTION: St. Louis is a municipality and the Maranhão state capital. It has a population, according to the IBCE 2017, consisting of approximately $1,091,868$ inhabitants. The ICD-10 was conceptualized to standardize and catalog the diseases and problems related to health, with reference to the International Classification of Diseases nomenclature established by the World Health Organization. The aim of this study is to conduct a retrospective analysis of a quantitative approach of classified deaths in ICD10 in the city of St. Louis. METHODS: the methodology involved data collection obtained from DATASUS TABNET and held in July 2019, involving the analysis of deaths confirmed in public hospitals in the city between 2010 and 2018. RESULTS: During the last 11 years have been recorded a total of 39. 115 hospital deaths in St. Louis. In 2010 there were 2,434 records and we can see a progression in the number of deaths over the years, reaching its peak in 2016 with more than double the 2010 record, 4,923 deaths. In the last two years there has been stability in the registry, even with a slight drop to an average of 4,681 . However, it is noteworthy that the last five years there has been a significant increase in the number of deaths from infectious diseases and malignancies (Chapters I and II ICD-10). CONCLUSION: We found that during the evaluation period there was a progressive increase in the number of deaths, especially the increased incidence of death from infectious and parasitic diseases as to be the leading cause of death by 2016, and the continuous increase in the number of deaths from neoplasms in the last two years was the leading cause of death in the public hospitals of St. Louis. Therefore, it is important that there be further study on the subject and that welfare policies are in place to prevent and reduce deaths in St. Louis.

\section{ANALYSIS OF POST-OPERATIVE PAIN INTENSITY IN PREGABALINE} PATIENTS

Mateus Ribeiro Conçalves Carvalho; Emanuel Cabral Pereira; Thamires Sales Ribeiro; Deborah Costa Alves; Raynan Costa Santana; Rossana Areia de Sousa; Plínio da Cunha Leal Universidade Federal do Maranhão (UFMA)

INTRODUCTION: Anterior cruciate ligament injury is very common and its reconstructive surgery is associated with moderate to severe postoperative pain. Anticonvulsants have been used as analgesics, including pregabalin, which is effective in neuropathic pain and postoperative pain. Thus, this study aims to analyze whether perioperative use of pregabalin compared to the placebo group has analgesic benefits. METHODOLOGY: 29 patients were randomized to receive $75 \mathrm{mg}$ pregabalin or placebo to be taken 1 capsule / day for 7 days before surgery and 7 days after surgery. Pain intensity was measured by Visual Analog Scale (VAS). The variables evaluated during $12 \mathrm{~h}$, $24 \mathrm{~h}, 7,14,30,60$ days after surgery were: pain duration, pain frequency, pain intensity, analgesic medication dose, sleep disturbance, movement restriction, pain factors. improvement and worsening factors, characteristic pain, pain irradiation and physical therapy, as well as demographic data. RESULTS: The demographics of the patients were similar in both groups.

\section{SUBDURAL EMPIEMA AS PANSINUSOPATHY COMPLICATION - CASE}

\section{REPORT}

Adriana Alves Propercio; Francisca Geysa da Silva Costa; Nathalia Silva Sousa.

Centro Universitário Tocantinense Presidente Antônio Carlos - UNITPAC Hospital Regional de Araguaína - HRA.

INTRODUCTION: Subdural empyema is a serious complication of rare bacterial sinusitis, affecting mainly male patients under the age of 20 , characterized by the presence of purulent collection between the dura and arachnoid. CASE REPORT: A 17-year-old female teenager with rhinosinusitis since childhood started on compressive occipital headache, grade 8, with improved dipyrone use; associated with high fever ( $40 / 41 \mathrm{c} C$ ), anorexia and drowsiness. She went to the Basic Health Unit twice and was treated with anti-inflammatory drugs without improvement. Day 01/08/2019 sought the Emergency Care Unit (UPA) due to worsening headache and permanence of fever, was medicated and was discharged. The next day, she presented mental confusion and fleeting amaurosis, progressing to syncope. He returned to the UPA, where he presented seizures associated with rhinorrhagia and involuntary loss of urine. Patient was referred on 08/03/2019 to the Araguaína Regional Hospital for leukocytosis $(23,000)$ and thrombocytopenia $(80,000)$ to be clarified. Upon admission, he underwent non-contrast skull tomography, which showed right midline deviation, left subdural empyema and pansinusopathy; Amikacin, Metronidazole and Cefepime were started. The same day, the parietal craniectomy was submitted to drainage of subdural collection, with purulent materia collected for culture. After neurosurgery, she remained in the ICU for 3 days and was referred to the neurology ward, where she was hospitalized, using antibiotics and anticonvulsants, progressing with progressive improvement, presenting dysarthria, absence of fever, headache and motor deficit; operative wound without phlogistic signs. CONCLUSION: The case described reinforces that the presentation of subdural empyema may be nonspecific, and for early diagnosis there must be a high level of suspicion. Appropriate and early treatment is a fundamental condition for the favorable evolution of this clinical entity.

12. PERCEPTION AND CONDUCT OF OBSTETRICS DOCTORS ON ORAL HEALTH

Valbiana Cristina Melo de Abreu Araujo; Rayssa Ferreira Cavaleiro; Priscilla Pereira Santos; José Ferreira Costa; Elizabeth Lima Costa Hospital/Maternidade de Alta Complexidade do Maranhão em São Luís-MA

INTRODUCTION: The dental consultation performed as a complement to the medical prenatal care is of paramount importance for the maintenance of the general health of the pregnant woman. It is possible that, if this information was given to the pregnant women by the obstetricians themselves responsible for it, fear, anxiety, discrimination to dentists and resistance to treatment were overcome. This study aimed to evaluate the perception and conduct of the obstetrician on oral health in the follow-up of pregnant women during prenatal consultations in the city of São Luis, Maranhão. METHODS: This is a cross-sectional study, carried out with 41 obstetrician physicians who provide care at the High Complexity Hospital / Maternity Hospital of São Luís-MA. The physicians answered a structured questionnaire containing 20 questions related to oral health in the gestational period. RESULTS: of this sample, $58.5 \%$ of physicians are male and $41.5 \%$ female; The age group $56.1 \%$ were between 29 and 49 years old $41.5 \%$ between 28 and 38 years and $2.4 \%$ over 60 years. $75.6 \%$ attend public and private services; $14.6 \%$ only in public service and $9.8 \%$ only in private practice; $22.0 \%$ always advise pregnant women about oral health and 51.2 from the third month of gestation; all the doctors have knowledge about oral health and $39.0 \%$ acquired in the specialization courses Result: of this sample, $58.5 \%$ of the physicians were males and $41.5 \%$ were females; The age group $56.1 \%$ were between 29 and 49 years; $41.5 \%$ between 28 and 38 years and $2.4 \%$ more than 60 years; $22 \%$ always advise pregnant women about oral health and 51.2 from the 3 rd month of gestation; All physicians received information on oral health. CONCLUSION: The relationship between obstetrician and dental surgeon should be narrowed, contributing to an effective multidisciplinary care of pregnant women and the baby. It is necessary a greater interdisciplinary action, between dental surgeons and physicians dedicated to the accompaniment of $t$.

\section{CLINICAL RESULTS AFTER MAIN HEPATECTOMY IN LOW COMPLEXITY CENTERS}

Anna Marieny Silva de Sousa; Luanna Lara Farias de Jesus Neves; Naiara Fonseca Ferreira; Kennya Raquel dos Santos Silva; Francisco Souza Neto; Ozimo Pereira Gama Filho Centro Universitário do Maranhão (CEUMA); Universidade Federal do Maranhão (UFMA)

INTRODUCTION: Major hepatectomies are routinely performed because they are often the only curative treatment for metastatic liver disease. There has been a trend to concentrate major hepatectomies in referral hospitals that perform these operations at high volumes. These high-volume referral centers are usually located in developed countries, but many patients in developing nations are not able to access these centers because of financia limitations, lack of social support and/or travel restrictions. Therefore, local hospitals are often the only options many of these patients have for surgical treatment of metastatic liver disease. METHODS: We prospectively studied all patients who underwent major liver resections over ten years. RESULTS: There were 57 major liver resections performed by one team at a mean case volume of 6 major resections/year. Fifth seven major hepatic resections were performed for: colorectal liver metastases 40, non-colorectal metastases 9 and hepatocellular carcinoma 8. Twenty patients had at least one complication, for an overall morbidity rate of $25 \%$. There were minor complications in 14 patients, major complications in 11 patients and 3 deaths. CONCLUSION: There are unique geographic, political and financial limitations to healthcare delivery in the Brazilian. Nevertheless, clinical outcomes are acceptable in the established, low-volume hepatobiliary centers in the Brazil. 


\section{DIFFUSED ERYTHRODERMIA: A CASE REPORT}

Marianna Sousa Maciel Gualberto de Galiza; Érika Karoline Sousa Lima; Iara Maria Dias Bandeira; Isabella Magalhães Assub; Marilia Meneses Souza; Ivan Abreu Figueiredo

Centro Universitário do Maranhão (CEUMA)

INTRODUCTION: Erythroderma is a pathology usually of unknown etiology characterized by generalized erythema and peeling, which over time develops a skin thickening associated with edema, lichenification and fissures. May occur systemic associations. Male studies with a mean age of 60 years are reported in different studies. Dermatological conditions, the most common to psoriasis and less common, are the first symptom of Tcell lymphoma. This study aims to report the case of an elderly man. CASE DESCRIPTION: Patient, 63 years old, male, brown, retired, married, resident in São Luís- MA. During consultation at a dermatology outpatient clinic, she had scaling and xerotic lesions on the feet, abdomen and scalp, with a nonspecific previous diagnosis of psoriasis for 2 months, due to erythema and scaling of the head on the head with craniocaudal evolution. It presented a histopathological with distinct morphological findings and suspicious for cutaneous infiltration by T lymphocytes (Basal Layer Vacuolar Degeneration). Computed tomography revealed hepatic steatosis, aortoiliac atheromatosis and spondylosis. Patient without adeno or peripheral visceromegalies and without lymphocytosis in peripheral blood.The clinical hypothesis is of unspecific diffuse Erythroderma based on the history of the current disease. He was referred to a Hematologist to investigate Fungus Mycosis. Treatment was performed with a prescription of 1 ampoule via Diprospan IM, 1 vial of Hydroporin body lotion $1 \mathrm{x} /$ day after bath and Desloratadine 5mg. aspect of the lesion. CONCLUSION: The study of erythroderma is of paramount importance, as it is a potentially unknown disease requiring correct diagnosis and treatment. Suspicion should occur in any patient with erythema and generalized peeling. Immediate treatment reduces patient embarrassment and possible complications.

\section{LACEMA DEVICE FOR NIPPLE - AREOLA COMPLEX RECONSTRUCTION:} EXPERIMENTAL MODEL

Roseline Braga de Carvalho; Alexandra de Oliveira do Carmo; Laura Sales de Carvalho Lima; Cláucia Mesquita Cordeiro; Luis Fernando Moura da Silva Júnior

UNIVERSIDADE FEDERAL DO MARANHÃO (UFMA)

INTRODUCTION: The double opposing flap technique is effective in reconstructing the nipple - areola complex (NAC) when there is surgical loss of this element in the treatment of breast cancer, because it allows planning its positioning, long-term projection of the papilla, has limited NAC scars and preserves vascularization. Experimental models are important for training professionals and introducing knowledge of elementary surgery techniques. Thus, this study aims to describe the LACEMA device for training reconstruction of the nipple - areola complex. METHODS: Methylene blue and wooden toothpick were used to make the markings of the flap in a piece of $8 \mathrm{~cm}$ ox tongue containing mucous and muscular planes. Initially, was erected at $90^{\circ}$ a rectangular flap $(1 \mathrm{~cm} \times 5 \mathrm{~cm})$ with a thickness of 2 $\mathrm{mm}$, connected to the rest of the piece by a $1 \mathrm{~cm}$ pedicle, whose edges were approximated and sutured with Nylon 3.0, giving rise to the papilla. The donor area of the papilla resulted in two opposite semicircular flaps (with radius of $2.5 \mathrm{~cm}$ ) that were dissected in its contour only in the mucosal plane allowing the advancement of one towards the other and sutured with Nylon 3.0, originating the areola. In the periphery of the NAC, a round-block suture with Catgut 3.0 was used. RESULTS: The device was presented to members of the Academic League of Experimental Surgery of Maranhão, who performed the steps of the procedure. The model proved to be efficient for training the technique, as it makes it possible to reproduce all the steps for NAC reconstruction with low cost and easily acquired materials. CONCLUSION: The practical model enables the learning and practice of the procedure and professional training. In addition, the materials used to make the model are low cost and easy to purchase, which allows reproducibility in a lot of conditions and in large quantities, ensuring the assembly of individual models for each student's practice.

\section{EPIDEMIOLOGICAL PROFILE OF PATIENTS WITH COMPLEX REGIONAL PAIN} SYNDROME

Alda Tereza Queiroz Lyra; Marcelo Serley Mondego Macedo Silva; Luis Augusto Silva Batista; Vinicius Conçalves Melo; João Batista
Santos Carcia; Thiago Alves Rodrigues; Rayanne Luiza Tajra Mualem de Araújo

Universidade Federal do Maranhão (UFMA)

INTRODUCTION: Complex regional pain syndrome (CRPS) refers to a chronic pain condition that is characterized by inflammatory and neuropathic pain disorder, with progressive worsening of spontaneous regional pain associated with motor, trophic and autonomic changes. It is classified as type I, when there is no apparent cause or definite nerve injury; or type II, when there is an identified lesion. The condition is not yet completely clear, being the subject of studies aiming at its accurate understanding. The aim of this study was to outline the epidemiological profile of patients diagnosed with CRPS and treated at the Chronic Pain Outpatient Clinic of the University Hospital of UFMA. METHOD: Descriptive study, based on the analysis of medical records of patients treated between August 2017 and January 2019. The variables described were: age, gender, color / race, residence, occupation and type of syndrome. Data were tabulated in Excel 2019 and analyzed using SPSS Statistics 25.1 software; RESULTS: The sample consisted of 23 patients, $60.9 \%$ male and $39.1 \%$ female. In the population, $17.4 \%$ were between 18 and 30 years old; $17.4 \%$ from 31 to 40 years old; $26.1 \%$ from 41 to 50 years old; $21.7 \%$ from 51 to 60 years old; $13 \%$ from 61 to 70 years old; and $4.3 \%$ from 71 to 80 years. Regarding color / race, $43.5 \%$ declared brown, $21.7 \%$ black and $13 \%$ white; $21.7 \%$ did not declare. Regarding occupation, $60.9 \%$ had a paid activity, $26.1 \%$ had no activity and $13 \%$ of the cases were on sick leave or retired. It was observed that $69.6 \%$ lived in the capital, São Luís, and $30.4 \%$ from other cities in the state of Maranhão. The study found that CRPS type I corresponded to $69.5 \%$ of cases, while $30.4 \%$ type II cases. CONCLUSION: The characteristics of the affected population reach especially adult men of economically active age, which creates a burden not only individual, but also to society.

\section{LAPAROSCOPIC SUBTOTAL COLECISTECTOMY FOR SEVERE}

CHOLECYSTITIS
Kennya Raquel dos Santos Silva; Francisco Souza Neto; Joama Marques Lobo Quariguasi; Anna Marieny Silva de Sousa; Matheus Lurine Guimarães Leitão; Ozimo Pereira Gama Filho

Centro Universitário do Maranhão (CEUMA) e Universidade Federal do Maranhão (UFMA)

INTRODUCTION: Laparoscopic cholecystectomy is one of the most accomplished surgical techniques in the field of general surgery, so it is of the utmost importance that the surgeon master the different alternatives when dealing with a complicated case. However, the concept of laparoscopic subtotal cholecystectomy (LSC), without addressing Calot's triangle to avoid laparotomy and serious complications, is not widely accepted. Therefore, the objective of this study is to evaluate the LSC results for severe cholecystitis when the cystic duct and cystic artery dissection consists of a risky procedure. METHODS: From January 2007 to December 2018, 43 consecutive patients who underwent CLS ligation of the cystic and vessels were included in this retrospective study. Their clinical records including operational records and results were entered into a database prospectively maintained and subsequently analyzed. RESULTS: The mean time of operation and blood loss were $233 \mathrm{~min}$ and $88 \mathrm{ml}$, respectively. All LSCs were completed without conversion to an open procedure. No injuries to the bile duct or vessels were experienced. Postoperative complications occurred in five patients, including subhepatic hematoma in one, bile leak in three, and subhepatic abscess requiring reoperation. During follow-up periods (mean of twenty-six months), symptomatic biliary stone disease recurred in one patient and were successfully treated by endoscopic management. CONCLUSIONS: Laparoscopic subtotal cholecystectomy without an attempt to dissect Calot' s triangle is a safe and feasible procedure, using a minimal access approach with all of its proven advantages in conversion to open cholecystectomy, such as faster postoperative recovery, less risk of infection, and shorter hospital stay.

\section{TREATMENT OF CENTRAL PAIN PATIENTS IN A CHRONIC PAIN CENTER IN} SÃO LUIS-MARANHÃO

Denise Ailine Monteiro Lopes; José Estevam Ribeiro Júnior; Clarissa Monteiro Melo; Luiza Sousa Soares; João Batista Santos Carcia; Thiago Alves Rodrigues; Rayanne Luiza Tajra Mualem de Araújo Universidade Federal do Maranhão

INTRODUCTION: Central pain syndrome is a chronic neuropathic pain disorder caused by a central nervous system injury. It is one of the most complex 
painful syndromes, frustrating obscure and difficult treatment. Therefore the aim of this study was to investigate the response to multimoda pharmacological strategy associated with non-pharmacological therapies of patients treated at the Chronic Pain Outpatient Clinic of the University Hospital of UFMA. METHODS: Cross-sectional study based on the analysis of medical records of patients diagnosed with central pain assisted at the Chronic Pain Service of the UFMA University Hospital, São Luís-MA, from 2010 to 2017. The following variables were evaluated: cause of pain, pharmacological and non-pharmacological treatment and improvement index. RESULTS: The sample consisted of 12 patients. Among the causes of central pain, stroke accounted for $75 \%$ of cases; $8.33 \%$ had as cause myelopathy; $8.33 \%$, brachial plexus avulsion; $8.33 \%$, not clarified. All patients underwent pharmacological treatment; Non-pharmacological therapy was associated with $75 \%$ of cases. The most used drugs as the first treatment option were gabapentin (58\%) and pregabalin (33\%). Amitriptyline was associated with $33.3 \%$ of therapeutic approaches. Tramadol $25 \%$. The main forms of non-pharmacological therapy were; physical therapy (50\%) and acupuncture (16.6). The treatment adherence rate was $66.7 \%$, and the lack of return to the outpatient clinic was the main reason. CONCLUSION: The multimodal strategy was very effective in the treatment of central pain. Anticonvulsants are the cornerstones of drug therapy, usually associated with a tricyclic antidepressant. Nonpharmacological therapy, mainly involving physiotherapy, proved to be a great ally to the beneficial effects of the drugs. Despite the significant percentage of improvement, a higher adherence rate would reflect a better picture of these patients.

\section{ACUTE LICHENOID AND VARICELLIFORM PITYRIASIS: A CASE REPORT}

Clara Albino de Alencar; Rafaella Furtado Perlmutter Lago; Luana Bogea Ribeiro; Cabriel Perlmutter Lago; Mauro Ribeiro Balata; Vanessa Cipriano Milhomem Soares e Silva; Ana Kelly Pinto de Melo Centro Universitário do Maranhão (CEUMA)

INTRODUCTION: Pityriasis lichenoides et varioliformis acuta (PLEVA) or Mucha-Habermann disease is an idiopathic inflammatory skin disease that develops in response to foreign antigens, characterized by papular lesions that rapidly progress to hematic pseudovesicles, ulceration and central necrosis causing varioliform scars. Systemic symptoms may be associated among the most common are high fever and lymphadenopathy. The pathophysiology of the disease, as well as its etiology, is not yet well understood, but it is believed that lymphoproliferation (mainly CD4 lymphocytes) occurs triggered by antigenic stimuli, being considered a benign reactive process. REPORT: W.L.B.S., male, 48 years old. Patient reports skin peeling and pain throughout the body for 6 years, recently evolving with disseminated bullous lesions throughout the body, culminating in necrotic crusts. He was hospitalized, performing biopsy of the lesions, diagnosed with PLEVA, and prednisone therapy was prescribed. It evolved with bilateral conjunctivitis, genital lesion, purulent discharge from the umbilical scar. An opinion was requested from the dermatology department, which indicated transfer to isolation bed and treatment with cephalexin 500mg EV 6 / $6 \mathrm{H}$ for 07 days, in addition to maintaining prednisone. Patient evolved with resolution after 123 days of hospitalization and was discharged. CONCLUSION: PLEVA is an uncommon desquamative dermatosis. Despite having complete remission, there are high chances of relapse due to asymptomatic onset. However, after a long period of remissions and relapses, spontaneous resolution of the condition may occur. Therapeutic options include systemic and oral corticotherapy, antimicrobials, phototherapy and methotrexate. There is no standard treatment for the disease, because due to their antigenic character, the medications used are subject to the individual response of each patient.

EPIDEMIOLOGICAL PROFILE OF MORTALITY IN AN INTENSIVE CARE UNIT IN SÃO LUIS-MA

lara Maria Dias Bandeira; Felipe Arduvini Casaroli Santos; Ana Victoria Pinho De Carvalho Pascal; Kalina Araujo Prazeres; Yasmine Mendes Gama; Amanda Cristina Silva Matos; Aminadabe Rodrigues Sousa

Hospital São Luis HSLZ

INTRODUCTION: For an adequate analysis of the health situation of a given population, timely and quality data should be used in order to elaborate the programs and policies related to the diagnosed diseases. The morbidity and mortality profile can be considered a relatively sensitive indicator of living conditions and the development model of a population, being the result of the interaction of several interdependent factors. Given the relevance of this approach, this study aims to determine the epidemiological profile of patient deaths in an intensive care unit in the city of São Luís, Maranhão. METHODS: It is a retrospective, cross-sectional and quantitative study using secondary data from the Epimed ${ }^{\circledR}$ system and death records and analysis by the death commission, referring to patients admitted to the São Luís Hospital ICU (HSLZ) from September 2018 to May 2019 with the following variables: age, gender, most frequent causes and comorbidities. RESULTS: From September 2018 to May 2019, there were 409 hospitalizations in the unit and 94 deaths, a rate of $23.97 \%$. The predominant gender was male with 51 deaths ( $54.8 \%$ ), and the average age was 69.7 years. In the death certificates, the immediate cause was pulmonary sepsis with 46 records. Among the comorbidities are diabetes mellitus with 24 cases, followed by systemic arterial hypertension and chronic kidney disease, were also stroke with 21 registered patients, 7 patients diagnosed with neoplasia and 8 cases conducted as palliative. CONCLUSION: The epidemiological profile and life expectancy of the unit are in accordance with the literature, characterized by an elderly population with chronic diseases and complications from infectious processes, hence the importance of knowing the epidemiological profile, as well as the correlated factors, search and treatment of underlying diseases.

\section{SEXUAL DYSFUNCTION IN PATIENTS WITH FIBROMYALGIA IN CHRONIC PAIN AMBULATORY}

Beatriz Morais Costa; Islanara Diógenes Urbano Sousa; Marcelo Ribeiro Mendes Júnior; Rayanne Luiza Tajra Mualem de Araújo Letácio Santos Garcia Ferro; Thiago Alves Rodrigues; João Batista Santos Garcia Universidade Federal do Maranhão (UFMA)

BACKGROUND: Fibromyalgia is poorly clarified, multifactorial and complex pain syndrome. It is characterized by musculoskeletal pain, increased sensitivity, fatigue and cognitive changes. Therefore, the objective of this study is to evaluate the sexual dysfunction in patients diagnosed with fibromyalgia accompanied at the Chronic Pain Ambulatory of the University Hospital of the Federal University of Maranhão. METHODS: Descriptive study, with female patients diagnosed with fibromyalgia according to the American College of Rheumatology 2010 criteria and attended the ambulatory between August 01, 2018 and March 31, 2019. It was applied the Female Sexual Function Index (FSFI), in which the following criteria were analyzed: Sexual Desire, Lubrication, Arousal, Satisfaction, Pain and Orgasm. Each one of these criteria can score from o to 5 points, and the minimum and maximum scores are 0 and 36, respectively. The data were analyzed by SPSS Statistics 25.1. The normalcy of distribution was tested by Shapiro-Wilk's test. RESULTS: There were 55 patients, median age of 49 years old. The FSFI median was 7.5 , which shows significative levels of sexual disfunction in a relevant part of the patients. CONCLUSION: The fibromyalgia has an important impact in the patients' life quality, which correlates the syndrome severity and the sexual disfunction. This way, by increasing the knowledge about the clinical characteristics that has impact on the disease, it will be possible to contribute to the adequacy of new proposals of treatment to the studied population reality. It is important to emphasize, based on the results, that there can have improvement in the care of this patients, by improving the self-esteem and understanding about the fibromyalgia.

\section{BENIGN OVARIAN TERATOMA IN CHILDREN: A CASE REPORT}

Beatriz Ortegal Freire; Gabriela Luiza Kich de Souza; Lorayne Lino Sousa; Julia Gomes Marques; Marilia Meneses de Sousa; Érico Brito Cantanhede; Marcos Santana Lorenzo Raices Centro Universitário do Maranhão. (CEUMA)

INTRODUCTION: Mature ovarian cystic teratoma is an ovarian germ cellderived neoplasm that presents well-differentiated tissues as three embryonic leaflets. It commonly affects fertile women, often being unilateral $(20 \%)$. The relevance of this case is justified by the early age of the patient described. CASE DESCRIPTION: S. M. M., female patient, 8 years. Mother of the patient refers that the child presents sporadic episodes of vomiting diarrhea, fever, vertigo and intermittent pain in the suprapubic region for three months, progressing with worsening of symptoms. On physical examination, compromised body condition, hypocolored mucous membranes, no fever, painful facies, abdomen slightly distended, with water present and painful to superficial and deep palpation, showing palpable mass in the right lower quadrant. Complementary tests: CBC showed leukocytosis; High C-reactive protein; Oral contrast-enhanced 
computed tomography suggested massive mesenteric cyst in the right lower quadrant. The patient underwent laparotomy and a cystic tumor partially adhered to the intestinal loops in the right ovary, suggesting teratoma. The surgical part was used for anatomopathological examination, measuring 6.0 $\times 5.9 \times 2.0 \mathrm{~cm}$. A histological study showed that it was a mature benign teratoma of firm, elastic and brown coloration with a presence of bone and hair in the content. CONCLUSION: In this case, considering the age of the pacient as a risk for malignancy according to the literature, unilateral laparotomic oophorectomy was performed. Patient follows with gynecological follow-up and no recurrence of symptoms. We emphasize the importance of accurate diagnosis in cases of pelvic mass in young patients in order to reduce the effects on their reproductive future.

\section{CONSTRITIVE PERICARDITIS: CASE REPORT}

Petra Samantha Martins Cutrim; Daniela Serra De Almeida; Annanda Carolina De Araújo Martins; Tácio Danilo Araújo Pavão; Thais Oliveira Nunes Da Silva; Vitor Ferreira Cerude; Byanca Pereira Borges Centro Universitário do Maranhão (CEUMA); Hospital Universitário da Universidade Federal do Maranhão (HUUFMA); Clinica Cardio Check up

INTRODUCTION: Constrictive pericarditis (CP) is due to the loss of pericardial elasticity, leading to restriction of ventricular diastolic filling. Among the etiologies are tuberculosis, collagenosis, neoplasms, cardiac surgery, idiopathic or secondary to viral pericarditis. In developing countries, the first cause of pericarditis is tuberculosis. As it is an uncommon pathology, its diagnosis is often made late, which interferes with its prognosis, as it is a potentially curable disease when treated early. CASE DESCRIPTION: AMTS, 43 years old, born and resident of Imperatriz-MA, stable union, bricklayer, with a history of moderate to moderate exertion, progressive dyspnea, associated with paroxysmal nocturnal dyspnea, orthopnea, persistent dry cough and limb edema inferior. The condition started 1 year ago, worsening in the last six months. Denies comorbidities. Physical examination with signs of systemic congestion, irregular heart rhythm. Electrocardiogram with atrial fibrillation rhythm. Chest X-ray and tomography showed extensive pericardial calcification. Transthoracic echocardiography showed alterations suggestive of constrictive pericarditis. Patient underwent partial pericardiectomy without complications. The patient evolved with nosocomial pneumonia, atrial fibrillation with high ventricular response, moderate right pleural effusion and maintained a high rate of pericardial drainage, which prolonged the length of stay. An antibiotic regimen was performed for 14 days, chest drainage was performed, and a mediastinal drain was removed. An empirical tuberculosis regimen was started, with good evolution, and was discharged from hospital. Pericardial biopsy demonstrated fibrosclerotic tissue with microcalcifications. CONCLUSION: Early diagnosis and implementation of appropriate therapy contributes to the patient's good prognosis, since pericarditis is a potentially treatable disease.

\section{HIV / AIDS MORBIMORTALITY PROFILE IN A NORTHEAST BRAZILIAN} STATE

Cícera Natália da Silva Rodrigues; Eduardo da Silva Pereira; Jesimarcus Guerra de Oliveira; Antônio Nunes da Silva; Pedro Gustavo Moura de Sousa; Joaquim José da Silva Neto; Aldicleya Lima Luz

Universidade Federal do Maranhão (UFMA)

INTRODUCTION: The worldwide epidemic of HIV / AIDS is still a relevant public health problem, despite the numerous advances made in recent years. This paper aims to evaluate the morbidity and mortality profile of HIV / AIDS in the state of Maranhão. METHODS: Descriptive, retrospective and quantitative study in the area of Collective Health. The epidemiological indicators of HIV / AIDS between 2002 and 2018 in the state of Maranhão were analyzed. Data were collected in the Health Notification System (SINAN NET). Survey on the subject was conducted in the databases Scielo, Medline and Pubmed with Descriptors in Decs HIV / AIDS. RESULTS: The incidence rate per 100,000 inhabitants / year increased from $6.3 \%$ in 2002 (lowest index) to $21.37 \%$ in 2015 (highest index). the highest mortality rate $(6.25 \%)$. Regarding the percentage of late diagnosis (HIV-positive cases with a first CD4 lower than 200 cells / mm3), a reduction in the rates was observed in $44.38 \%$ in 2009 and 33.73 in 2018. Regarding the number of patients undergoing treatment An important increase was seen in the period, and in 2008 there were 2,248 patients, reaching a higher value in 2016 with 9,590. When analyzing the percentages according to race / color, it is seen that brown race dominates the indicators with $77.34 \%$ of cases in 2013 (higher index) against $55.49 \%$ in
2002 (lower index). The percentage of deaths by race / color follows that of morbidity for the same, being the dominant brown race in this indicator, representing $64.04 \%$ of deaths in 2006 versus $19.83 \%$ of white race in the same year. CONCLUSION: HIV / AIDS cases still have a high incidence and mortality rate with a significant predominance of brown race. In addition, a percentage reduction in late diagnosis rates was observed, as well as an increase in the number of patients undergoing treatment, which demonstrates greater demand and adherence to HIV / AIDS treatment.

\section{RAPID THYROID CARCINOMA: A CASE REPORT}

Letícia Coretti Moura de Jesus; Francisco Silva Ferreira; Marcos Teodoro Viana Brito; Sara Maria Gomes Bié Universidade Federal do Maranhão

INTRODUCTION: Papillary carcinoma is the most frequent and best-predicting malignant neoplasm among thyroid patients, most prevalent in the third and fourth decades of life, especially in the female population. Incidence of papillary thyroid carcinoma has increased in Brazil, related to environmental factors, external radiotherapy in childhood and adolescence, exposure to ionizing radiation, pre-existing thyroid disease, and genetic factors. The objective of this report is to evaluate the clinical outcome of a papillary thyroid carcinoma. CASE DESCRIPTION: A 28-year-old female patient reported to the gastroenterologist, mucus in the year ago. Diagnosed with reflux but no improvement of throat clearing. Routine consultation with an endocrinologist was ordered with color-pulsed and color-flow Doppler thyroid ultrasound. with partially defined margins of microcalcifications lobulated arteries exhibiting Chammas III flow pattern, measuring $1.2 \mathrm{~cm} \mathrm{x}$ $0.9 \mathrm{~cm}$, another of regular, heterogeneous contours, with Chammas II flow pattern, $0.6 \mathrm{~cm} \times 0.5 \mathrm{~cm}$. Hurthle cell follicular neoplasia category IV was suspected. Total thyroidectomy was performed. Histopathologically, papillary carcinoma in the right thyroid lobe, variant of oxyphilic cells, about $0.8 \mathrm{~cm}$ along its longest axis extending to the perithyroid fibroadipose tissue. One month after surgery, the patient was admitted after stimulation with recombinant TSH for therapy with $150 \mathrm{mCi}$ of radioiodine $\left(\mathrm{I}^{131}\right)$. It presented good evolution. CONCLUSION: Thyroid cancer can go unnoticed by specific signs and symptoms, requiring greater professional expertise in clinical management. It is concluded that an accurate diagnosis, following the protocols was essential for the good prognosis of the patient. The technique with radioiodine therapy was effective in the treatment of papillary thyroid carcinoma of the case.

\section{CARDIOPROTECTION OF EQUISETUM ARVENSE IN RATS ASSESSED BY ELECTROCARDIOGRAPHIC PARAMETERS}

Vinícius Santos Mendes; Marcos Vinícius Araújo Brito; Rachel Melo Ribeiro; Gabriel Gomes Oliveira; Vitor Paixão Cruz; Matheus Fagundes da Silva

Universidade Federal do Maranhão (UFMA)

INTRODUCTION: Heart diseases are the leading cause of death globally and have a major public health impact. Thus, it is important to search for medicinal plants that can expand the therapeutic arsenal against heart diseases. The present study investigated the cardioprotection of the Equisentum arvense ("horsetail") aqueous extract by analyzing the electrocardiographic (ECG) pattern of experimental models of Isoproterenol (ISO) ischemic injury treated with E. arvense (EEA) extract. METHODS: EEA Stem Lyophilized Extract was prepared for oral administration. Wistar rats (Rattus novergicus), adult and male, were used in the study, divided into in groups: Healthy Control (water $0.5 \mathrm{ml} / \mathrm{kg} /$ day v.o.), ISO Control (water $0.5 \mathrm{ml} / \mathrm{kg} /$ day v.o.), EEA (EEA extract $50 \mathrm{mg} / \mathrm{kg} /$ day v.0.), Atenolol (atenolol $50 \mathrm{mg} / \mathrm{kg} /$ day v.o.). After 30 days, Acute Myocardial Infarction (AMI) was induced by ISO ( $85 \mathrm{mg} / \mathrm{kg}$ S.C., 2 consecutive days) except for Healthy Control (received $\mathrm{NaCl} 0.9 \%$ s.c.). Then, the ECG pattern of the animals (anesthetized) was analyzed. RESULTS: It was observed in ISO Control: $23 \%$ ST-segment elevation, $77 \%$ isoelectric potential, T-wave $100 \%$ increased, 30\% ventricular tachycardia, 40\% mortality. In Atenolol group: $40 \%$ ST-segment elevation, $60 \%$ isoelectric potential, T-wave $40 \%$ increased, $20 \%$ ventricular tachycardia, $20 \%$ mortality. In EEA group: $20 \%$ ST-segment elevation, $80 \%$ isoelectric potential, T-wave $50 \%$ increased, absent ventricular tachycardia, $30 \%$ mortality. alterations and mortality were not observed in the Healthy Control group. CONCLUSION: E. arvense exhibited a preventive effect against myocardial injury induced by ISO, with modulation of cardiac electrical activity. The EEA extract and atenolol (used as a standard of cardioprotection) reduced AMI mortality. When compared, 
atenolol showed greater mortality reduction, but the extract is more effectively in reverse ECG changes.

27. EPIDEMIOLOGICAL PROFILE OF PATIENTS IN THE ICU OF THE HOSPITAL SÃO LUÍS - HSLZ

Felipe Arduvini Casaroli Santos; Iara Maria Dias Bandeira; Ana Victória Pinho de Carvalho; Aminadabe Rodrigues Sousa; Rodrigo Da Silva Oliveira; Renato Coelho Abreu; Daniella Fahd Jacone Hospital São Luís (HSLZ)

INTRODUCTION: In Intensive Care Units (ICUS), knowing epidemiological characteristics helps to define qualitative and quantitative strategies in order to improve patient care, given the growing number of critically ill patients admitted to this sector and the high cost of service with high technology equipment and qualified multidisciplinary team. Thus, the present study aims to trace the epidemiological profile of ICU inpatients of Hospital São Luis, HSLZ, located in the municipality of São Luís, Maranhão. METHOD: Retrospective, cross-sectional and quantitative study, using as data: age, sex, days of hospitalization and diagnosis, which were collected from the Epimed $®$ system from September 2018 to May 2019. RESULTS: HSLZ has 114 beds, which 20 are intended for ICU. During the study period, 409 predominantly clinical patients were admitted. $55.39 \%$ male and $44.61 \%$ female. The average age range was 68.9 years, of which 227 patients, aged 65 to 80 years. Regarding the reason for hospitalizations, 240 were due to pneumonia infection/sepsis followed by neurological causes such as ischemic stroke. Among surgeries, biliary tract surgeries were the most frequent, followed by vascular surgeries in diabetic patients. Of the inpatients 317 (79.45\%) had comorbidities such as hypertension, diabetes mellitus and chronic dialytic kidney disease. The average Charlson index is 1.39. CONCLUSION: It can be inferred that hospitalizations were more frequent in elderly patients, and the main causes were infections associated with comorbidities. These data lead to outline training strategies to serve this population. Knowing the characteristics of the hospitalized population allows us to provide resources, organize processes and train people to improve intensive care, as it enables consistent data for better care planning.

\section{RESISTANT PULMONARY TUBERCULOSIS: A CASE REPORT}

Amanda Patrícia Vasconcelos; Aléxia Eduarda da Fonseca Pinto; Glaucia Galindo Silva; Lais da Hora Lucena Silva; Maria Clara Xavier Macedo Costa; Vitória Conçalves Alves de Oliveira Universidade Federal do Maranhão (UFMA)

INTRODUCTION: Tuberculosis (TB) is an infectious disease caused by bacteria and mainly affects the lungs. Treatment consists of a combination of drugs, and monotherapy, improper prescription of association or lack of patient collaboration may lead to the emergence of strains resistant to one or more drugs (multidrug resistance, MDR). Recent data show that MDR-TB cases tripled between 2009 and 2013, contributing to increased mortality from the disease. CASE DESCRIPTION: Male, 36 years old, resident of the countryside city of Maranhão, admitted to a regional hospital complaining of breathlessness for 07 days. She reported moderate chest pain that started about 02 years ago. He was diagnosed with pulmonary TB and then underwent standard regimen treatment without improvement. He was referred to a hospital in the capital, where there was a change in the therapeutic scheme, but reported not using the prescribed medications for one month. It progressed with worsening, presenting dry cough, with exacerbations at night, along with night sweats and afternoon fever. With the progression of the condition, she presented episodes of dyspnea, with progressive worsening, evolving to dyspnea on exertion and paroxysmal nocturnal dyspnea with weight loss of $10 \mathrm{~kg}$. He was hospitalized again with ventilatory support and alteration of prescription. Still without improvement, the patient developed acute respiratory failure and septic condition, with death 4 days after hospitalization. CONCLUSION: Given the clinical investigation performed with the patient, the main hypothesis raised should be MDR-TB. In such cases, information, education and communication are essential for adherence to treatment and for the prevention of disease transmission. The patient should obtain clear information from the health team about their condition, as well as the care they should take in about yourself and others. MDR-TB is a serious disease, but it can be cured through treatment.
29.

\section{LUZIA DO PARUÁ - MA}

Aryanne Cristine Braga Castro; Silmonir Silva Praseres; Romário do Nascimento Barbosa; Fabiana Viana Maciel Rodrigues; Matheus Caíck Santos Brandão; Thirza Rafaella Ribeiro França Melo; Marcos Roberto Campos de Macêdo

Faculdade Estácio São Luís

INTRODUCTION: Several studies have pointed out the important relationship between dietary and nutritional conditions and their effects on the aging process. In this context, healthy food consumption is one of the determinants of nutritional status and is related to health at all stages of life. Thus, the present study aimed to evaluate the food intake of a group of elderly from Santa Luzia do Paruá - MA. METHODS: This is a descriptive and cross-sectional study, consisting of 60 elderly men and women, participants of the group "Best Age Moving" Living and Learning. For data collection, we used the adapted food frequency questionnaire and the socioeconomic questionnaire of the Brazilian Association of Research Companies - ABEP. Data were tabulated and analyzed using the Microsoft Excel $2013 \AA$ program, using descriptive statistics, presented as absolute and relative frequency. RESULTS: We evaluated 60 elderly men and women, 14 men and 46 women. Regarding socioeconomic classification, 60,0\% $(n=36)$ belonged to the economic class $D-E$. Consumption of vegetables and vegetables was observed by $83,3 \% \quad(n=50)$ of individuals at daily/weekly frequency, $75,0 \%(n=45)$ of fruits at daily/weekly frequency and $73,4 \%$ $(n=44)$ in the meat and fish group at daily/weekly frequency. Consumption of unhealthy foods was observed, especially with daily/weekly intake of chicken or turkey skin, which was reported by $31,7 \%(n=19)$ of individuals and daily/weekly intake of visible meat fat cattle or swine, which was reported by $28,3 \%(n=17)$ of the individuals. CONCLUSION: The elderly evaluated presented, in general, an adequate food intake. Thus, nutritional education actions are suggested aiming to strengthen and maintain a balanced diet.

\section{SEVERE TETANUS BY FIREARM: A CASE REPORT}

Maria Eduarda Andrade e Andrade; Anne Nathaly Araújo Fontoura Rafael Pereira Camara de Carvalho; Jéssica Estorque Farias; Rayla Bezerra Rocha; Fábio Henrique Nunes Pacheco; Isabella Ferreira Saraiva

Centro Universitário do Maranhão (CEUMA), Hospital Municipal Djalma Marques

INTRODUCTION: Tetanus is a non-contagious acute infectious disease transmitted by the bacillus Clostridium tetani, producer of tetanospasmin, syndrome-related toxin. The diagnosis is clinical and based on the triad: trismus, muscle spasms and dysautonomia, with maintenance of the state of consciousness. Treatment consists of neutralization of the toxin with serotherapy and removal of the source of infection, control of spasms and dysautonomia associated with the use of antibiotic therapy. CASE DESCRIPTION: Male patient, 20 years old, without comorbidities, was admitted to the Djalma Marques Municipal Hospital with fever, stiffness of the thoracic and cervical spine for one day, and dysphagia for solids and involuntary mandibular contracture after gunshot injury to the left lower limb for two days. He did not know vaccination history and did not perform tetanus prophylaxis. He had a perforated contusion lesion in the left lower limb, without signs of inflammation or dirt. On examination, the patient was febrile, tachydyspneic, tachycardic and with the presence of trismus. The laboratory identified: read 18,700, CPK-TOTAL-18000, $\mathrm{Cr} 1,8$ and Ur 135. The patient was diagnosed with severe tetanus, complicated with rhabdomyolysis and acute kidney injury. As an initial treatment plan, she received 6,000 units of tetanogamma, as well as the DT vaccine. The antibiotic therapy of choice was crystalline penicillin 20,000,000 IU / day associated with metronidazole $1,5 \mathrm{C} /$ day. It was also performed: volume expansion with crystalloid solution, furosemide, sodium bicarbonate, surgical tracheostomy and debridement of the left lower limb lesion. The patient was admitted to the ICU with isolation to auditory and visual stimuli, evolved satisfactorily and was discharged after 32 days. CONCLUSION: Tetanus is a clinical condition of compulsory notification and relevant in medical practice. Appropriate therapy is of fundamental importance to avoid negative outcomes and reduce the morbidity.

31. DEATH BY WHITE WEAPON REGISTERED ON A PUBLIC HOSPITAL IN SÃO LUÍS BETWEEN 2015 E 2018. 
Paulo Gabriel Sacramento da Silva; Vitoria Coutinho dos Santos; Gustavo Manfio Leme de Campos; Lucas Eduardo Mendes Silva; Matheus Cutrim Carvalho; Artur Augusto Santos Batista; Santiago Cirilo Noguera Servin

UNIVERSIDADE FEDERAL DO MARANHÃO (UFMA), HOSPITAL MUNICIPAL DJALMA MARQUES (HMDM)

INTRODUCTION: Violence has been consolidating as a serious public health problem in Brazil, increasing the mortality rates due to external causes, among which there is a special focus on gunshot wounds (FAB). In this sense, the present study aims to present the epidemiological profile of deaths caused by $F A B$ registered at Hospital Municipal Djalma Marques (HMDM) - MA between 2015 a 2018. METHODS: This was a retrospective descriptive study involving deaths from FAB between 2015 - 2018 through hospital records. Data were stored and analyzed using Microsoft Excel. The variables evaluated were: origin, age, gender and length of stay. RESULTS: Between 2015 and 2018, 5586 deaths were registered in the HMDM, of which $56(1.10 \%)$ were due to $\mathrm{FAB}$. There were $16(28.57 \%)$ deaths in 2015,9 $(16.07 \%)$ in $2016,17(30.36 \%)$ in 2017 and $14(25 \%)$ in $2018.83 .92 \%$ of the victims came from the capital, the others (16.08\%) from the interior of the state. The most affected age group was $21-40$ years old $(53.57 \%)$. Males $(89.29 \%)$ were reached in a 10: 1 ratio in relation to females $(8.93 \%)$. We had an unknown gender case. Most patients were hospitalized for a maximum of one day (78.58\%), $10.71 \%$ of cases for up to 1 week, $7.14 \%$ for up to one month and $3.57 \%$ for more than one month before. to die. CONCLUSION: In the present study, it can be seen that the deaths were mainly from men in the capital, in a proportion of 10: 1 in relation to women, and in the age group of 21-40 years, which fits the current statistics of mortality in Brazil, given that according to the Ministry of Health (2018), mortality from external causes in Brazil is higher in males, with a higher incidence in the age group between 21 and 49 years.

\section{RELATIONSHIP BETWEEN NUTRITIONAL STATE AND BASAL METABOLIC} RATE IN FUTSAL PLAYERS

Ester da Silva Caldas; Diogo Matheus Barros da Silva; Bruno Luiz Galvão de Miranda; Bianca Silva Frazão; Andressa Frazão Pereira; Antonio Coppi Navarro; Marlon Lemos de Araújo

Universidade Federal do Maranhão (UFMA), Centro Universitário Leonardo da Vinci (UNIASSELVI).

INTRODUCTION: Futsal has intermittent high intensity characteristics with incomplete recovery intervals, thus having mixed metabolic needs for the maintenance and supply of energy requirements during the practice of this sport. Such specifics of futsal may promote changes in the body composition of its practitioners. The aim of the present study was to analyze the nutritional status and basal metabolic rate of futsal players and to correlate the variables to identify possible links. METHODS: The sample consisted of 12 players from a futsal team, with average age $26.5 \pm 5.38$ years, average height $165.4 \pm 2.41 \mathrm{~cm}$ and total body mass $60.8 \pm 9.68 \mathrm{~kg}$. For termination of nutritional status and basal metabolic rate (BMR) the following specific equations were used: Body mass index $(\mathrm{BMI})=$ body weight $/$ height $^{2}$ and $\mathrm{BMR}=655+(9.6 \times$ weight in $\mathrm{kg})+(1,8 \times$ height in $\mathrm{cm})-(4.7 \times$ age in years), for classification the World Health Organization (WHO) reference values were used. The statistics were performed by Bioestat 5.3 software, using the tests: Kolmogorov-smirnov and Spearman correlation. RESULTS: The nutritional status of the players presented three classifications: eutrophic (50\%), overweight (40\%) and underweight $(10 \%)$. The basal metabolic rate was in kcal / day to a minimum of 1283,5 , in kcal / day to a maximum of 1536,56 , in kcal / day with an average of $1416,26 \pm$ 92,8402 . The correlation between the variables was positive, very strong $(r$ $=0.9785)$ and significant $(p<0.0001)$. CONCLUSION: We conclude that the players' halves are eutrophic, and others present nutritional disagreement, being underweight and overweight. Basal metabolic rate showed low value for regular sports practitioners. Correlation indicates that nutritional status may be another intervening factor in the basal metabolic rate of futsal players.

33. HANSENIASIS: OBSERVATIONAL DESCRIPTIVE STUDY OF HEALTH DATA OF MARANHÃO AND SANTA CATARINA

Richardson Chaves de Abreu; Willyanna Ravanielly Oliveira de Carvalho; Raquel Araújo Salvador; Catalina Ribeiro Gonçalves Santos; Sanny Pinheiro Oliveira

Universidade Federal do Maranhão (UFMA)
INTRODUCTION: Hanseniasis an infectious disease transmitted by bacteria, is a neglected illness in Brazil. The country occupies the second place worldwide in number of cases. In this context this paper executes an epidemiologic analysis of Brazil and compares the data of the states of Maranhão (MA) and Santa Catarina (SC). METHODS: This paper consists of a descriptive observational study that compares the Hanseniasis diagnosis rates per age group in the states of MA and SC based on data obtained through DATASUS from the years of 2007 to 2017 . The age groups derive from SID-10's classification of Hanseniasis wich separates the individuals under and over 15 years old. For the diagnosis rate the study took into consideration the brazilian population from 2010 (Instituto Brasileiro de Ceografia e Estatística's census). The rating represents the incidence of Hanseniasis per 100.000 people. RESULTS: As for the total of cases in the country, it fell from 41.549 in 2007 to 28.064 in 2017 . SC went from 3,62 to 1,61 cases/100.000 people and MA went from 61,99 to 44,50 cases/100.000 people. The number of cases among individuals under 15 years old in Brazil didn't reach 100 until 2012 but in 2013 rised to 1885 falling to 1258 in 2017. As for MA in the same category the numbers were over 10 until 2012 reaching 111 in 2013 and around 66 to 73 later. SC presented zero cases until 2012 and then a total of 1 to 4 cases each year. CONCLUSION: The number of cases of Hanseniasis in Brazil decreased between the years of 2007 and 2017. It is possible to deduce that there has been an improvement in disease control. Even though the states have a similar population there is a discrepancy in the number of cases. MA's Hanseniasis cases were about 45 times bigger than SC'S. Moreover, it can be assumed that gathering data of individuals under 15 years old is the primary indicator that the endemy is being monitored wich suggests that SC focuses more on "atenção básica" and on prevention mecanisms.

\section{REPERCUSSION OF UPPER AND LOWER TOOTH LOSS ON THE MAXILLARY-}

\section{MANDIBULAR STRUCTURE AND RELAT}

Luisa Maria Padre Mendes; Vandilson Pinheiro Rodrigues; Izabel Cristina Vieira De Oliveira; Gabriel Gomes Oliveira; Amanda Laryssa Pinheiro Santos

Universidade Federal do Maranhão (UFMA), Fundação de Amparo à Pesquisa e ao Desenvolvimento Científico e Tecnológico do Maranhão (FAPEMA)

INTRODUCTION: Tooth loss can modify the occlusion pattern of affected individuals, as well as generate a negative impact on quality of life, depending on the location and distribution of the losses. Thus, the aim of this study was to investigate the possible association between tooth loss in relation to structural changes and maxillo-mandibular relationships. METHODS: A cross-sectional study was conducted with a sample of 123 adults of both sexes, over 18 years old, with at least 10 erupted teeth. Individuals with orthodontic treatment or previous orthognathic surgery, incomplete or failed imaging exams and presence of osteointegrated implants were excluded. Variables related to tooth loss pattern, mandibular condyle morphology, as well as facial and occlusal factors were collected. These variables were evaluated by digital panoramic radiographs, lateral cephalometric and photographs. Descriptive statistics included measures of frequency, mean and standard deviation. In addition, a structural equation model was proposed to analyze the influence of exposure factors on mandibular condyle changes. RESULTS: The results showed the prevalence of higher tooth loss in lower molars, while the lowest was in lower anterior teeth. The variables significantly associated with tooth loss were age, age groups from 30 years, patients with Class II molar relationship, individuals with facial asymmetry and presence of alteration of mandibular condyle. The variation in age directly influenced the loss of posterior teeth. The loss of posterior teeth directly influenced the presence of facial asymmetry. CONCLUSION: The loss of posterior teeth had a significant direct effect in the presence of mandibular condyle changes. The findings suggest that referent tooth loss that may be associated with mandibular condyle changes.

\section{DIMORFOVIRCHOWIAN HANSENIASE SIMULATING RHEUMAID ARTHRITIS:}

\section{A CASE REPORT}

Horácio Jorge De Macedo Segundo; Amanda Karine Santos Firmo Julliana Ribeiro Assunção; Ricardo Tadeu Villa; Ana Carolina Fortes Braga Brederodes Villa; Pedro Vasques Rodrigues Cotini; Amanda Sakaguthi Figueiredo

UNIVERSIDADE FEDERAL DO MARANHÃO (UFMA), CENTRO UNIVERSITÁRIO PRESITENTE ANTONIO CARLOS (UNITPAC)

INTRODUCTION: Leprosy is a contagious infectious disease considered endemic in Brazil caused by Mycobacterium leprae, with affinity for 
peripheral nerve cells and skin tissue cells. This disease may present osteoarticular manifestations very similar to those observed in rheumatic diseases in general. CASE DESCRIPTION: Patient, 23 years old, student, reports that 15 years ago, he started arthralgia in the ankles and hands, associated with paresthesia in both feet. The patient looked for medical assistance, where was diagnosed with Rheumatoid Arthritis and oriented to use prednisone and anti-inflammatory, but there was no clinical improvement. On physical examination, she had brownish nodular and papular skin lesions on the face, chest and limbs with decreased thermal sensitivity, mild edema in the hands and feet, bilateral ulnar nerves thickened. Negative anti-CCP and negative RF and lesion biopsy showed perineural inflammatory infiltrate. That said, the diagnosis of dimorphovirchowian leprosy was confirmed. Treatment with MDT mb adult was started, however it had a reaction outbreak that was treated with thalidomide and prednisone for control. After 12 months of treatment, there was involution of the cutaneous lesions and marked improvement of the articular picture. CONCLUSION: In this case, an atypical onset was observed, with joint manifestations mimicking rheumatic diseases, which erroneously led the clinical reasoning and thus postponed the appropriate diagnosis and therapy. Given this, in a place with a high prevalence of leprosy, it is essential to keep it in mind as a differential diagnosis in cases of diagnostic difficulty or when there is no good response to specific therapy for another disease.

\section{ABRIKOSSOF TUMOR IN ASYMPTOMATIC PATIENT: CASE REPORT}

Carla Maria Da Silva Santos; Amanda Sávio Correia Araújo; Thales José Ribeiro Gonçalo De Sousa

CENTRO UNIVERSITARIO DO MARANHÃO (CEUMA)

INTRODUCTION: Granular cell tumor (CCT) was described, for the first time, in 1926 by Abrikossof. It is an uncommon benign neoplasm of soft tissue, histologically characterized by a proliferation of polygonal cells with granular appearances. It can appear in any organ, including the tongue, skin and mammary gland, being the most commonly affected sites. The involvement of the digestive tract occurs in about $5 \%$ of cases, of these $1 / 3$ are located in the esophagus and can be multiple. Esophageal localized tumors predominantly affect male patients, most of which are routine endoscopic findings. CASE DESCRIPTION: We report a case of a black autonomous, 46-year-old asymptomatic patient who search the Digestive Endoscopy center for routine evaluation. When the procedure was performed, it was detected in the esophageal mucosa by the distal third, a nodular lesion, whitish, firm, well delimited, subpediculate, measuring 2.0 $\mathrm{cm}$ in diameter. Endoscopic biopsy was collected and material sent for histopathological examination, resulting in granular cell proliferation without atypias, characterizing granular cell tumor or Abrikossof tumor. CONCLUSION: Granular cell tumors may appear throughout the gastrointestinal tract, but they are more common in the esophagus, especially in lower segments. Most are slow growing, and predominate at ages 40 to 60 years. These tumors may be multiple in 10 to $15 \%$ of cases and are usually indistinguishable from leiomyomas, which are the most common tumors among submucosal esophageal lesions. They are usually discovered randomly in Upper Gastrointestinal Endoscopy, ordered as in the case. Although almost always benign, the granular cell tumor can also be malignant in about $2 \%$ of cases. After definitive diagnosis of CCT benignity, it is agreed that the treatment of choice is surgical resection of the widemargin nodule.

\section{DESCRIPTION OF MENINGITIS CONFIRMED CASES IN MARANHÃO BETWEEN 2014 AND 2018}

Rafaela Macedo Pires Ferreira; José Alberto Pereira Pires; Sueli De Souza Costa; Rayssa De Oliveira Dominice; Sergio Antônio De Melo E Silva Borges; Beatriz Fontenelle Costa UNIVERSIDADE FEDERAL DO MARANHÃO (UFMA)

INTRODUCTION: meningitis is a public health problem worldwide distributed. In Brazil, it is endemic and an immediate compulsory notification disease. OBJECTIVES: the present research aims to characterize the epidemiology of confirmed meningitis cases in Maranhão from 2014 to 2018. METHODOLOGY: descriptive, quantitative and retrospective study describing confirmed meningitis cases which symptoms manifested for the first time between 2014 and 2018 in Maranhão. Data were collected from Notifying Disorders Information System (Sinan - Net), available online. RESULTS: in the five-year period studied 711 confirmed cases of meningitis were reported; $24,92 \%$ of these cases died. Viral meningitis was responsible for most cases $(19,12 \%)$ and bacterial meningitis accounted for $10,82 \%$. Males has dthe highest number of cases $436(61,3 \%)$, average incidence rate of 2,53 per 100 thousand individuals and average lethality of $24,92 \%$. Under 1 -year old subjects accounted for $13,64 \%$ of all cases; individuals from 20 to 39 years old represented $27,42 \%$. Among all causes of meningitis, the highest lethality (50\%) was found in 65 to 69 years old group; for this same group, the lethality rate was $100 \%$ for haemophilus meningitis and pneumococcal meningitis. Specific confirmation criteria data was inappropriate registered in Sinan and the absence of specification was designated as blank in 97,4\% confirmed cases. CONCLUSION: it is noticed that meningitis mainly affects men, has worse prognosis in elderly and its main etiological agent is viruses. Children under 1 year still have significant mortality from the disease. Difficulty in obtaining information on confirmatory methods reflects an obstacle to epidemiological study: data registration fails. Knowing the profile of compulsory notification health problem is essential for planning preventive actions and preparing professionals for early disease identification and best practice.

\section{NASAL CAVITY FOREIGN BODY COMPLICATIONS}

Ethnary Monteiro de Melo; Ihales Michel Carvalho Brandao Sousa; Rayla Bezerra Rocha; Ingrid Albuquerque de Araújo Self; Olívia Carvalho Couto; Renata Salomão Ribera; Patrick Rademaker Burke Centro Universitário do Maranhão(CEUMA)

INTRODUCTION: The presence of foreign bodies in the nostrils is among the most common causes of occurrence in Otorhinolaryngological Emergency, especially in the infant age group, providing the possibility of extreme complications, bronchial aspiration of the EC and or mucosal injury. Rhinoscopy is often possible only with the use of a clinical flashlight, but a nasal speculum may be required for better visualization of the cavity. In more extreme cases, nasofibroscopy and / or radiological examinations are used to verify the complexity of the cases. OBJECTIVE: To report on the analysis of 20 cases of foreign body patients with nasal cavities, with differentiation between age and types of EC. METHOD: Characterized by a retrospective study, with 20 patients treated at Hospital Socorrão 1 from January 15 to July 28,2019 . RESULTS: The highest incidences were in children from 0 to 4 years old; food grains (corn and beans) prevailing as the main foreign bodies found, totaling $40 \%$ of the cases, mostly in males, with rare cases presenting epistaxis as a complication. CONCLUSION: Otorhinolaryngological urgency of this type is the most common in younger children, so there is a need for a specialized approach with appropriate surgical instruments for foreign body removal in order to prevent internal nasal injury at the time of removal.

\section{TETRAPLEGY SECONDARY TO SPONDYLODISCITIS: CASE REPORT}

Rayla Bezerra Rocha, Wesley Costa Barros, Tiago Comes Arouche, Levy Chateaubriand Feller, Mario Jorge Batista Lima Cunha UNIVERSIDADE CEUMA; UNIVERSIDADE NOVE DE JULHO

INTRODUCTION: Spondylodiscitis corresponds to an infectious process involving two vertebral bodies and the adjacent intervertebral disc. It may be pyogenic or granulomatous, with the hematogenous route being the most common form of dissemination. The main risk factor is Diabetes Mellitus (DM). Early diagnosis and treatment are essential to avoid complications, such as vertebral collapse and spinal compression syndrome. CASE DESCRIPTION: Female patient, 58 years old, with cervical and lumbar pain for 3 months, refractory to opioids, left hemiplegia, difficulty walking and progressive motor loss in lower limbs. Presents a diagnosis of decompensated type $2 \mathrm{DM}$. He evolved with 4 -segment motor deficit, lower limb plegia, sphincter changes and afternoon fever of undetermined origin. CSF cytology showed research for negative BAAR and bacterioscopy, with other normal parameters. At CT of the cervical spine, bilateral neuroformal stenosis of $\mathrm{C}_{5}-\mathrm{C} 6$ and $\mathrm{C} 6-\mathrm{C} 7$ and fracture line of the lower plateau of $C_{5}$. MRI showed inversion of the cervical spine, deformity and alteration of vertebral bodies suggestive of spondylodiscitis, spina inflammation of $\mathrm{C}_{5}-\mathrm{C} 6$ and soft tissues, compression of the spinal cord at the level of $C_{5}$ and marked stenosis of the $C_{5}-C_{6}$ spinal canal. In the opinion of neurosurgery, diagnosis of spinal cord injury and spondylodiscitis, Meropenem $1 \mathrm{~g}$ was prescribed for 60 days. It evolves with the recovery of the sensitivity of the upper limbs and the abdomen to deep palpation. Awaits an end to antiobiotic therapy and reassessment for hospital discharge. CONCLUSION: It is a rare disease and nonspecific symptomatology, which makes its diagnosis more difficult and postpones the start of treatment, affecting its morbidity and mortality. The diagnosis 
of spondylodiscitis was confirmed through imaging tests associated with the clinical hypothesis raised by the history of the current disease, but it did not prevent the condition of complete motor deficit, due to late complications and low prevalence of the disease.

\section{ANALYSIS OF THE RELATIONSHIP BETWEEN MIGRAINE, HYPERTENSION AND STRESS LEVELS}

Karen Lopes de Sousa Ferreira; Thamires Sales Ribeiro; Emanuel Cabral Pereira; Mateus Ribeiro Gonçalves Carvalho; Déborah Costa Alves; Raynan Costa Santana; Plínio Cunha Leal Universidade Federal do Maranhão (UFMA)

BACKGROUND: Studies have shown a possible association between migraine and systemic arterial hypertension (SAH), but with contradictory results, however no studies to date have investigated the relationship between SAH, migraine and biomarkers of stress and inflammation, nor considered the role of neuropsychological comorbidities for analysis. METHODS: Quantitative, observational, analytical, case-control study. The sample consisted of 70 participants of both genders, aged $>18$ years, divided into four groups: hypertensive with migraine, hypertensive without migraine, normotensive with migraine, normotensive without migraine. Scientifically validated questionnaires specific to each variable analyzed were used. The unstimulated saliva was also collected from each patient in the morning shift for a period of 10 minutes. RESULTS: The normotensive ones are younger than the hypertensive ones and regarding the other demographic data there was no statistical difference between the groups. Groups with migraine have a poorer overall quality of health and a greater disability for work / school and domestic tasks. In addition, individuals with migraines are subjected to a higher intensity of chronic pain, stress and anxiety. Hypertensive individuals with migraine have a lower salivary $\mathrm{pH}$ than those without migraine. The collected saliva will be used for further analysis of cortisol and C-reactive protein levels, as both are stress biomarkers. CONCLUSIONS: The association between migraine and anxiety, stress, chronic pain and an impact on life quality was found in the study, and it was also found that this may even be a risk factor for the development of these signs, symptoms and comorbidities. Furthermore, the finding of biomarkers associated with migraine is of great interest for clinical practice regarding the prevention and treatment of this condition.

\section{PATHOGENIC VARIANTS IN THE ARPC 1 B GENE ASSOCIATED WITH PLTEID:} CASE REPORT

Rayssa Mayara Rodrigues de Souza; Lívia Castro dos Santos; Ana Paula de Castro Ahid; Maria Juliana Rodovalho Doriqui

Universidade CEUMA (UNICEUMA); Hospital Infantil Dr. Juvêncio Mattos.

INTRODUCTION: Abnormal platelet disease with eosinophilia and inflammatory immune mediators (PLTEID), autosomal recessive, caused by mutation in the $A R P C 1 B$ gene leads to severe clinical repercussions such as skeletal, gastrointestinal, dermatological, immunological (eosinophilia and elevated IgE) and haematological abnormalities. (vasculitis and platelets abnormallity). This report is about a PLTEID case with a mutation never described in literature before, aiming to disseminate the knowledge about the main manifestations of the disease, stimulating early diagnosis and adequate genetic counseling. CASE DESCRIPTION: Female, 1 year and 9 months, no parental consaguinity, deceased brother with similar condition. $\mathrm{He}$ had diffuse erythematous lesions at birth, which became pruritic afterwards. He had abdominal distension, alternating diarrhea and constipation; low weight gain; diffuse hypochromic cicatricial macules; scaly erythema on the scalp and skin pustules that progressed to ulcers. History of various hospitalizations due to skin lesions, diarrhea and fever. Physical examination showed lesions suggestive of atopic dermatitis, pyoderma scars and pustules, without significant dysmorphia. Additional tests revealed eosinophilia; elevated total IgE (1270); fecal occult blood and positive fecal fat and leukocytes; skin biopsy with nonspecific chronic inflammatory process. An exoma focusing on genes of clinical interest identified two heterozygous variants in the ARPC1B gene, Chr7:98.988.854CAG>C and Chr7:98.983.402G>A. CONCLUSION: Pathogenic variants in this gene are associated with immunomediated inflammatory disease with great clinical variability, from recurrent infections, vasculitis and platelet changes. It is emphasized the importance of genetic investigation in the face of clinical conditions not responsive to conventional therapy, or rec, besides alerting to the history of similar cases in relatives, infant deaths of undefined etiology.

\section{EPIDEMIOLOGIC PROFILE OF DEATHS BY RESPIRATORY INFECTIONS ON MARANHÃO FROM 2014 TO 2017}

Victor Hugo Morais Costa; Thuane do Nascimento Bezerra; Danielle de Araújo Nunes Pereira; Ruthe Rawenny Costa; Jheovanna Cally Oleveira; Tamires Conceição do Carmo Silva; Fernando Ribeiro Castro

Universidade Estadual do Maranhão (UEMA)

BACKGROUND: The respiratory infections are a vast group of diseases which involves influenza, pneumonia and pertussis. The etiology changes depending on the disease (virus, bacteria or both) and, besides being responsible for a great number of hospitalizations, they can also be commonly transmitted inside hospitals. Sneezes, sore throat, fever, chills, runny nose are the main symptoms, but there are other ones more specific to each illness. On a general perspective, respiratory infections cause airways inflammation, fact that leads to associated conditions. Therefore, this work aims to analyze the epidemiologic profile of deaths caused by respiratory infections on Maranhão in the period of 2014 to 2017. METHODS: The search was made on DATASUS (site: http://datasus.saude.gov.br/), in which were selected: vital statistics; mortality - 1996 to 2017 , according to CID-10; deaths by evitable causes - 5 to 74 years old. The search operators were fulfilled considering the period of interest. RESULTS: The respiratory infections were responsible for $35,18 \%$ of evitable deaths by prevention of infectious diseases. Almost one third $(29,1 \%)$ of the cases happened on 2017 and it was shown that men $(56,06 \%)$, people between 60 and 69 years old $(29,18 \%)$ and the ones with low schooling (762 cases - of 2232 - on those who had none schooling). CONCLUSION: Regarding the exposed data, it's possible to see the main groups affected by respiratory infections, what justifies directing more efforts to those. It was also observed the crescent incidence on men (low difference, but it can be explained by the fact that women are more likely to go after the health service), elderly because of the natural immunological weakness and on low schooling people.

\section{SYSTEMIC ARTERIAL HYPERTENSION ANALYSIS AS A NEONATAL RISK FACTOR}

Rayssa Mayara Rodrigues de Souza; Larissa Balby Costa; Thaiana Abas de Moraes Rego; Marianna Sousa Maciel Gualberto de Galiza; Gabriela Coutinho Amorim Carneiro; Maria do Perpetuo Socorro de Azevedo Veras

Centro Universitário do Maranhão ( CEUMA)

INTRODUCTION: Pregnancy is a physiological phenomenon for most women, however, in some of them there may be problems in its evolution, putting at risk the health of the mother and the concept. Among maternal diseases of this period, systemic arterial hypertension (SAH) as one of the most harmful effects on the maternal, fetal and neonatal organism. The most frequent repercussions for the concept associated with this disease in pregnancy are: intrauterine growth restriction, low birth weight, prematurity and perinatal mortality. Thus, it is one of the main public health problems. The objective of this study is to evaluate the prevalence of hypertension in pregnancy relating to low birth weight, prematurity and neonatal deaths. METHODS: This was a retrospective cross-sectional study from 2015-2018, conducted through analysis of the Brazilian Neonatal Research Network (REDCap) in a public university hospital in the city of São Luís, a reference in high complexity. RESULTS: of a total of 535 parturients admitted to the hospital, $174(32.5 \%)$ had hypertension in this pregnancy, $22(4.1 \%)$ with chronic hypertension. As for newborns of hypertensive mothers, 39 were observed. (22.4\%) neonatal deaths, there were 115 preterm infants under 32 weeks $(66.09 \%), 51$ preterm infants weighing $<1000 \mathrm{~g}(29.3 \%)$, and 6 of them were weighing $<600 g(12 \%)$. CONCLUSION: SAH was significantly associated with prematurity and low birth weight, also indicating a relative frequency of perinatal mortality, confirming and demonstrating the damage to the maternal-fetal binomial and the prevalence of this disease in our country. It becomes important early diagnosis of hypertension in pregnancy plus intervention at an opportune time in order to conduct a pregnancy without maternal complications and health problems.

44. EWING SARCOMA (PNET) IN AN UNHABITUAL AGE BAND: A CASE REPORT Karen Lopes de Sousa Ferreira; Thaynara Lindoso Silva Veloso; Plínio da Cunha Leal; Marcus Vinicius Lindoso Silva Veloso; Deborah Cristina Marquinho Silva; Maria Tenório Dantas Britto; Maria Eduarda Coelho Pessoa Universidade Federal do Maranhão (UFMA), Centro Universitário do Maranhão (CEUMA) 
INTRODUCTION: Ewing's Sarcoma (ES) is a rare bone malignant neoplasia. ES along with Primitive Neuroectodermal Tumor (PNET) are part of the Ewing Family of Tumors (EFTs). EFTs are more common in young patients up to 30 years old, predominant in men, and are considered very rare in the black population. CASE DESCRIPTION: P.L.S, male, 46 years old, brown was diagnosed with Ewing's sarcoma (PNET). In August 2018, a patient began to experience severe pain in the right iliac fossa that made him seek an emergency hospital. Subsequently, an abdominal tomography (09-2018) was requested, which showed an expansive, heterogeneous formation (10X 8.2X $7.6 \mathrm{~cm}$ ) in the right pelvis inseparable with seminal vesicle, anus, rectum, prostate, bladder floor, internal obturator muscles and right piriformis. In addition, it involved branches of the right internal iliac artery and veins. The histopathology indicated fragments of connective tissue with aggregated cells most likely of inflammatory origin. Immunohistochemistry demonstrated that the morphological aspect was suggestive of Ewing's sarcoma (PNET). Another biopsy (by laparoscopy) was performed (02-2019) and presented the same aspect found previously. He started the neoadjuvant chemotherapy regimen (vincristine, doxorubicin and cyclophosphamide + ifosfamide and etoposide) in March 2019. In July of the same year, pelvic tomography showed a lesion measuring $13.6 \times 12.7 \times 10$ $\mathrm{cm}$, showing no radiological improvement. Patient continues to do chemotherapy cycles. Twenty-five neoadjuvant radiotherapy sessions were scheduled. CONCLUSION: We report a case of a rare cancer in an uncommon age group. To make a tumor diagnosis, it is important to make a clinical and radiological correlation. Although uncommon, knowledge about Ewing's sarcoma is relevant to avoid confusion with other tumors as well as better cases follow-up.

45.

\section{CLASSIC DIAGNOSIS OF RHEUMATIC FEVER: A CASE REPORT}

Sérgio Antônio de Melo e Silva Borges; Amanda Patrícia Vasconcelos Matos; Nathaly Vitória Portela Santos; Gustavo Emanuel Lima Pinheiro; Andresa Alves de Lima Galvão; Laís Fernanda Vasconcelos Câncio

UNIVERSIDADE FEDERAL DO MARANHÃO (UFMA)

INTRODUCTION: Rheumatic fever (RF) is a multisystem inflammatory disorder that presents with self-limiting migratory arthritis and may also be accompanied or followed by carditis and less frequently by chorea and cutaneous involvement. It is related to post-infectious autoimmune mechanisms directed to group A streptococcal antigens. CASE DESCRIPTION: Male, 18 years old, student, single, resident of Amapá do Maranhão (MA), sought medical attention complaining of "chest pain, pain in joints of hands and feet and lump in head and right elbow". The patient evolved, after the onset of feverish flu, with migratory arthritis, starting at the right wrist joint, lasting three days and following the same symptoms on the contralateral side, with subsequent improvement. It also refers to the emergence of fixed, solid and painless nodulations in the right parieto-occipital region and posterior face of the forearm. She sought care about two months ago in her municipality complaining of precordial pain due to spontaneous cessation of inspiration and dyspnea, underwent symptomatic treatment. After worsening, he was referred and admitted to the Macroregional Pinheiro Hospital (MA). On admission, he had deep inspiratory chest pain and fixed, solid and painless nodulations in various regions, in addition to murmuring in mitral focus on cardiac auscultation. In the complementary exams: ASLO: 968.20lU / mL; P CR: 3.9mg / Dl; ESR: 70mm; TTE: eccentric hypertrophy of the left ventricle, mitral valve presenting thickening at the leaflet ends, with a hockey stick opening. CONCLUSION: Rheumatic fever has no pathognomonic manifestations. Thus, its classical diagnosis is based on the recognition of the Jones criteria, evidenced throughout the report. Chief among these are the presence of arthritis, carditis, subcutaneous and antibody titers against streptococcal exoenzymes.

46. SELF-PERCEPTION OF UNIVERSITY STUDENTS FROM SÃO LUÍS-MA AS TO ITS SLEEP QUALITY

Edinalva De Morais De Sousa; Lanna Laíse Rodrigues Da Silva; Mara Dalila Rodrigues Prazeres; Fabiana Viana Maciel Rodrigues; Matheus Caíck Santos Brandão; Thalita de Albuquerque Veras Câmara; Marcos Roberto Campos de Macêdo Faculdade Estácio São Luís
INTRODUCTION: Sleep has as its main roles the restoration of energy, maintenance of concentration, memory consolidation and the processes that involve learning. In this context, academic activities can interfere with eating habits, due to the large routine transition, where students go to sleep and eat at irregular times. Thus, the present study aimed to evaluate the perception of students of a Private College in São Luís regarding their sleep quality. METHODS: This is a descriptive, cross-sectional study with a quantitative approach, consisting of 47 college students from the last period of the nutrition course, of both sexes. The instrument used to meet the objective of this research was the Pittsburgh Sleep Quality Index (PSOI-BR) questionnaire, which assesses sleep quality in the period prior to the interview and contains nineteen self-administered questions. In the present study, only the subjective sleep quality component was used, which selfrated sleep quality as: very good, good, bad and very poor. RESULTS: It was observed that $53,19 \%(n=25)$ students rated their sleep quality as good, $10,63 \%(n=5)$ as very good, $29,63 \%(n=14)$ classified as poor and $6,38 \%(n=3)$ rated it very bad. CONCLUSION: Most students rated their sleep quality as good or very good, however there is the smallest part that rated their sleep quality as poor or very poor. Given this, the negative perception of sleep quality may be related to changes in performance and academic learning, thus deserving special attention.

\section{ASSOCIATION BETWEEN THIRD LOWER MOLAR POSITION AND MANDIBULAR MORPHOLOGY}

Gabriel Comes Oliveira; Vandilson Pinheiro Rodrigues; Izabel Cristina Vieira de Oliveira; Luisa Maria Padre Mendes; Amanda Laryssa Pinheiro Santos Universidade Federal do Maranhão (UFMA)

INTRODUCTION: Third molars are usually the last teeth to erupt in the ora cavity. Incomplete eruption is a serious problem due to its high incidence and association with pathological processes such as the formation of caries lesions, pericoronitis and neoplastic lesions. Thus, the reduced arch space has been considered the main factor that interferes with third molar eruption. Thus, the aim of this study was to investigate the association between lower third molar anatomical positioning and mandibular cephalometric patterns. METHODS: A cross-sectional study was conducted with a sample of 70 orthodontic cephalometric documentations of both sexes, regardless of malocclusion, of patients aged 11 to 30 years and at least one lower third formed or in formation. Documentation of patients previously undergoing orthodontic treatment or orthognathic surgery was excluded. The Modified Pederson Index was used for visual analysis of panoramic radiographs in order to classify the spatial relationship, depth and relationship with the mandibular branch. Cephalometric data were collected from lateral cephalograms and panoramic radiographs in order to evaluate the mandible position, vertical growth and dental pattern. RESULTS: The data showed an inverse correlation between the worsening of the third molar spatial relationship and the Sn.Plo angle $(r=-0.23)$, and also an inverse correlation between SNB angle increase and depth worsening $(r=$ o. 19) and worsening of the relationship with the branch $(r=-0.19)$. In the final classification for surgical difficulty, most of the sample had the third molar in a moderately difficult position ( $45.71 \%$ ). CONCLUSION: Data indicate that variations in vertical growth and jaw positioning may be associated with the lower third molar spatial position.

\section{CHOLEDOCHODUODENOSTOMY IN THE ERA OF MINIMAL INVASIVE PROCEDURES}

Eduarda Felipe Meinertz; Rebeca Lara da Costa Carvalho; Luiza Mariana Batista Lima Cunha; Luana Lara Farias de Jesus Neves; Ozimo Pereira Gama Filho

Centro Universitãrio do Maranhão (CEUMA)

BACKGROUND: Present era of endoscopic and laparoscopic approaches have revolutionized surgical management of Common Bile Duct (CBD) stones. open procedures like Choledochoduodenostomy (CDD) have become a rarity but are not completely obsolete. It may be considered a relatively safe alternative when dealing with recurrent, too large or impacted stones, a failed Endoscopic Retrograde Cholangiopancreatography (ERCP), and CBD stricture with stones. The aim of this study was to establish safety, efficiency, cost effectiveness and easy availability of CDD in selected patients. METHODS: In this observational study, the outcome of 26 consecutive patients undergoing CDD between 1st January 2007 and 31st December, in surgical unit of Digestive Surgery of Progastro Clinic was reviewed. Choledochoduodenostomy was offered to patients who refused 
or had a failed ERCP and when CBD size was more than $2 \mathrm{~cm}$. Common Bile Duct was anastomosed to Duodenum using standard technique. RESULTS: Medical records of 26 patients (age range 19-81years) were reviewed; complication rate was $11 \%(n=3)$ including respiratory complications in $(n=1)$, wound infection in $(n=1)$ and Cholangitis in $(n=1)$ and Mortality in $(n=1)$. There was no evidence of Sump Syndrome. The Length of stay (LOS) was 9 days with a standard deviation of 6 . CONCLUSIONS: Choledochoduodenostomy is a safe procedure, with fewer complications and in case of ERCP failure, CDD is recommended.

\section{FUNCTIONAL REHABILITATION OF ONCOLOGICAL PATIENTS WITH PARTIAL} LOSS OF THE PALATE

Valbiana Cristina Melo de Abreu Araujo; Rayssa Ferreira Cavaleiro Rômulo Diego Marinho Siqueira; João Paulo Dutra Lobo Sousa; Luciano Almeida Muniz; Ana Maria Lima

Universidade Federal do Maranhão (UFMA)

INTRODUCTION: The buccal-maxillofacial prosthesis allows the rehabilitation of individuals with craniofacial deformities, resulting from traumas, congenital malformations or tumors. This occurs, among many other factors, due to the surgical removal of an injury, which generates sequelae with functional and aesthetic impairments. Thus, the dentist seeks, by means of prosthetic rehabilitation, to reinsert the individual into society, returning to him the self-esteem and function previously lost. CASE DESCRIPTION: Female patient, 72 years old, sought the integrated clinic of the dentistry course of UFMA, complaining of dysfasia and difficulty to feed and breathe, consequences of partial loss of the palate after surgical removal due to oncologic treatment by a pleomorphic carcinoma. After detailed and thorough anamnesis, the physical examination was performed, in which a morphological alteration with buccal-antral communication was observed. For treatment, a prosthetic rehabilitation was proposed with a superior partial obturator prosthesis. Initially, a molding was made to obtain the test base and the orientation plan. Then, the aesthetic and functional test of the piece, the assembly of the teeth and then the acrylization of the prosthesis, with the posterior finishing and polishing were done. Finally, the prosthesis was installed and the patient was being proservated. CONCLUSION: Clinical success was obtained, since it was returned function to the patient, also improving its aesthetics and self-esteem, and, as a consequence, its quality of life.

50. GINGIVAL HYPERPLASIA INDUCED BY ANLODIPINO USE: A CASE REPORT Amanda Sakaguthi Figueiredo; Rafael Gomes de Lucena; Alinne Katienny Lima Silva Macambira

UNITPAC

INTRODUCTION: Gingival hyperplasia is an alteration first reported as an adverse effect in 1939. Among the most common medications that can lead to this condition are immunosuppressive, anticonvulsant and antihypertensive drugs. Some risk factors may be related to the severity of gingival hyperplasia, including poor oral hygiene, existing gingival inflammation, and combined pharmacological therapy for gingival enlargement drugs. This condition is benign, most often regressing only with discontinuation of the causative medication. CASE DESCRIPTION: FJNL, male, 43 years old, married, self-employed, hypertensive for 4 years, presenting pain and gingival enlargement 2 months after starting the use of Anlodipino, also using Losartan and Hydrochlorothiazide for blood pressure control, without other comorbidities, former smoker (ceased 10 years ago), denies allergies and previous surgery. After diagnostic elucidation, the medication was discontinued and the patient was referred for treatment with a dentist who underwent surgical procedure to treat the case, evolving with improvement of the condition. CONCLUSION: Gingival hyperplasia is considered a serious adverse effect and has been widespread in the periodontal scientific literature. In cases caused by antihypertensive drugs, Nifedipine stands out; however, cases related to the use of Anlodipine have increased in the literature, as well as in the literature. case described. Detailed anamnesis and knowledge of medical history along with the professional's domain about the adverse effects of medications help in the differential diagnosis of this pathology.

\section{SERIOUS SECONDARY MYCOARDIOPATIA TO SARCOGLICANOPATIA}

Thaís Oliveira Nunes Da Silva; Daniela Serra De Almeida; José Albuquerque De Figueredo Neto; Annanda Carolina De Araújo Martins; Petra Samantha Martins Cutrim; Tácio Danilo Araújo Pavão; Illana Catharine De Araújo Martins

Centro Universitário do Maranhão (CEUMA); Hospital Universitário da Universidade Federal do Maranhão (HUUFMA); Clinica Cardio Check up

INTRODUCTION: The onset of symptoms usually occurs in the first decade of life, and may vary from the first to 18 years. The involvement of the proximal and symmetrical muscles, starting at the pelvic waist, with progression similar to Duchenne and Becker's muscular dystrophy, in 50\% of the cases. It can also occur early in young adulthood and have varying progression of symptoms. Facial muscles may be affected in the advanced stages of the disease, calf hypertrophy is a common finding. Cardiac changes are uncommon. Early and regular cardiac evaluation is required for some muscular dystrophies, as the risk of sudden cardiac death is present before cardiac symptoms occur and obvious signs of cardiomyopathy. CASE DESCRIPTION: We present a case report of a patient with dilated cardiomyopathy associated with waist-type muscular dystrophy. Patient started dyspnea on exertion associated with orthopnea, paroxysmal dyspnea, nocturnal dry cough and lower limb edema. He was diagnosed with Dilated Cardiomyopathy with Ejection Fraction of $24 \%$, and standard treatment for Heart Failure (HF) and diuretic therapy was initiated. Patient with Girdle Muscular Dystrophy diagnosed at 11 years, with normal cardiac function and follow-up interrupted after 4 years of diagnosis. She evolved with clinical improvement and was discharged with optimized clinical treatment. After seven months, in outpatient consultation, it was detected that the patient had atrial fibrillation and was chosen to perform anticoagulation and subsequent electrical cardioversion. Patient is classified as NYHA class II and presents improvement of ventricular dysfunction. CONCLUSION: Despite being a known prognostic cardiomyopathy without specific therapy for the underlying disease, early diagnosis allows the introduction of palliative measures that improve and prolong life.

\section{BORN ALIVE WITH PROFILE DEFORMITY CONGENITAL MUSCULOSKELETAL IN MARANHÃO IN 10 YEARS}

Andreia Dos Santos Muniz; Amanda Lopes De Freitas; Aryadnne Cristinne Machado Costa; Bruna Cristina Cunha Leite; Lorena De Sousa Mendes; Antonio Luis Rodrigues Costa Junior Universidade Federal do Maranhão (UFMA) - CAMPUS PINHEIRO

INTRODUCTION: In the state of Maranhão (MA), the osteomuscular system is the one that most presents cases of congenital malformations (MCS). The dignostics of such anomalies cause great impact in the family context and their occurrence is related to the presence of some maternal and newborn characteristics (RN). OBJECTIVE: To profile congenital deformities of the osteomuscular system in the state of Maranhão. METHODOLOGY: Descriptive study, considering secondary data from the Department of Information Technology of the Unified Health System (DATASUS), on the total number of live births (NVs) and MCs of the osteomuscular system, as well as maternal and RNs-related variables of MA through SINASC/DATASUS data, in the period from 2007 to 2016. RESULTS: Period 2007-2016: 1.196.086 NV children (as) of mothers resident in MA; $4.532(0.4 \%)$ some type of MC; $1.986(43 \%)$ MC of the osteomuscular system; Male sex $1.115(56.1 \%)$; Increase of MC of the osteomuscular apparatus (2016/2007) $(0.12 \%) / 253$ (2.3\%); Among the NV with MCs of the osteomuscular system: $1,233(62.1 \%)$ in the $1 \sim$ minute Apgar within the interval of 8 to $10 ; 1,577(79.5 \%)$ in the 5 th minute Apgar within the interval from 8 to 10 ; Weight at birth: 995 (50.0\%) per cent) $(46.1 \%)$ children born to mothers who attended between 4 and 6 prenatal visits; $1,534(77.2 \%)$ gestation lasting from 37 to 41 weeks; mother age: $615(31 \%)$ 20 to 24 years; maternal education: $1,024(51.6 \%)$ incomplete secondary education; Single-type pregnancy: 1,929 (97.1\%); 1,069 (53.8\%) vaginal delivery. CONCLUSION: The profile of MCs in the state of Maranhão is of boys, with birth weight between 3.000 g and 3.999 g, children of mothers with incomplete high school, who had between four and six prenatal visits.

53. SCREENING FOR REACTIVE ADDICTION DISORDER IN IMPERATRIZ INSTITUTIONALIZED CHILDREN 
Agata Layanne Soares da Silva; Alexsander Silva De Oliveira; Michaele Barbosa Cruz Lira; Hianca Mirelle da Silva; Andreza Maués Dias Nascimento; Guilheme Zacarias Queiroz de Barros Braga; Jullys Allan Guimarães Gama

Universidade Federal do Maranhão - UFMA, Campus Imperatriz.

INTRODUCTION: Reactive Attachment Disorder (ART) constitutes aberrant social behaviors that reflect the environment to which the child is subjected and subdivided into inhibited and uninhibited. From this, this work aims to track the triggering factors for ART in institutionalized children. METHODS This is a quantitative research carried out with 13 children from 02 to 08 years old, coming from the Casa da Criança de Imperatriz. Data were collected through information contained in the registration forms. The instrument for collection was a semi-structured questionnaire based on risk factors and symptomatology, by signing the informed consent form by the manager. RESULTS: According to data obtained $46.1 \%$ are female and $53.8 \%$ male. Regarding the economic profile and education of the former manager all were low income and had only fundamental level. In addition, $46.2 \%$ of the children had mothers with psychiatric problems, and $46.6 \%$ had parents with chemical abuse, highlighting the main reasons for institutionalization. Moreover, $15.4 \%$ of the children who arrived recently had no relationship with any caregiver or the other children. With regard to known traumas $92.3 \%$ corresponds to the abandonment of incapable, $7.7 \%$ death of the responsible person, emotional neglect, physical abuse and abuse. Finally, regarding the emotional state after admission, were: $84.6 \%$ fear and sadness, $53.8 \%$ malnutrition and signs of poor care, $7.7 \%$ inhibition, $23 \%$ hyperactivity, cognitive retardation, language delay. CONCLUSION: Therefore the results showed that family history and type of trauma suffered by sheltered children are a triggering factor, prevailing the type inhibited when arriving at the institution and uninhibited after being received. However, a study with larger sampling and more variables to accurately predict how it occurs and ways to prevent its development is urgent.

\section{HEMORRAGY IN ADENOAMIGDALECTOMY: CASE STUDIES}

Ethnary Monteiro De Melo; Patrick Rademaker Burke; João Pedro Costa Junguer; Rayla Bezerra Rocha; Ingrid Albuquerque De Araújo Self; Ihales Michel Carvalho Brandão Sousa; Renata Salomão Ribera Centro Universitário do Maranhão(CEUMA)

INTRODUCTION: Adenoamigdalectomy is an otorhinolaryngological surgica procedure, indicated for the removal of tonsils and adenoids, due to the conditions of upper airway obstruction due to the hypertrophy of these structures; It is characterized as a procedure of low complexity, except in the incidence of postoperative hemorrhage. OBJECTIVE: To observe the number of patients who present hemorrhage during the immediate and postoperative period. METHODS: Twenty-eight patients who underwent adenotonsillectomy were prospectively observed at a municipal hospital in the interior of Maranhão, Brazil, from April to May, 2019. RESULTS: Two out of 28 patients underwent surgery. (24h after the procedure) in the immediate postoperative period. CONCLUSION: Currently, adenotonsillectomy represents on average $70 \%$ of ENT procedures, where laser and radiofrequency have currently been proposed to replace techniques such as dissection and BALLENGER-SLUDER; However, what can be noticed is that, considering all the proposed techniques, the incidence of hemorrhage is low and quickly resolved.

\section{EPIDEMIOLOGICAL PROFILE OF THE DEBT OF ACUTE APPENDICITIS IN A} PUBLIC HOSPITAL OF SAO LUIS

Rodrigo Matheus Santos Alves; Paulo Cabriel Sacramento da Silva; Gustavo Manfio Lemes Campos; Ricardo José Guimarães de Sousa Mourão; Ana Josephy da Silva Costa Oliveira; Larissa Rolim de Oliveira Sales; Santiago Cirilo Noguera Servin Universidade Federal do Maranhão - UFMA

INTRODUCTION: To present the epidemiological profile of appendicitis deaths registered at Djalma Marques Hospital (HDMD) of São Luís - MA between 2015 and 2018. METHODS: Retrospective study involving appendicitis death survey between 2015 and 2018, through consultation with the HMDM medical records. Data were stored and analyzed using Microsoft Excel version 2013. The following variables were analyzed: origin, age, gender and length of stay. RESULTS: From 2015 to 2108 we had an incidence of deaths from acute appendicitis of 12 cases. There were no deaths from appendicitis in 2015 , there were $1(8.34 \%)$ in $2016,6(50 \%)$ in 2017 and $5(41.66 \%)$ in
2018. Both genders were equally affected, with $6(50 \%)$. men and $6(50 \%)$ women. The origin of the victims was mainly from the interior of Maranhão $(66.66 \%)$, while the others $(33.34 \%)$ came from the capital. The most affected age group was over 60 years old with $5(41.66 \%)$ deaths, $4(33.34 \%)$ deaths at 41-60 years and $3(25 \%)$ deaths at $21-40$ years. Length of stay related to the highest number of deaths was in patients with up to 01 month of hospitalization $(41.66 \%)$, compared to deaths with up to 01 day of hospitalization (16.67\%) and up to 01 week (16.67\%) and more than 01 month ( $25 \%)$. CONCLUSION: Deaths were mainly in the elderly ( $>60$ years), coming from the interior of the state and who were hospitalized for a period longer than 1 week and less than 1 month. The delay in performing the surgical treatment is an extremely important factor, since the treatment can vary from a simple appendectomy when identified early to stepped approaches requiring percutaneous drainage and extensive laparotomies that increase the complications and mortality of the disease, especially when there is delay in diagnosis and treatment.

\section{DIAPHRAGMATIC HERNIA RIGHT BY AUTOMOBILE ACCIDENT - CASE REPORT}

Manuela Correa Dos Santos Reis; Lia Gabriela Luciano Gonçalves Centro Universitário do Maranhão (CEUMA)

INTRODUCTION: Diaphragmatic hernia (HD) refers to protrusion of the contents abdominal into the chest through diaphragm anomaly. Usually if manifested in the posterolateral portion of the diaphragm (Bochdalek's hernia) and occurs in the left side in $93 \%$ of cases; at $2 \%$, it is bilateral. Diaphragmatic rupture at The right side occurs in only $5 \%$ of cases. This disparity in incidence between sides is given by the protective effect of the liver to the right diaphragm. The compression pulmonary disease may cause persistent pulmonary hypertension. The treatment is correction surgical CASE DESCRIPTION: DJN, 39, Female, Mixed, Married, resident in Viana - MA, 2 days ago sought the service of the Emergency Hospital and Emergency Dr. Clementino Moura - First Aid, with severe abdominal pain skin intensity and pallor. Patient reports having suffered car accident 5 years ago. CT scan of the total abdomen: herniation of intestinal loops and liver to the right hemithorax, with deviation of the structures mediastinal to the left. Liver in anomalous position, in thoracic projection, suggesting right diaphragmatic hernia of probable traumatic cause. Little amount of free fluid in the lateral flanks and in the right iliac fossa, suggestive pelvi-peritonitis, with an image suggestive of an inflammatory appendix. Was performed appendectomy after findings. The patient was referred for thoracic surgery. treatment for treatment of diaphragmatic hernia. CONCLUSION: The HD on the right, although uncommon, it is extremely relevant to medical knowledge in the face of its gravity. Surgical intervention prevents the advancement of compression of the whole chest causes restrictive obstructive mechanisms over the entire center of the hemodynamics and ventilation.

\section{PROGRESSIVE MULTIFOCAL LEUKOENCEPHALOPATHY IN AIDS CARRIER: CASE REPORT}

Gabriel Costa Ferreira Andrade; Amanda Angelo Angelo Pinheiro Camila Souza Maluf; Ingrid Macedo Araújo; Maria Eduarda Andrade e Andrade; Gabriela Coutinho Amorim Carneiro; Emille Ananda Lucena Pereira

Centro Universitário do Maranhão (CEUMA)

INTRODUCTION: Progressive multifocal leukoencephalopathy (PML) is a rare and fatal neurological disease caused by opportunistic infection of the central nervous system (CNS) papovavirus JC. Opportunistic disease leads to progressive focal or multifocal demyelination, and is generally associated with immunodeficiency due to neoplasms, iatrogenesis and currently Acquired Immune Syndrome (AIDS). PML affects between 5 and $10 \%$ of AIDS patients, and clinical manifestations are variable as it depends on the affected area. This paper aims to report the case of an AIDS patient with PML. CASE DESCRIPTION: MPSF, 47-year-old female, was admitted to the São Luís Public Network Hospital with Altered Level of Counsciusness, Glasgow 10, mental confusion, asthenia, slight tremor of the hands (hands), upper limb paraesthesia and moderate paresis of lower limbs beginning 2 weeks ago. Patient has been positive for HIV (Human Immunodeficiency Virus) for 8 years, receiving irregular treatment. After 1 week of hospitalization, the patient developed Clasgow 9, grade 4 tetraparesis, disorientation, urinary and fecal incontinence. Cranial computed tomography without significant alterations and Magnetic Nuclear Resonance showed alterations compatible with the suspicion of PML. After diagnostic confirmation by CSF Polymerase Chain Reaction (PCR) for JV virus, supportive treatment was initiated. The 
patient died after 30 days of hospitalization. CONCLUSION: As in the case described, PML is a fatal disease with a poor prognosis even with supportive therapy. There is significant appeal for a broader knowledge of this disease as there is no specific and effective treatment. The problem of the increase of AIDS cases in Brazil is another important point, as it is the main infection adjacent to PML, almost always associated today.

\section{BODY ADIPOSITY INDEX AND LEVEL OF FLEXIBILITY IN ACTIVE AND} SEDENTARY ELDERLY.

Bruno Luiz Galvão De Miranda; Diogo Matheus Barros Da Silva; Ester Da Silva Caldas; Roger Medeiros Xavier; Diego Antonio De Jesus Macau; Raphael Furtado Marques; Marlon Lemos De Araújo Centro Universitário Leonardo da Vinci (UNIASSELVI), Universidade Federal do Maranhão (UFMA)

INTRODUCTION: The aging leads to a progressive loss of organic functional capacities, with reduction of flexibility and joint mobility, decreased muscle mass and increased body fat. The physical exercise (PE) is strategic to reverse this process, contributing to improvements in health and maintenance of physical fitness of the elderly. The objective of this study was to compare body adiposity index and flexibility levels of active and sedentary elderly. METHODS: The sample consisted of 10 elderly of both sexes, divided into two groups (active and sedentary) with five participants ( 2 men and 3 women), with age $(69.3 \pm 4.5$ years), total body mass ( $66.2 \pm$ $10.1 \mathrm{~kg})$, height $(157 \pm 1 \mathrm{~cm})$. The body adiposity index $(\mathrm{ACl})$ was calculated and classified by the protocol equation and reference values. The hip and knee flexibility was assessed bilaterally in degrees by a pendular fleximeter (Sanny, FL-6010). The hip in the extension, flexion, adduction and abduction movements, the knees in the extension and flexion movements. The statistics were made by BioEstat 5.0 software using the independent student's t test $(p<0.05)$. RESULTS: The ACl of the groups showed significant differences $(p=0.0144)$. Hip joint flexibility on the right side showed statistical differences in movement: extension $(p=0.0015)$, flexion $(p=0.0121)$ and adduction $(p=0.0867)$, the abduction showed no differences. The left hip presented differences in extension $(p=0.0028)$ and flexion $(p=0.0016)$, while adduction and abduction showed no differences. Flexibility of the knees bilaterally showed differences in extension movement $(p=0.0156$ and $p=0.0381$ ), with flexion showing opposite results. CONCLUSION: Therefore, older adults who exercise presented better levels of body adiposity and joint flexibility when compared to sedentary ones.

\section{MENINGOCOCEMIA WITH MULTIPLE COMPLICATIONS IN LACTENT: CASE \\ REPORT}

Ingrid Macêdo Araújo; Gabriel Costa Ferreira Andrade; Mirella Costa Ataídes; Amanda Angelo Pinheiro; Joessica Katiusa da Silva Muniz; Emille Ananda Lucena Pereira; Matheus Rizzo de Oliveira

Centro Universitário do Maranhão (CEUMA)

INTRODUCTION: Meningoccemia is a serious generalized infection that is part of the group of manifestations of meningococcal disease. The Neisseria meningitidis (Meningococcus) is the causative etiological agent, a gramnegative diplococcus acquired by the airway. Clinical manifestations may vary from one asymptomatic carrier state to a fulminant disease, in which death occurs within hours of the first symptoms. The incidence of the disease meningococcal disease is approximately 1.8 cases per 100,000 inhabitants, despite remarkable underreporting. Since $50 \%$ of cases occur in child under 5 years. This paper aims to report the case of an infant affected by this disease. CASE DESCRIPTION: N.P.C.B, male, 1 year and 5 months was admitted to the Intensive Care Unit of the Public Health Network. São Luís already sedated and intubated with previous diagnosis of Disease Meningococcal and clinical suspicion at Meningococcemia. At admission was anasarca $(2+/ 4+)$, cellulitis in the thoracic region and face and scalp infiltration, fever 39ćc, amputation of hands and transtibial amputation with slight superficial necrosis in the sutures. After a Inpatient week, patient evolved with Septic Shock, Septic Embolism. The CT scan revealed intraparenchymal hemorrhage and cerebral edema. Treatment with Ceftriaxone, Ciprofloxacin, Teicoplanin, Fluconazole, Dexamethasone and Support. Died after 2 months of hospitalization diagnosed with Brain Death (BD). CONCLUSION: The study of meningococcemia is extremely important because it is a potentially fatal disease, requiring early diagnosis and treatment. The Immediate intervention reduces possible complications. The suspicion must occur in any patient with onset of fever especially with the appearance of skin rash and / or meningeal signs. Currently the vaccine against Meningococcus $C$ is offered up to 2 years of age by the Government.

\section{KLIPPEL FEIL SYNDROME ASSOCIATED WITH AORTIC COARCTATION: CASE REPORT}

Vinícius Santos Mendes; Luciana da Veiga Kinoshita; Bárbara Tanaka; Raphael Ferreira Faleiro; Beatriz Melo Santos Lima Paulino; Jhennifer Santos Botelho; Natália Carvalho Fonseca

Universidade Federal do Maranhão (UFMA), Universidade de São Paulo (USP)

INTRODUCTION: The Klippel Feil Syndrome is a rare congenital disease characterized by a fusion of cervical vertebrae. Clinically, It manifest itself through the presence of short neck with low mobility and a low posterior hairline. Patients with this syndrome may show more congenital malformations, like defects at the urinary, nervous and cardiovascular tracts. CASE DESCRIPTION: T.R.F., female, 40 years old, forwarded by the neurosurgery to the congenital cardiopathy ambulatory at the São Paulo's Clinic Hospital, with a cervical vertebrae fusion diagnosis without compression, referring tiredness and a aortic coarctation correction at her twenties. At the physical exam, showed up $1+/ 6$ breath in left parasternal heave. Radiography presented scoliosis in inverted "S" and electrocardiogram didn't showed any relevant alteration. Echocardiogram revealed augmented left cavities, ejection fraction of $62 \%$, aortic valve with bivalvularized opening and a $47 \mathrm{~mm}$ ascending aortic dilatation. Angiotomography found a annuloaortic ectasia extending to the brachiocephalic trunk, with a bigger dimension at the pulmonary artery level, plus an ectopic kidney. Submitted to an aortic valve resection and ascending aortic with a valvulated tube interposition. Satisfactory postoperative evolution. CONCLUSION: It's a rare and complex pathology with a phenotype close to the Turner Syndrome one. It's association with others malformations reiterates the importance of early diagnosis to the precise therapeutic determination and complications prevention.

\section{1. "LACEMA" DISPOSITIVE FOR SEBACEOUS CYST EXCISION: EXPERIMENTAL MODEL}

Adriana Leite Martins; Karina Castello Branco Arruda; Luan Henrique Honório Rocha

Universidade Federal do Maranhão (UFMA)

INTRODUCTION: The sebaceous cyst is the most common benign lesion found in dermatology. The most common treatment of an uninfected cyst is surgical excision. Given the importance of this procedure in primary care, the objective of this article is to present a viable experimental device that seeks to simulate the anatomical conditions of the skin and the cyst found by the health professional. METHODS: In order to simulate skin and subcutaneous tissue, latex balloon and E.V.A (Ethylene Vinyl Acetate) were used, united by adhesive tape and fixed on wooden board. As for the cyst, a plastic wrap was produced filled by imitated sebum, composed of starch in water and yellow paint, and positioned below and centrally to the model. When the procedure was initiated, appropriate aseptic and antisepsis measures were taken. Anesthesia was simulated using a hypodermic needle by regional field block technique, and lidocaine was introduced in the middle of the lesion. Shortly after, a scalpel incision was made until the cyst's capsule was identified. Using a rat-tooth forceps and curved scissors, the tissue nearby the cyst's capsule was disrupted from it, and the cyst was removed from it is cavity without any leak. Finally, the cavity was cleaned with saline and gauze, being performed simple interrupted stitch. RESULTS: The experimental model proved to be efficient for student training, as it allows to reproduce all stages of the sebaceous cyst excision. Therefore, improving learning and professional training in small surgeries. The materials used for its manufacture are of low cost and easy acquisition, which allows its easy reproducibility. CONCLUSION: The developed model is important whereas apply theoretical knowledge in practical experience, presenting good applicability and didactic character, wich helps undergraduate medical professionals to develop this procedure in primary care.

\section{EQUISETUM ARVENSE REDUCES RAT BIOCHEMICAL PROFILE AFTER} ISOPROTERENOL ISCHEMIA

Marcos Vinícius Araújo Brito; Vítor Paixão Cruz; Gabriel Gomes Oliveira; Vinicius Santos Mendes; Rachel Melo Ribeiro

Universidade Federal do Maranhão(UFMA)

INTRODUCTION: Cardiovascular diseases are the main cause of death today and, as an important part of this group, cardiac ischemic disorders 
represent the majority of death events, especially acute myocardia infarction. The present study evaluated the effect of the plant species Equisetum arvense L. ("cavalinha") on animals submitted to isoproterenol induced ischemic injury. METHODOLOGY: Aerial parts of the plant were used to obtain E. arvense Lyophilized Extract (EEA). Adult male Wistar rats Rattus novergicus were randomly divided into four groups: Healthy Control Group (0.1 ml / 100g oral water); ISO Control Group (0.1ml / $100 \mathrm{~g}$ oral water); EEA $50+$ ISO group (extract of $50 \mathrm{mg} / \mathrm{kg} /$ day, oral, gavage). After 30 days of treatment, the last two groups received two subcutaneous injections of isoproterenol (ISO, $85 \mathrm{mg} / \mathrm{kg}$, s.c.), except for the healthy group, which received $0.9 \% \mathrm{NaCl}$ solution by the same route of administration. The animals were anesthetized for blood collection and biochemical analysis, prioritizing glycemia and lipidogram. RESULTS: Changes in serum glucose and lipidogram in treated animals, such as Total Cholesterol, Triglycerides and HDL-C (High Density Lipoprotein) were determined and analyzed. There were no changes in the glycemic levels of the animals studied, but the administration of ISO increased the serum levels of Total Cholesterol and Triglyceride, with a drop in the HDL-c level compared to the healthy group. However, for the groups that underwent pretreatment with EEA $50 \mathrm{mg} / \mathrm{kg}$ / day for 30 days, the lipid profile was restored to near normal levels, corroborating the cardiopreventive effect of E. arvense. CONCLUSION: The results show that $E$. arvense reestablished the lipid profile of animals submitted to ischemic injury, suggesting that this plant has cardiopreventive potential.

\section{PSYCHIATRIC DISORDERS IN PATIENTS WITH NOCIPLASTIC PAIN IN} CHRONIC PAIN AMBULATORY

Letícia Arrais Rocha; Sâmia Jamile Damous Duailibe de Aguiar Carneiro Coelho; Marcelo Ribeiro Mendes Júnior; João Batista Santos Garcia; Thiago Alves Rodrigues; Raynan Costa Santana; Beatriz Morais Costa

Universidade Federal do Maranhão (UFMA); Casa da dor do Hospital Universitário da UFMA (HUUFMA)

INTRODUCTION: The term "Nociplastic Pain" is used to refer to a painful condition that comes from a change in nociception, although there is no evidence of either real tissue threat or damage to the somatosensory system causing the pain. It is proposed that nociplastic pain be considered as a pain descriptor, together with neuropathic and nociceptive pain, aiming to cover pictures that did not fit the definition of classical descriptors. Clinically, there are different painful syndromes, such as fibromyalgia, type 1 complex regional pain syndrome, and nonspecific chronic low back pain. METHOD: Descriptive study through the review of medical records of patients treated at the Psychiatric Patient Care Center (NAPP) of the HUUFMA Chronic Pain Outpatient Clinic. All patients with chronic pain treated at NAPP from 2014 to 2018 were included, totaling 44 patients. RESULTS: Data analysis showed that among the 44 patients, 18 were diagnosed with Anxious and Depressive Mixed Disorder (F41.2); 14 of Generalized Anxiety Disorde (F41.1); 11 of Recurrent Depressive Disorder (F33); 4 of Personality Specific Disorders (F60); 1 of Phobic-Anxious Disorder (F40); 1 severe stress reaction (F43); 1 did not have a psychiatric diagnosis according to the criteria of the Diagnostic and Statistical Manual of Mental Disorders (DSM-5). CONCLUSION: The literature shows that Nociplastic Pain, especially fibromyalgia, is related to psychiatric disorders, especially depression and anxiety. The analysis of the results of this study confirms the prevalence of these disorders, especially anxiety and depressive joint disorder, generalized anxiety disorder and recurrent depressive disorder, highlighting the importance of both psychiatric support for Nociplastic Pain patients, and screening for behavioral changes, focusing on depressive and anxious symptoms.

\section{POSITIVE ONCOTIC COLPOCYTOLOGIES IN MARANHÃO 2010-2013: A} DESCRIPTIVE STUDY

Roseline Braga de Carvalho; Leonardo Silva dos Santos; Amanda Laryssa Pinheiro Santos; Beatriz Morais Costa; Leonardo Domingues Gomes; Thamires Sales Ribeiro; Raimunda Ribeiro da Silva UNIVERSIDADE FEDERAL DO MARANHÃO (UFMA)

INTRODUCTION: Cervical cancer results from progression of lesions caused by the Human papillomavirus (HPV) and it is the most incident in the female population from Maranhão. In Brazil, there is a steady advance in the identification of lesions suggestive of disease using colpocytopathological examination, culminating in the implementation of the Cancer Information System (SISCAN). Thus, it is possible to gather epidemiological information about the disease that allows the strengthening of cancer care in the
Brazilian public health system. This research aims to describe the epidemiological profile of positive oncotic colpocytologies in Maranhão from 2010 to 2013. METHODS: Retrospective descriptive study based on secondary data available in SISCAN, considering cervical cytopathological exams performed in Maranhão from 2010 to 2013, with high grade intraepithelial lesion (HSIL) or invasive lesion and characterizing them according to the variables municipality of residence, education, age and race, expressed in their absolute and relative frequencies. Data were compiled and analyzed in Microsoft Excel 2016®. RESULTS: Among the lesions considered, HSIL was the most frequent in all years $(85.84 \%)$, the most frequent education was incomplete elementary school, and among women with complete higher education, only HSIL was detected. The most frequent breed was brown. Most of the invasive lesions occurred in the northern Maranhão mesoregion, especially in the São Luís urban agglomeration. About $60 \%$ of the invasive lesions were within the age range recommended by the Ministry of Health (25-64 years). CONCLUSION: In Maranhão, from 2010 to 2013, high-grade and invasive lesions were identified mainly in women with low education, brown, between 25 and 64 years, in the northern mesoregion. However, some consideration should be given to the lag in SISCAN-registered examinations and the large amount of unreported data.

\section{CASE REPORT: LYMPHANGIOMA ON A 2-YEAR-OLD CHILD}

Vivianne Maria Laranjeiras Monte Freire; Isabele Arruda de Oliveira; Maria Gabriela Martins Silva; Acácia Pinto Morais; Adriana Leite Xavier Bertrand

Centro Universitário do Maranhão (CEUMA)

INTRODUCTION: The orbital lymphangioma is an unusual malformation of the lymphatic vessels, that can reside around the orbit or all the way to the eyelids, conjunctiva and periorbital tissues and results in a benign tumour. Usually the signs and symptoms are noticeable in the first decade of life and are frequent at birth. Due to their involvement with the various orbital structures, they may limit eye movement and may present with ptosis, proptosis or even loss of visual acuity. In addition to ophthalmic ectoscopy can be assessed by imaging as magnetic resonance imaging. The most usual treatment is surgical. CASE REPORT: 2-year-old patient, female, natural of São Luís - MA and resident of Balsas - MA, only child, was brought by mother reporting that her daughter was presenting a volume in her right eye, that it was increasing in size along this year. The mother also referred that her daughter had no comorbidities, denied any trauma ou previous eye surgery.Born at tern by vaginal delivery, with $3.120 \mathrm{Kg}$, complete antenatal care without complications. All vaccinations up to date. Resides in a masonry house with father, mother, the mother's sister and grandmother from her mother side, all of them help take care of her. No family history of neoplasms or ocular diseases. On the ectoscopic examination it was evident a slight increase in volume of the right-sided orbit with an S-shaped ptosis on the lateral corner of the ocular slit. The observed volume was badly delimeted, softened, painless and was not adhered to deep plans. ocular biomicroscopy was normal. The child could see and track objects with her sight, normal motility and fundoscopy. Image examination was observed a mass, of hyperogenic consistency, badly delimeted, located at the lateral and posterior side of the right eye globe, of extra-conal location. It was then opted for an excesional biopsy of the lesion under general anesthesia. The surgery occurred with no complications, with transconjunctival access a

\section{SEVERE SYSTEMIC ERYTHEMATOUS LUPUS WITH TRANSVERSE MYELITIS} Thamires Sales Ribeiro; Andreia Coimbra Sousa; Raquel Moraes da Rocha Nogueira; Raphael Aguiar Diogo; Flávia Costa da Silva; Afonso Melo Machado de Oliveira Júnior; Thiago Igor Aranha Comes Centro Universitário do Maranhão (CEUMA); Universidade Estadual do Maranhão (UEMA); Universidade Federal do Maranhão (UFMA)

INTRODUCTION: Myelitis is a possible initial manifestation of systemic lupus erythematosus (SLE) and is present in 1 to $2 \%$ of cases. Due to its high morbidity and mortality, it was included in the new disease criteria. CASE DESCRIPTION: Female, 16 years old, previously diagnosed with polycystic ovary syndrome for 2 years, being treated with combined oral contraceptive. One year ago, she started with polyarthralgia and symmetrical polyarthritis with morning stiffness, as well as ascending lower limb paresthesias (lower limbs), progressing with decreased lower limb muscle strength, dyspnea, fever, moderate headache, nausea and vomiting. He sought emergency with quadriplegia and lumbosacral pressure injury, being diagnosed with transverse myelitis associated with high-activity SLE (SLEDAI 67). Fan 1: 640 
(dense thin dotted cytoplasmic nuclear type mixed dotted pattern); antiDNA 1: 1280, anti-sm 110.7; anti-ro 17.3; anti-it 5.7; negative lupus anticoagulant. Spinal magnetic resonance imaging (MRI) has shown hypersignal from cervicothoracic transition to L1-L2. She was hospitalized, evolving with nephritis and lupus myocarditis, requiring intensive care and hemodialysis care. Doppler echocardiography with marked systolic dysfunction, pericardial effusion and ejection fraction of $24 \%$; creatinine 1.16; urea 204; cpk 54; ck-mb 3.11; ultrasensitive troponin 5.96 and bnp> 5000. After pulse therapy with methylprednisolone $1 \mathrm{~g} /$ day for 3 days and 3 pulses of cyclophosphomide $1 \mathrm{~g}$, had sensory and motor improvement of the upper limbs and renal and cardiac conditions. She was discharged from the hospital with low activity SLE (SLEDAI 2). Referred for multidisciplinary outpatient follow-up. CONCLUSION: Patients with sensorimotor alterations and diagnosed with SLE should be suspected of myelitis whenever possible due to its high morbidity and mortality, thus allowing an early diagnosis and appropriate treatment.

\section{EPIDEMIOLOGICAL ASPECTS OF VISCERAL LEISHMANIASIS IN THE STATE OF MARANHÃO, BRAZIL}

Rebeca Silva de Melo; Anna Beatriz Trindade Lopes

Centro Universitário do Maranhão (CEUMA).

INTRODUCTION: Visceral leishmaniasis (VL) is caused by a protozoan of the species Leishmania chagasi, in Brazil, remains with high incidence and wide distribution. The objective of this work is to analyze epidemiological aspects of VL in the state of Maranhão, from 2007 to 2017, by the data obtained from the Notification Disease Information System (SINAN). METHODS: It is a retrospective epidemiological study of a population nature, which used secondary criteria of cases of patients with VL, assessing aspects related to gender, age, race, confirmation of the disease, number of cases in the municipalities of the state of Maranhão and the clinical evolution of the disease. For this, it was used data registered in SINAN and made available on the DATASUS website. Data were tabulated using the Tabnet program, which was then exported for graphical analysis in Tabwin 3.6 and Microsoft Office Excel 2016. RESULTS: There was an increase in the number of confirmed cases of VL, and 2017 is the year with the largest number of confirmed cases in Brazil, with 3,987 patients and in Maranhão, with 653 registered individuals. The people most affected by the disease are male $(64.32 \%)$, aged between 01 and 04 years. The predominant breed is brown $(69.68 \%)$. In relation to the municipality with the highest incidence of confirmed cases, São Luis is in first place (34.6\%). It is noted that the most widely used criterion for diagnosis is laboratory (75.65\%) and the main form of clinical evolution is cure $(69.68 \%)$. CONCLUSION: The results show that this zoonosis is endemic in Maranhão. Thus, the importance of control that must be performed constantly, as well as the adequate training of health professionals, is highlighted

\section{GLABELAR RETAIL AS A SURGICAL APPROACH IN SPINOCELLULAR} CARCINOMA EYELID

Sarah Mota goncalo; Ana Maria Neves Sampaio da Luz; Pryscilla Oliveira Melo; Luan Pinho Farias; Adriana Leite Xavier Bertrand Centro Universitário do Maranhão

INTRODUCTION: Squamous cell carcinoma (CPB) corresponds to $25 \%$ of skin cancer cases in Brazil. The eyelid region is among the hardest hit due to location and chronic exposure to sunlight. It most commonly affects older, white male patients. CPB originates from the epidermis, is very aggressive and has a high risk for metastasis. Early diagnosis and extent of injury are important factors for prognosis. CASE DESCRIPTION: An 82-year-old male patient, leucoderma, sought medical attention complaining of an injury to the medial corner of his right eye about 1 year ago. It reports that the lesion appeared as a small nodule, hardened and slightly painful to palpation, being diagnosed and treated after 3 months of evolution with a hordeole. No regression of the lesion and possible diagnosis of skin cancer was referred to the ophthalmologist. Biomicroscopic examination revealed a deep ulcer-like lesion in the medial corner and extending to the lower eyelid, irregular, vascularized, amelanotic, with fibrin and scattered clots. Excision biopsy was performed with primary reconstruction and intraoperative freezing biopsy. The glabellar flap was the surgery of choice for eyelid synthesis. Histopathological examination confirmed the diagnosis of morphineform squamous cell carcinoma with free surgical margins. Patient evolves with good healing, without complications. CONCLUSION: In the case described, late diagnosis of malignancy led to an increase in the extent of the lesion and a worse prognosis of the patient. Excisional biopsy and intraoperative freezing biopsy provided efficacy and rapid treatment. The glabellar flap was important for the preservation of the lacrinal apparatus and eyelid functionality, with good aesthetic results.

\section{EXTENSIVE MELANOMA IN YOUNG PATIENT}

Raylenne Moreira dos Reis; Thalita Martins Bezerra; Ingrid Monteiro Tramontin; Amanda Angelo Pinheiro; Amanda Cordeiro Santos; Virna Maria Araujo de Oliveira

Centro Universitário do Maranhão (CEUMA), Instituto Maranhense de Oncologia Aldenora Belo (IMOAB)

INTRODUCTION: Cutaneous melanoma is a malignant neoplasm originating from melanocytes that can affect the skin ( $90 \%$ of cases), mucous membranes, eyeball and leptomeninges. Melanocytic lesions are asymmetrical, with irregular edges, color alteration and diameter greater than $6 \mathrm{~mm}$. It represents the most aggressive cutaneous neoplasm, due to its high metastatic potential. It can affect both sexes, being rare in the 50 years, as in the case that will be reported. CASE DESCRIPTION: GPG, male, 25 years old, butcher, resident in São Luís, reports that for about 1 year he had a nodular lesion on the right back with progressive enlargement. Three months ago, he sought care at the Aldenora Belo Hospital with a biopsy performed at another service, which showed a lesion of $21 \times 15.5 \times 1.5 \mathrm{~cm}$, with a suggestive result of melanoma. On physical examination, an extensive exophytic lesion on the back and right axillary lymph node enlargement were evidenced. The patient underwent resection of melanoma on the right back, flap reconstruction - leaving an area of $7 \mathrm{~cm}$ open - and axillary dissection on the right without complications. The histopathological study showed a tumor lesion compatible with the diagnosis of melanoma. The lesion was ulcerated nodular and Breslow index of $3 \mathrm{~cm}$. On the 13th postoperative day (POD), he underwent $7-\mathrm{cm}$ autograft reconstruction of the right thigh. At the 16th POD, the patient had a reconstructed area with full graft grip and well-vascularized flap. Patient continues to follow up with clinical oncology. CONCLUSION: Cutaneous melanoma can affect several tissues, causing asymmetrical lesions with irregular borders and color alteration, representing intense aggressiveness with its high metastatic potential. Even under unusual clinical conditions, the patient developed well and without complications.

\section{ASSESSMENT OF BASIC LIFE SUPPORT TRAINING (BLS) FOR A MULTIPROFESSIONAL TEAM}

Paulo Gabriel Sacramento da Silva; Ciro Bezerra Vieira; Santiago Cirilo Noguera Servin; Daniela Cristina Cardoso Aroucha Campelo; Andrey Salgado Moraes Filho; Micael Marques Vieira Silva; Rodrigo Matheus Santos Alves

UNIVERSIDADE FEDERAL DO MARANHÃO (UFMA), UDI Hospital (UDI).

INTRODUCTION/PURPOSE: Basic Life Support (SBV) consists of techniques and initial actions to be performed in cardiopulmonary arrest situations until the arrival of advanced support. This work aims to evaluate the effectiveness of a BLS training conducted with the multi-professional team of a private hospital in São Luís - Maranhão - Brazil. METHODS: This is an evaluative, descriptive and quantitative study, conducted between November/2018 and March/2019 with hospital administrative and care professionals. The variables analyzed were: age, gender, education, time since graduation, function, sector and grade in assessment tests applied before and after training (pre and post-tests). Data were stored in Microsoft Excel 2015 and analyzed in Stata 12. RESULTS: The study included 111 professionals from the Hemodynamics, Imaging and Oncology sectors, of which $90(81 \%)$ performed the evaluation tests. The sample consisted of $64 \%$ women, $57 \%$ of professionals had completed high school and held positions of administrative assistants in the areas of care (receptions). The average age of the participants was 32 years. Nurses, nursing technicians and radiology technicians represented $43 \%$ of respondents, with an average of 6 years of technical / higher education. The average pre-test scores in the administrative areas were 2.4 in the pre-test and 5.7 in the post-test ( $p$ value $<0.001$ ); in the care areas were 2.8 in the pretest and 6.3 in the posttest ( $p$-value $<0.001)$. CONCLUSION: Training in basic life support improved the professionals' knowledge about the primary stages of action in the face of cardiopulmonary arrest. The qualification of this team is fundamental to improve care, with impact on quality of life and potential reduction in hospital mortality. It is believed that the results may encourage continued BLS training for multi-professional teams in the hospital setting. 


\section{ADULT LYMPHANGIOMA}

Amanda Araújo de Sousa; Alanna Gomes Dominici; Bruna Martins Pereira; Gabriela Luiza Kich de Souza; Ingrid Macêdo Araújo; Lianna Paula Guterres Corrêa; Adriana Leite Xavier Bertrand

Centro Universitário do Maranhão, Universidade Federal do Maranhão

INTRODUCTION: This study aims to report the case of a patient diagnosed with lymphangioma, a benign tumor of the lymphatic system. Mostly found in the region of the head and neck, it represents about 0.3 to $4 \%$ of al orbital tumors. It can attack the conjunctiva and eyelid. It usually affects children. DESCRIPTION: A 72-years-old female patient was brought by her daughter, indicating that she has a volume in her right eye, which has increased over the last 10 years. The mother says that he has been burning and tearing frequently and his vision has worsened a lot in the last 6 months. He reports SAH ant type II diabetes under control. She denies trauma and refers to previous cataract surgery in both eyes for about 8 years without any Family history of neoplasms. Ectoscopy revealed a large increase in volume in the right orbit with moderate axial proptosis. The volume was poorly delimited, softened, painless, not adhered to the deep planes with enlarged vessels. Ocular biomicroscopy showed marked conjunctival congestion on the right and the presence of an intraocular lens in the both eyes. Visual acuity of 20/25 in OE and 20/400 in OD, motility and normal fundoscopy in the left eye and pallor of the optic nerve on the right. on imaging, a heterogeneous mass was observed, posterior to the right eyeball, filling the entire orbit with inaccurate limits and without cleavage plane. $\mathrm{Na}$ incisional biopsy of the lesion was the chosen under genera anesthesia. CONCLUSION: The surgery was uneventful, with transpalpebral access in the upper and lower sulcus. In the postoperative period, ciprofloxacin $0.03 \%$ ointment was used every 6 hours and vidadexa eye drops every 4 hours for 7 days, associated with ciprofloxacin 500 every 12 hours and nimesulide $100 \mathrm{mg}$ every 12 hours for 7 days. The anatomopathological examination revealed that this was an orbital lymphangioma.

\section{ANALYSIS OF CHILD MORTALITY FROM CONGENITAL SIFILIS IN} MARANHÃO FROM 2013 TO 2018.

Jéssica Magalhães de Barros; Nathaly Vitória Portela Santos; Ítalan de Jesus Portela Santos; Italo Constâncio de Oliveira

Universidade Federal do Cariri (UFCA) e Universidade Federal do Maranhão (UFMA)

INTRODUCTION: Congenital sifilis occurs with haematogenous spread of Treponema pallidum, through transplacental via and is subdivided in early and late. In Brazil, since 1986, it became compulsory notification, though its incidence is still alarming. Therefore, our objective is to identify the main causes associated to continuity of high levels through analysis of gestation, mother and child data. METHODOLOGY: It is a epidemiological study, descriptive and retrospective with quantitative approach, with analysis of congenital sifilis records ranging from 2013 and 2018, through Notification of Harm Information System (SINAN). The variables used were: mother's age mother's scholarity, prenatal realization and evolution of conffirmed cases. RESULTS: In the period from 2013 to 2018, were diagnosed, on SINAN, 2505 congenital sifilis cases, being 2491 in children aged under 1 year old. Beyond that, about gestation, $83,4 \%$ of mothers did have prenatal care, but only $44,9 \%$ were diagnosed during pregnancy. Between them, $63,5 \%$ were $20-34$ years old and only $20,5 \%$ were high schooled. Furthermore, it was observed that $91,6 \%$ of congenital sifilis cases were diagnosed in newborns aged less than 7 days old that, according to Mortality Information System (SIM), 44 sifilis deaths of children under one year occurred. CONCLUSION: Although Maranhão represents less than $2 \%$ cases on national level, there was, on this period, a growing in cases of congenital sifilis. This reality denotes need for interventions on state government level, favoring mother's and its partnes diagnosis and treatment, in order to reduce levels of children affected by the disease.

\section{TREATMENT OF COMPLEX REGIONAL PAIN SYNDROME}

Luís Augusto Silva Batista; Denise Alane Monteiro Lopes; Vanessa Vieira Pinheiro; Thiago Alves Rodrigues; João Batista Santos Garcia; Vinicius Gonçalves Melo; Rayanne Luiza Tajra Mualem de Araujo Universidade Federal do Maranhão (UFMA), Hospital Universitário da Universidade Feral do Maranhão (HUUFMA)

INTRODUCTION: Complex regional pain syndrome is a chronic pain condition composed of autonomic and inflammatory characteristics. It occurs acutely in about $7 \%$ of patients with limb fractures, limb surgery or other injuries.
Its treatment is multidisciplinary, involving pharmacological and nonpharmacological therapy. The present study aims to describe how a Reference Center for pain in São Luís, Maranhão, conducts the treatment of complex regional pain syndrome and the patients' response to the described intervention. METHODOLOGY: Twenty-four patients diagnosed with complex regional pain syndrome and neuropathic pain symptomatology were followed up at the Chronic Pain Service of the University Hospital of UFMA, whose last consultation took place between August 2017 and January 2019. Data were collected. from medical records of the institution and the variables evaluated were: pain location and intensity, associated symptoms, previous pharmacological and non-pharmacological treatment, prescribed treatment, medication response and adherence to the instituted therapy. RESULTS: Of the 24 patients studied, 20 had treatment segment, of these 12 had improvement or partial improvement, and 8 without improvement. Among those that have improved Among the pharmacological therapies used are Gabapentin, Amitriptyline, PACO, Pregabalin, Tramadol, Methadone, Duloxetine, Carbamazepine and Dipirone. Among the nonpharmacological ones were physical therapy, blockages, hydrotherapy and acupuncture. The patients who performed the fidelity treatments of both treatments obtained better results, especially in the treatments combining anticonvulsants and tricyclic antidepressants with physiotherapy. CONCLUSION: The results of this study showed that adherence to the integral treatment of CRPS in the pharmacological and non-pharmacological areas is associated with partial or effective improvement of the pain.

\section{INTERNAL SEAL SYNDROME BURIED: THERAPEUTIC AND DIAGNOSTIC APPROACH}

Lia Gabriela Luciano Gonçalves; Manuela Correa Dos Santos Reis Centro Universitario Do Maranhao(CEUMA)

INTRODUCTION: gastrostomy (GTT) consists of placing a probe in the stomach of patients affected by some basic clinical or surgical condition, requiring enteral access for a prolonged period (more than 15 days) for the introduction of food directly into the light Gastric. This method can infer in minor complications (dermatitis, local pain...) and greater as the buried internal retainer syndrome (BBS). The BBS stems from the excessive traction of the probe, causing a counterposition of the internal retainer with the abdominal wall, resulting in leaks and difficulty in injecting the diet. CASE DESCRIPTION: JAR, 84 years old, female, Brown, widow, resident of St. Louis, carrier of SAH, DM, Alzheimer, admitted to emergency Hospital Dr. Clementino Moura (Rescue II). A patient previously gastrostomized requiring prolonged use of a probe due to difficulty swallowing and inability to oral feeding, resulting from neurodegenerative disease. Due to the maintenance of hypoglycemic levels ( 58 Glycemia) and leakage at the time of administration of the diet, an endoscopic evaluation was performed to verify the position of the probe. At the examination of Upper digestive endoscopy, the presence of internal GTT orifice was seen in the gastric mucosa. In the procedure of withdrawal of retained probe, passed guide wire and introduced another GTT probe ballooned, with instillation of $20 \mathrm{ml}$ of distilled water in the internal flask, the diet leakage was interrupted and the glycemic levels of the patient were normalized. CONCLUSION: The buried internal retainer syndrome is considered a rare situation of greater CTT complication, yet easy to manage. This report aims to broaden the knowledge about BBS in order to ensure a correct diagnosis and a rapid conduct in the face of this clinical picture. In the case exposed, the intervention was performed by confirming the diagnosis by means of upper digestive endoscopy and subsequently replacing the GTT probe with a qualified professional.

\section{SLEEP ANALYSIS OF HIGH YEAR RUNNERS}

Diogo Matheus Barros da Silva; Isabela Mendonça Rodrigues dos Santos; Bruno Luiz Galvão de Miranda; Ester da Silva Caldas; Dayanne Leice Feitosa Barros Dias; Antonio Coppi Navarro; Marlon Lemos de Araújo

Universidade Federal do Maranhão (UFMA), Centro Universitário Leonardo da Vinci (UNIASSELVI), Faculdade Laboro (LABORO)

INTRODUCTION: Street running is a sport of athletics, considered one of the most practiced in the world, involves the participation of aerobic and anaerobic metabolism. Thus, much is discussed about the importance of sleep in the sports environment, as it restores neurophysiological capabilities and functionalities. Inappropriate habits are associated with sleep disorders and impaired sports performance. Objective: Given this perspective, this study aims to identify the degree of sleepiness of high- 
performance runners. METHODS: The study followed the recommendations of Resolution 466/12 of the National Health Council, sample was integrated, for convenience, with 12 high performance male suit runners. Mean age $29.17 \pm 5.64$ years, height $1.71 \pm 4.6 \mathrm{~cm}$, weight $63 \pm 6.1 \mathrm{~kg}$, body mass index $21.6 \pm 1.2 \mathrm{Kg} / \mathrm{m}^{2}$ classified as normal weight, drowsiness was assessed by the Epworth Sleepiness Scale (ESE-BR). ) validated by Bertolazi et al. (2009). BioEstat 5.3 software was used for statistical treatment, performing a descriptive analysis followed by the application of the Kolmogorov-Smirnov tests. RESULTS: There was homogeneity in the variables. The sleepiness score resulted in 121, the average score $10 \pm 4.2$, and individuals were classified as follows: ( $42 \%)$ presented values within the normal range, $(50 \%)$ presented excessive daytime sleepiness and (8\%) presented severe sleepiness. CONCLUSION: The runners presented discrete values within the normal range; however, the superiority in the sum between the excessive daytime sleepiness and severe sleepiness classifications stands out. This requires attention to avoid possible sleep disorders that may affect sports performance. In view of this situation, an intervention regarding sleep hygiene and healthy habits is necessary, aiming at guaranteeing effective performance.

\section{EPIDEMIOLOGICAL PROFILE OF CONGENITAL SYPHILIS CASES IN} ARAGUAÍNA-TO IN YEAR 2017

Amanda Karine Santos Firmo; Paula Cecilia P Do Nascimento; Layanne Hellen Da Cruz Brandão

CENTRO UNIVERSITÁRIO PRESITENTE ANTONIO CARLOS (UNITPAC)

INTRODUCTION: In Brazil, syphilis seropositivity rates in women of childbearing age range from 1.5 to $5.0 \%$, with higher levels in higher risk groups, low socioeconomic status, and complex access to education and health services. The disease can be detected and treated during prenatal care, and screening for the presence of maternal infection is highly effective. OBJECTIVE: To present the epidemiological profile of the cases reported in Araguaína-TO during 2017. METHODOLOGY: A retrospective and descriptive study of the cases notified through the records of the SINAN (Health Information and Notification Information System) was performed. After data collection was completed, data were analyzed and tabulated in Excel and Epilnfo programs. RESULTS: 281 cases of the disease were reported in the state, among them $102(36.29 \%)$ occurred in Araguaína. Regarding the sex of newborns $46(45.09 \%)$ were with males and $56(54.91 \%)$ with females. $100(98.03 \%)$ cases were confirmed within 6 days of life, $2(1.97 \%)$ between 28 days less than 1 year. 94 mothers $(92.15 \%)$ had prenatal care, $7(6.86 \%)$ did not have it and $1(0.98 \%)$ ignored. 71 mothers with syphilis $(69.60 \%)$ were diagnosed during prenatal care, $28(27.45 \%)$ at delivery / curettage, 2 $(1.96 \%)$ after delivery and $1(0.98 \%)$ were ignored. 13 partners $(12.74 \%)$ underwent treatment, $83(81.37 \%)$ were not treated and $6(5.88 \%)$ were ignored. $97(95.09 \%)$ of the cases remained alive, $4(3.92 \%)$ died and 1 $(0.98 \%)$ ignored. All were considered recent congenital syphilis. CONCLUSION: A greater number of cases were observed in female newborns and most were confirmed before the first week of life. Most cases are confirmed at prenatal, demonstrating the importance of correct prenatal care and $80 \%$ of partners did not receive appropriate treatment, which may increase the risk of reinfection or treatment failure.

\section{PROFILE OF PATIENTS WITH PAINFUL SYNDROME AFTER COLUMN} SURGERY ATTENDED IN AMBULATORY

Luiza Sousa Soares; Islanara Diógenes Urbano Sousa; Fernanda Lago de Araujo; João Batista Santos Carcia; Thiago Alves Rodrigues; Rayanne Luiza Tajra Mualem Araujo

Hospital Universitário da Universidade Federal do Maranhão, Universidade Federal do Maranhão

BACKGROUND: Postoperative spinal surgery pain syndrome is defined as spinal low back pain that persists in the same location as the original pain despite surgical interventions or after such procedures. Factors such as nerve compression by fibrotic tissue, direct nerve injury during surgery and regional inflammation may be associated with the maintenance of pain. Thus, the present work aims to outline the profile of patients in this context and who are assisted at the Chronic Pain Outpatient Clinic of the University Hospital of the Federal University of Maranhão (HUUFMA). METHODS: This is a descriptive cross-sectional study based on the analysis of medical records of patients diagnosed with postoperative spinal surgery pain syndrome, referred between January 2003 and March 2019. Variables described: gender, age, intensity, pain characterization in the first consultation and types of treatments used. RESULTS: The sample consisted of 55 patients. Regarding gender, $62 \%$ of the patients were male and $38 \%$ female. Regarding age, $6 \%$ of patients were 21 to 30 years old; $27 \%$ from 31 to 40 years old; $36 \%$ from 41 to 50 years old; $18 \%$ from 51 to 60 years old; and $13 \%$ from 61 to 71 years. Regarding the treatments used, $69 \%$ had pharmacological treatment associated with non-pharmacological treatment, such as physical therapy, hydrotherapy, acupuncture and occupational therapy, and $31 \%$ only the drug. CONCLUSION: Postoperative spinal pain syndrome is a frequent condition in the HUUFMA Pain Outpatient Clinic, representing a clinical condition that affects individuals, especially men, in the adult age group. In addition, the intensity of postoperative pain is mostly intense, directly affecting the quality of life of this population.

\section{PREVALENCE OF ATTENTION DEFICIT / HYPERACTIVITY DISORDER IN SÃO LUÍS - MA SCHOOLS}

Ana Luiza Medeiros Mota dos Reis; Tertuliana Medeiros Mota Dos Reis; Gabriel Comes Oliveira Universidade Federal do Maranhão (UFMA)

INTRODUCTION: Attention Deficit Hyperactivity Disorder (ADHD) is defined as neurobehavioral or developmental disorder affecting school-age children (4 - 7 years). A thorough and detailed assessment of the child is an important step in ADHD management, because the diagnosis is clinical. Thus, the present study analyzed the prevalence of ADHD in school-age children according to gender. METHODS: An analytical cross-sectional study was conducted with 266 children enrolled from the 1st to the 3 rd year of public schools in São Luís - MA. Four schools were drawn, but only 2 met the required criteria. Students were chosen by lot, and those with neurological pathologies leading to agitation and / or inattention were not included. In each school there were two meetings, one with parents and another for teachers, both explaining about the research. Parents and / or guardians of students who agreed to participate answered the SNAP-IV questionnaire, which is based on the symptoms of the 4 th Edition Diagnostic and Statistical Manual (DSM IV), which is used to assist in the diagnosis of ADHD. RESULTS: Data showed that 145 children $(54.51 \%)$ were male and $121(45.49 \%)$ female. Thus, the analysis of the scores indicated that 19 students $(7.14 \%)$ were positively diagnosed with ADHD, with 4 females (21.05\%) and 15 males (78.95\%). On the other hand, of the total children without ADHD (92.86\%), $52.62 \%$ males and $47.37 \%$ females, presenting approximate values for both sexes. CONCLUSION: The prevalence of ADHD in both schools surveyed was relatively low $(7.14 \%)$, which is similar to the national literature, but still needs multidisciplinary follow-up. Due to the scarcity of research, we suggest other studies covering a larger number of schools with sample diversification.

\section{MICROBIOLOGICAL ANALYSIS OF RESEVOIR WATER IN VARGEM GRANDE, MARANHÃO}

Ingrid Monteiro Tramontin; Fábio Mendonça da Costa; Juliana Silva Carvalho; Gabriela Luiza Kich de Souza; Bárbara Fernandes Costa de Araújo; Pryscilla Oliveira Melo; Maria Raimunda Chagas Silva Centro Universitário do Maranhão (CEUMA)

INTRODUCTION: Grande-MA was established by law no. 005/97 as the Municipal Moisinho Spa. It is intended primarily for primary contact recreation, class 2 (CONAMA No. 357/05). OBJECTIVES: To determine the microbiological parameters and to evaluate the bacteriological analysis of the reservoir water by sampling at five different points from 2017 to 2018 during both the dry season and rainy season in the region. Methodology: Bacteriological analysis by the Colilert method (APHA, 2012). RESULTS: The water samples ranged from (20.2 ĆC to 36.1 ćC) for temperature and presented $\mathrm{pH}$ range between (7.08 to 8.63 ) which characterizes alkalinity. The presence of the bacterium Escherichia coli, which was considered within the appropriate limits for the maintenance of aquatic life, was detected according to the limits established by Resolution No. 357 of CONAMA/2005. CONCLUSION: The artificial reservoir water is allowed for bathing, since its values are in accordance with the parameters established by CONAMA $n{ }^{\circ}$ $357 / 05$ and $n^{\circ} 274 / 00$.

\section{DEATH IN CHILDREN AND ADOLESCENTS IN A PUBLIC HOSPITAL OF SAO} LUIS BETWEEN 2015 AND 2018

Rodrigo Matheus Santos Alves; Gustavo Manfio Lemes Campos; Micael Marques Vieira Silva; Kevin Waquim Pessoa Carvalho; Ana Josephy da Silva Costa Oliveira; Larissa Rolim de Oliveira Sales; Santiago Cirilo Noguera Servin 
Universidade Federal do Maranhão - UFMA

INTRODUCTION: To identify the causes of deaths in children and adolescents at the Djalma Marques Hospital (HDMD) of São Luís - MA between 2015 and 2018. METHODS: A retrospective study involving the investigation of deaths in children and adolescents (o to 19 years old). 2015 and 2018 by consulting the HMDM registry records. Data were stored and analyzed using Microsoft Excel version 2013. The following variables were analyzed: origin, age, gender and length of stay. RESULTS: Between 2015 and 2018, 256 deaths were recorded in children and adolescents (0-19 years) in the HMDM, of which $199(77.73 \%)$ were male and $57(22.27 \%)$ female. Among the injuries that evolved to death occurred in males $72(36.18 \%)$ occurred by firearm perforation (FAP), $42(21.10 \%)$ by traumatic brain injury (TBI), $11(5.53 \%)$ have already reached cardiac arrest (CRP), $10(5.03 \%)$ due to exogenous poisoning and $64(32.16 \%)$ due to other causes. Among the 57 injuries that died in females, $9(15.79 \%)$ were due to $\mathrm{TBI}, 7(12.29 \%)$ to septic shock of pulmonary focus, $6(10.52 \%)$ to sepsis from other foci, $6(10.52 \%)$ for firearm perforation and $29(50.88 \%)$ for other causes. CONCLUSION: During this period the injuries that resulted in the death of children and adolescents were higher in males, mainly due to external causes related to accidents and violence (TBI, FAP and poisoning), results that confirm what is seen in the literature related to this. age range. We observed a lower number of deaths in females, in which there was a higher occurrence of other causes compared to males. Extreme poverty and abandonment are the main factors contributing to this statistic, the incidence is of only one city hospital, it is very likely that it will be higher. Thus, investment in education and security policies has to be a priority.

\section{NURSING CARE IN SURGERY CENTER: PATIENT'S PERCEPTION}

Laís Barreto Aragão; Mayllane Lays Barbosa; Paula Pires de Azevedo Sandrin; Suzane Carvalho Silva

Hospital São Domingos (HSD)

INTRODUCTION: The physical and emotional well-being of the surgical patient should be the main objective of the nursing team that assists them. In this context, the reception is the key point and has the role of ensuring that customers are heard carefully, and can have their questions answered and their fears and wishes minimized, with the fulfillment of their needs and respect for their rights. The research aimed to understand the experiences and feelings of patients undergoing elective surgery, related to nursing care received at the Surgical Center of a private hospital in São Luís / MA. METHODS: A descriptive exploratory study with a qualitative approach conducted with 15 patients in the immediate postoperative period admitted to the surgical clinic of the institution through an open-ended individual interview using guiding questions. After the consent of the participant, the interviews were started and recorded, later transcribed and analyzed using the Content Analysis technique. RESULTS: After the analysis process, four categories emerged: Care and nursing staff, encompassing the role of nursing in patient care during their stay in the operating room; Feelings experienced during the perioperative period, seeking to portray the close relationship between the care process and the maintenance of clients' wellbeing; Nursing contribution in the process of coping with the patient in fron of the operating room, in which communication, safety and welcoming are elements of fundamental importance in the therapeutic process; Suggestions for process improvement, as a way to improve the assistance offered. CONCLUSION: The analysis of the findings contributed to obtain more knowledge about the factors that involve nursing care and enabled the detection of the assessed dimensions, important to improve the care provided and ensure safe care.

\section{EPIDEMIOLOGICAL PROFILE OF MANSONIC SCHISTOSOMOSIS IN BRAZIL} FROM 2007 TO 2017

Marcos Fernando Câmara Maranhão; Andressa Barros de Sousa Nascimento; Ana Celeste Machado Bastos; Mylenna Diniz Silva Monique Santos do Carmo

Centro de Ciências da Saúde, Medicina, Centro Universitário do Maranhão, São Luís, BR

INTRODUCTION: Schistosomiasis mansoni is a parasitosis caused by the Schistosoma mansoni trematode that has as its intermediate host the freshwater snail of the genus Biomphalaria. The pathology ranges from asymptomatic conditions to severe clinical forms, being caused by the presence of worms that shelter in the mesenteric vessels for years in adul and sexually differentiated forms. Thus, the objective of this study was to perform a retrospective analysis of the quantitative approach of the incidence and evolution profile of schistosomiasis in the Brazilian population from 2007 to 2017. METHODS: The methodology employed involved the evaluation of data obtained from the Disease Notification System (SINAN). ) from the Ministry of Health from the percentage calculation. RESULTS: Over 10 years, 144,755 cases have been reported. In the distribution by region it was observed that the Southeast and Northeast Regions had a higher number of records, with 96,411 and 45,774 cases, representing $66.60 \%$ and $31.62 \%$ of the total, respectively. The most prevalent age group was 20 to 39 years old, with 58.347 cases $(40.30 \%)$ and the brown race was the most prevalent with $49.63 \%$. Regarding clinical evolution, 88,631 cases evolved to cure, representing $61.22 \%$ of the total, while 670 cases of schistosomiasis led the patients to death, representing $0.46 \%$. CONCLUSION: Data collection identified gaps regarding the completion of notification fields, which made it impossible to know all cases. However the importance of better surveillance, monitoring and elaboration of prevention strategies for this infectious disease is emphasized, which generates several clinical repercussions for patients and burdens on the public health system.

\section{EPIDEMIOLOGICAL PROFILE OF VISCERAL LEISHMANIASIS IN ARAGUAÍA FROM 2015 TO 2019}

Naualy Cunha Alencar; Cecília Jácome Carvalho; José Walter Lima Prado

Centro Universitário Tocantinense Presidente Antônio Carlos (UNITPAC)

INTRODUCTION: Visceral Leishmaniasis is a systemic infectious disease caused by a protozoan of the genus Leishmania. In Brazil there are $90 \%$ of the cases of kala azar in the Americas. It is considered one of the five priority endemics for the actions of the World Health Organization (WHO), and the northern region is considered hyperendemic with the highest incidence observed in Tocantins (TO). The aim of this paper is to describe the clinical and epidemiological profile of cases of visceral leishmaniasis in the city of Araguaína-TO. METHODS: A retrospective and descriptive study of the cases of visceral leishmaniasis in the city of Araguaina - T0 from 2015 to 2017 , through SINAN records. After collecting the information, the data were analyzed and tabulated in the Microsoft Excel and Epi Info programs. RESULTS: There were 256 cases of patients with confirmed diagnosis of Visceral Leishmaniasis during the period from 2015 to 2017 . Of these, $60.1 \%$ were male. Being $16.01 \%$ in children under 1 year. With the highest incidence of $32.03 \%$ in the age group of 1 to 4 years. $16.79 \%$ in the adultyoung age group of 20-39 years. Regarding the area of residence of the affected population, it was observed that $89.45 \%$ is in the urban region. Notifications were made from 28 municipalities in the state of Tocantins and $39.1 \%$ of cases were in the city of Araguaina. CONCLUSION: Thus, it is concluded that the most affected population is male and aged between 1 and 4 years. Being the city of Araguaina with the largest number of cases in the state of Tocantins. The urban area had a higher number of cases compared to the rural area. Given the data obtained, it is considerable to articulate educational measures as a form of prevention, with greater attention to the home area.

\section{EQUISETUM ARVENSE L. REDUCES HISTOLOGICAL CHANGES BY ACUTE MYOCARDIAL INFRARATION IN RATS}

Gabriel Gomes Oliveira; Marcos Vinícius Araújo Brito; Matheus Fagundes Da Silva; Vinícius Santos Mendes; Vítor Paixão Cruz; Rachel Melo Ribeiro

Universidade Federal do Maranhão (UFMA)

INTRODUCTION: Acute Myocardial Infarction (AMI) is the leading single cause of death among heart diseases, occurring when oxygen supply and myocardial metabolites are below their needs, causing cell death. Thus, the present study evaluated the cardioprotective action of Equisetum arvense L. (horsetail) on isoproterenol (ISO) myocardial injury through histopathological analysis of the cardiac apexes. METHODS: Male adult Wistar rats, Rattus norvegicus, received E. arvense Stem Lyophilized Extract (EEA) for 30 days. The groups for oral administration were divided into: Healthy Control ( $0.05 \mathrm{ml} / 100 \mathrm{~g}$ water), EEA ( $50 \mathrm{mg} / \mathrm{kg} /$ day), ISO (0.05 m / $100 \mathrm{~g}$ water) and Atenolol ( $50 \mathrm{mg} / \mathrm{Kg} / \mathrm{day})$. At the end of treatment, the groups received subcutaneous injection of ISO ( $85 \mathrm{mg} / \mathrm{kg} /$ s.c.), And the Healthy Control received saline (s.c.) for two consecutive days. Histological slides were produced from the cardiac apexes for microscopic analysis. RESULTS: The healthy control group cardiac tissues showed clear, intact cell membrane, normal striated myofibrillar structure, branched appearance and continuity of adjacent myofibrils. However, the cardiac tissues of ISO-treated 
rats showed necrosis, with leukocyte infiltration and interstitial edema. EEA treatment shows a potential reversal of these ISO-induced changes, similar to the Atenolol group, revealing potential cardioprotective effect against injury. CONCLUSION: Despite being a pioneer study on the action of $E$. arvense on the cardiovascular system in preclinical experimental models, it was observed that the extract exhibited a potential cardiopreventive effect against ISO-induced myocardial injury. However, further studies are needed to clarify the mechanisms of action of this medicinal plant in cardioprotection, as well as to evaluate possible antiarrhythmic activity.

\section{PROFILE OF PATIENTS WITH TRIGEMINAL NEURALGIA FROM A PAIN} CENTER IN SÃO LUÍS

Vanessa Vieira Pinheiro; Luís Augusto Silva Batista; Luiza Sousa Soares; Raynan Costa Santana; João Batista Santos Carcia; Thiago Alves Rodrigues; Rayanne Luiza Tajra Mualem De Araujo UNIVERSIDADE FEDERAL DO MARANHÃO (UFMA)

BACKGROUND: Trigeminal neuralgia is one of the most common neuropathic pains in the head and neck region. Non-painful stimuli may trigger its manifestation, usually unilateral involving one or more nerve divisions. This paper describes the profile of patients with trigeminal neuralgia undergoing treatment at a referral center for pain. METHOD: A descriptive cross-sectional study based on the analysis of medical records of patients with trigeminal neuralgia assisted at the chronic pain service of the University Hospital of the Federal University of Maranhão (HUUFMA), from 2009 to March 2019. The analyzed variables were indicated: gender, age at diagnosis, race, initial drug therapy, current drug therapy, non-drug therapy, treatment adherence, and improvement rate. RESULTS: The sample comprised 15 patients with a predominance of diagnosis in women ( $73 \%$ ) compared to men (27\%). Eighty percent of the patients were over 40 years of age at diagnosis and by race, $40 \%$ declared brown, $33 \%$ black, $13 \%$ white and $13 \%$ had no record. Regarding the initial treatment, Carbamazepine (26\%) and Gabapentin (13\%) were the main choices. In the current treatment, Carbamazepine was determined in $46 \%$ of cases and Gabapentin in $26 \%$. Non-pharmacological therapy was adhered to in $40 \%$ of the cases analyzed. As for the improvement rate, $40 \%$ had partial improvement, $26 \%$ significant improvement, and $13 \%$ did not improve. CONCLUSION: Trigeminal neuralgia is a frequent condition in the HUUFMA pain service, representing an important clinical condition that affects mainly women over 40 years of age. The disease has a relevant improvement rate, and drugs such as carbamazepine and gabapentin are effective in treatment, along with nonpharmacological therapy.

\section{REPLACEMENT RENAL THERAPY IN YOUNG PATIENT - CASE REPORT}

Maria Ana Salviano de Sousa; Bruno Cerqueira Lima; Francisca Ceysa da Silva Costa

Centro Universitário Tocantinense Presidente Antônio Carlos - UNITPAC. Hospital Regional de Araguaína - HRA.

INTRODUCTION: Terminal chronic kidney disease is a serious public health problem in the country, with the majority of male patients undergoing renal replacement therapy, with an average age of 50 to 55 years. Multiprofessional follow-up is required for good treatment adherence. CASE REPORT: Patient, male, 26 years old, $50 \mathrm{~kg}$, previously healthy, admitted with anasarca, dyspnea, hypertensive peak and oliguria, denies use of antiinflammatory, antibiotic and previous infections. On physical examination testicular and penile hypotrophy. Laboratory tests: $\mathrm{Ht} 22 \%$; $\mathrm{Hg}$ : 7.6; Ur: 309; Cr: 19.4; K: 5.3; Cl-CR: 4.1. Urinary tract US showed small kidneys with alteration of parenchymal texture bilaterally. Indicated renal replacement therapy, water restriction, diuretic and antihypertensive for blood pressure control. Patient resistant to treatment, does not respect medical prescription of lower fluid intake, on the 12th day of hospitalization, develops acute respiratory failure, bronchial aspiration pneumonia and sepsis, used broad spectrum antibiotic for 10 days, and remained in the ICU for 5 days. Patient evolves with improvement of respiratory condition and remains on dialysis treatment, with interdisciplinary support, and improvement of acceptance of his clinical condition. CONCLUSION: Chronic kidney disease causes sudden changes in patients' daily life, creates limitations to perform activities of daily living and generates a great impact on their emotions and quality of life. Aiming the good management of patients with chronic kidney disease, a multidisciplinary team is indispensable for adherence to treatment.
87. PARTIAL MONOSOMY OF THE SHORT ARM OF CHROMOSOME 1 AND ITS PATHOLOGICAL IMPLICATIONS

Beatriz Ortegal Freire; Ana Karollyne de Araujo Pontes; Carolina Almeida Balluz; Ingrid Germano Azevedo Silva; Wanderson de Moura da Silva; Maria Juliana Rodovalho Doriqui; Jucelia Sousa Santos Canz Centro Universitário do Maranhão, Hospital Infantil Doutor Juvêncio Matos

INTRODUCTION: Around $75 \%$ of genetic diseases manifests in childhood. Congenital anomalies, neuropsychomotor development delay, growth and behaviour alterations are alarm signs for specialised investigations. This case report justifies itself due to its rarity and diagnostic complexity. CASE DESCRIPTION: male, 6 years old, young parents, no consanguinity. 16 years old mother at the time of birth, denies use of teratogens. Caesarean delivery at term, with $2725 \mathrm{~g}, 48 \mathrm{~cm}$ and cephalic perimeter of $32 \mathrm{~cm}$, Apgar $7 / 8$, sucking difficulty, prenatal pelvicalyceal dilatation, discharged within 9 days. It was referred frequent falls and speech delay. Physical examination: axial hypotonia, microcephaly, bilateral epicanthus, low implantation ears and posteriorly rotated, short neck with excess skin at the nape of the neck. Complementary exams: CPK and elevated transaminases; right kidney agenesis and vicarious left kidney on ultrasound; paroxysmal graph elements in epileptiform foci at right centro-temporo-parietal segment; brain magnetic resonance imaging - enlargement of the retrocerebellar cerebrospinal fluid, dilated perivascular infraputaminal spaces and in the bilateral semioval center spaces; G banding karyotype 46, XY; SNP-ARRAY showed $12 \mathrm{Mb}$ chromosome 1 interstitial deletion, at 1 p21.1p13.2 region containing around 173 genes. There are descriptions of patients with deletions with breaking points and variable sizes involving this region in variants database of individuals with phenotypes. Similar deletions were not identified in general population individuals. Alterations with these characteristics are considered pathogenic. CONCLUSION: Partial monosomy of the short arm of chromosome 1 varies clincally along with the chromossomic segment involved, and this is na unique case in literature. It is emphasized that after the Array advent, around $20 \%$ of intelectual defiency/genetic anomalies cases have its etiology clarified, which can be substituted in the line of investigation.

\section{PREVALENCE OF ENDOSCOPY-IDENTIFIED FOREIGN BODIES IN INDIVIDUALS O TO 19 YEARS}

Leticia Muniz de Abreu Murad; Maria Tereza Pereira Conçalves; Carla Maria da Silva Santos; Laisa Brenda Corrêa Santos; Ana Lais Pinto Macena; Isabella Fróes Souza; Keila Regina Matos Cantanhede Centro Universitário do Maranhão (CEUMA)

INTRODUCTION: Foreign body is any object or substance that inadvertently enters the body or its cavities. Ingestion of foreign bodies is a common problem in the pediatric population, children often mouth objects being investigated by them and the objects are accidentally swallowed. According to the World Health Organization, childhood is divided into: Early Childhood (o to 2 incomplete years), Second Childhood ( 2 to 6 incomplete years), School (6 to 12 incomplete years) and Adolescence ( 12 to 12 years). 19 years old). Most intakes occur in children, with a peak incidence ranging from 6 months to 6 years (early and second childhood). In the resolution of these cases High Digestive Endoscopy may be indicated as a diagnostic and / or therapeutic method. METHODS: Cross-sectional, descriptive and quantitative study, performed through the analysis of medical records in the database of the endoscopy service in a hospital in São Luís, Maranhão. RESULTS: A total of 46 cases of accidents involving ingestion of foreign body were found. from January 1, 2016 to May 5, 2018. Of these, 16 (34.8\%) cases were female and $30(65.2 \%)$ were male. Regarding age groups in childhood, $7(15.21 \%)$ cases in early childhood, $30(65.23 \%)$ in early childhood, $3(6.52 \%)$ in school and $6(13.04 \%)$ in childhood. adolescence. Foreign bodies found by upper digestive endoscopy ranged from: 7 coins $(15.21 \%)$, 6 fish bones $(13.04 \%)$, 2 chicken bone $(4.34 \%), 3$ plastic $(6,52 \%)$ and 28 others $(60.86 \%)$. CONCLUSION: Foreign body intake is not always identified by third parties ( $40 \%$ or more of accidental EC intake will not be diagnosed). Thus, there is a need and urgency for endoscopic FB removal, depending on several factors, including type, presence or absence of symptoms, and location. It is never too much to remember that the best treatment for EC intake is prevention, especially in early childhood, found in this study to be at higher risk. Parental education and information regarding the dangers and risks of $\mathrm{EC}$ ingestion.

89.

THERAPEUTIC PROFILE OF HEART FAILURE PATIENTS IN A UNIVERSITY HOSPITAL 
Bruna Costa de Albuquerque Bogéa; José Albuquerque de Figueiredo Neto; Alana de Oliveira Castro; Viviane Melo e Silva de Figueiredo; André Melo e Silva de Figueiredo; Juan Marcos Araújo Reis; Gabrie Brandão Neves de Souza

Hospital Universitário da Universidade Federal do Maranhão (HU-UFMA)

INTRODUCTION: Heart failure (HF) is a complex and highly prevalent condition, responsible for high mortality and hospitalization rates. The treatment instituted is fundamental for its prognosis: the use of angiotensin-converting enzyme inhibitors (ACE inhibitors), angiotensin receptor blockers (ARBs), beta-blockers (BB) and vasodilators reduces morbidity and mortality, while diuretics and digitalis help in improvement of symptoms. METHODS: Data collection was performed by searching the medical records of 301 patients with reduced ejection fraction HF who were followed up in a specialized outpatient clinic at the University Hospital of the Federal University of Maranhão. Data were expressed as mean and standard deviation (continuous and discrete variables), absolute and relative frequencies (categorical variables) in Stata 14.0 software. RESULTS Among the patients, there were $180(59.8 \%)$ men and $121(40.2 \%)$ women. Among these, there were $136(45.2 \%)$ whites, 126 (41.9\%) browns, $27(9 \%)$ blacks and $12(4 \%)$ did not report race. Idiopathic Dilated Cardiomyopathy was the most prevalent etiology, occurring in $75(24.9 \%)$ patients, followed by Ischemic in $60(19.9 \%)$ patients and Hypertensive in $55(18.3 \%)$ cases. In addition, $220(73.1 \%)$ had hypertension, $118(39.2 \%)$ had dyslipidemia, and $114(37.9 \%)$ had diabetes. The absolute number prescription (\%) found was: ACEI or ARB were prescribed for 201 (66.11\%) patients, BB for $238(78.28 \%)$, spironolactone for $135(44.4 \%)$, hydralazine for 44 patients. (14.47\%), nitrat for $34(11.18 \%)$, furosemide for $105(34.5 \%)$, hydrochlorothiazide for 89 (29, $27 \%)$, and digoxin for $24(7.89 \%)$ patients. CONCLUSION: There was a need to optimize drugs that reduce mortality, especially ACEI / ARB and spironolactone. The use of diuretics and digoxin are in line with the latest guidelines, with lower use of these drugs.

RELATE OF TONIC CLONIC CONVULSIVE CRISIS IN A PATIENT WITH TAYSACHS DISEASE

Levy Chateaubriand Feller; Rayla Bezerra Rocha; Wesley Costa Barros; Raylenne Moreira dos Reis; Izabelle da Silva Oliveira; Stephanie Cristina Rodrigues Sousa; Raissa Sousa Aragão

Centro Universitário do Maranhão (CEUMA)

INTRODUCTION: Tay-Sachs is an autosomal recessive genetic disease, rare characterized by the lack of hexosaminidase $A$, which makes an accumulation of sphingolipids (CM2) in neural cells. There is a progressive neurological loss, compromising physical and mental skills since the very beginning of life, resulting in death in about 4 years. The disease generates a white chalk mark in the retina, called "red cherry mark". It is developed a cognitive and motor deterioration, amaurosis, dysarthria, dysphagia ataxia and spasticity. CASE DESCRIPTION: Male patient, 1 year and 9 months old, hospitalized in an Intensive Therapy Unit (ITU), relating tonic clonic convulsive seizures in the past 3 days, approximately 4 times a day associated with bronchitis and aspirating pneumonia. In the physical exams the patient presents REG, anicteric, not cyanotic, not feverish, hypo-colored mucosa $(++/++++)$, hydrated, eupneic, TEC $<2$ seconds. In the neurological exam, CCS: 15 and nystagmus. Without alterations in the remaining equipment. Previously diagnosed with Tay-Sachs disease, accompanied by a geneticist medic and neuropediatric medic, was indicated to a treatment with specific medicine not allowed by ANVISA (Tanganil Cé 500mg), that was maintained in regular use to do not disturb the disease's treatment. An encephalogram was done and presented a disorganized base activity, occasional paroxysm epileptiform in the frontal left region with rare irradiations to the right hemisphere and outbreak of slow delta waves in the left hemisphere. Without electrographic crises. The patient got better then the living conditions evolved because the discharge. CONCLUSION: The diagnoses may be done during the antenatal, which helps in the decrease of the incidence rate of the disease. However, because the lack of epidemiological data and the unusual contact by the professionals with the disease makes its evolution easy to evolve.

\section{PRIMARY ADRENAL FAILURE: A CASE REPORT}

Camila Batista Alves; Mariana Soares Mendes; Ana Luiza Holanda Carneiro

Centro Universitário do Maranhão ( CEUMA) e Hospital Dr. Carlos Macieira $\mathrm{HCM})$
INTRODUCTION: The adrenal glands are components of the endocrine system responsible for the production of hormones that control the metabolic hydroelectrolytic and steroid processes. Primary adrenal insufficiency, also known as Addison's disease, has a prevalence of 2 to 10.000 individuals and is characterized by poor secretion of mineralocorticoids and glucocorticoids, which result in clinical manifestations of the disease. The aim of this paper is to report the case of a patient with signs and symptoms indicative of primary adrenal insufficiency. CASE DESCRIPTION: R.S.A.A, 44 years old, female, brown skin, married, teacher, native and resident of Matinha-MA. Patient was admitted to a university hospital on 02/07/2019 reporting asthenia, accompanied by vertigo, nausea, vomiting, hyporexia, chills, hypotension and arthralgia for 5 days; denies fever and syncope. She reports weight loss of approximately $15 \mathrm{~kg}$ and cutaneous hyperpigmentation in the last 3 months. She has had a history of total thyroidectomy for 4 years, taking hormone replacement with Puran T4 50mg. Denies family history of similar cases. The complementary exams found: hyponatremia, negative BAAR test, low levels of Dehydroepiandrosterone sulfate, androstrenedione and cortisol, high levels of adrenocorticotropic hormone and erythrocyte sedimentation rate. Based on clinical data and laboratory tests, the diagnosis of Addison's disease was established and treatment with fludrocortisone and prednisone was initiated, showing clinical improvement. CONCLUSION: The case report presented was diagnosed as primary adrenal insufficiency based on data collected from anamnesis and physical examination, including the classic triad of hypotension, hyponatremia and mucocutaneous hyperpigmentation, as well as the alterations found in the complementary exams.

\section{ANALYSIS OF VACINAL COVERAGE AGAINST MENINGITIS IN MARANHÃO BETWEEN 2014 TO 2018}

Beatriz fontenelle costa; Rafaela Macedo Pires Ferreira; Sérgio Antônio de Melo e Silva Borges; Rayssa de Oliveira Dominice; Sueli de Souza Costa

UNIVERSIDADE FEDERAL DO MARANHÃO (UFMA)

INTRODUCTION: Meningitis is an inflammatory process of meninges, which are membranes that surround the central nervous system. Its main etiological agents are Streptococcus pneumoniae, Neisseria meningitidis and Haemophilus influenzae type B. Prevention of the disease is through vaccination, with special attention to meningococcal C, 10-valent and pentavalent pneumococcal, which includes protection against Haemophilus influenzae B. OBJECTIVE: To analyze vaccine coverage rates against meningitis and to verify the evolution of disease mortality in the state of Maranhão between 2014/2018. METHODOLOGY: Secondary data obtained from DATASUS Tab for Windows (TABWIN) software were used. Regarding vaccination coverage, only the vaccines were considered: meningococcal $C$ and 1st booster, pneumococcal and 1st booster, and pentavalent. Thus, for the analysis of mortality due to meningitis, only three etiological agents were considered: pneumococcus, meningococcus and Haemophilus influenzae type B. From the data collection, a table listing the values found in the study period was produced. RESULTS: Accordingly, between 2014 and 2018 , vaccination coverage in the State of Maranhão against meningococcus reached $81.53 \% ; 84.80 \% ; 76.84 \% ; 75.06 \%$ and $72.65 \%$; for pneumococcus, $77.59 \%$; $80.31 \%$; $74.09 \%$; $76.23 \%$ and $79.46 \%$; while for Haemophilus influenzae reached $89.15 \%$; $91.17 \% ; 73.12 \% ; 72.22 \%$ and $79.01 \%$. With respect to mortality, between 2014 and 2018, 22 deaths were recorded within the state, 7 due to meningococcal meningitis, 13 due to pneumococcal meningitis and 2 to Haemophilus influenzae. CONCLUSION: Thus, it is clear that mortality from meningitis from a given etiological agent is directly related to low specific immunization coverage, ie vaccination rates below $80 \%$ have a greater influence on deaths.

\section{INFECTION BY HISTOPLASMOSIS ON PEDIATRIC HEART TRANSPLANT}

\section{PATIENT}

Beatriz da Silva Ferreira de Lima; Bárbara Tanaka; Estela Azeka; Raphael Ferreira Faleiro; Ana Carolina Aires Braga; Edgard Barboza de Melo; Marina Vaz Rodrigues

Universidade Federal do Maranhão (UFMA)

INTRODUCTION: Histoplasmosis is a fungal infection low prevalent in Brasil caused by the inhalation of Histoplasma Capsulatum. The fungus infects the pulmonary alveoli, induces inflammatory response, gets multipled and reaches the systemic circulation. Most of infections are asymptomatic with immune response and cure in the firsts weeks. Immunosuppressed people can develop acute, severe and disseminated forms of the disease. CASE 
DESCRIPTION: IAB, 15 age, coming from Belém(PA), postoperative heart transplantation in 2009 with congenital cardiomegaly. Hospitalized with fever complaint, weight loss and adynamia a month ago transferred from the city of origin after treatment to pneumonia and cytomegalovirus, without upgrade. Admitted with an important tachydyspineia quickly progressive, needing noninvasive medication and vasoactive drugs. Laboratory tests with leukopenia and thrombocytopenia, diffuse bilateral infiltrate chest $\mathrm{x}$-ray, tomography with diffusely distributed centrilobular nodules and normal marrow biopsy. It was suggested hypotheses of tuberculosis, atypical hospital or fungal pneumonia, then he was submitted to treatment with multiple antimicrobials, the results were not positive. The diagnosis of histoplasmosis came after his bronchoalveolar lavage and lung byopsi. Relatives were questioned about exposition. His mother mentioned an eventual presence in a church with pigeons. After the diagnosis, it was realized a directioned treatment with liposomal anphotericin B in 30 days. The patient evolved with gradual improvement, he was discharged with itraconazole and a treatment plan for 6 months. CONCLUSION: In view of the increasing number of opportunistic diseases, which develop better in patients with weakened immune systems, such as transplanted ones, the suspicion for this type of pathogen should be encouraged, thus facilitating therapeutic direction.

\section{NOCICEPTIVE PAIN FOR CUSHING SYNDROME: A CASE REPORT}

Alda Tereza Queiroz Lyra; Raynan Costa Santana; Sérgio de Jesus Moraes Junior; João Batista Santos Carcia; Thiago Alves Rodrigues; Marcelo Ribeiro Mendes Junior; Rayanne Luiza Tajra Mualem de Araujo

Universidade Federal do Maranhão (UFMA)

INTRODUCTION: Cushing's syndrome (CS) is a condition resulting from prolonged exposure to excess glucocorticoids. The chronic pain in this case report is due to prolonged use of this drug due to a hypophysectomy; CASE REPORT: C.S.D, female, 48 years old, born in São Luís- MA. In October 2016, the date of her first consultation at the Chronic Pain Outpatient Clinic of the University Hospital of the Federal University of Maranhão (HUUFMA), the patient reported generalized and intermittent pain, with feeling of "tiredness", weight, burning and shock started after hypophysectomy 7 years ago. Physical examination showed allodynia, decreased strength and paraesthesia at various body sites, with Visual Numerical Scale (EVN) $=10$ most of the time and partial improvement with paracetamol and physical therapy. Patient diagnosed with CS, making continuous use of prednisone, sodium alendronate and acetaminophen in pain crises. Raised the possibility of nociceptive pain, Tramadol $(37.5 \mathrm{mg}$ ) and Paracetamol (325 $\mathrm{mg}$ ) were prescribed every 8 hours in seizures and Pregabalin ( $75 \mathrm{mg}$ ) 1 oral tablet at night. After 3 months, the patient reported an $E V N=4$. After 2 years of follow-up, with exchange of pregabalin for gabapentin and new dose adjustments (900 mg daily), the patient returns reporting pain extinction, including being able to adhere to rehabilitation therapy (physical therapy and physical activity). On physical examination no changes were found. $E V N=0$; DISCUSSION: Clucocorticoids are used in medical practice due to their high anti-inflammatory power. However, when introduced in high doses or over a prolonged period can trigger Cushing's syndrome as a side effect; CONCLUSION: The relevance of this report is given about the cause of Cushing's syndrome, which was triggered by prolonged glucocorticoid treatment.

\section{SULFONE SYNDROME AND LEPROSY: A CASE REPORT}

Ingrid Macêdo Araújo; Matheus Rizzo de Oliveira; Rosana Maria Paixão Castello Branco; Thiago Arôso Mendes de Araújo; Mirella Costa Ataídes; Amanda Angelo Pinheiro; Gabriel Costa Ferreira Andrade

Centro Universitário do Maranhão (CEUMA)

INTRODUCTION: Sulfone syndrome (SS) or Dapsone Hypersensitivity Syndrome (DDS), also known as "six-week dermatitis," usually appears within six weeks of starting this medicine. It is characterized by a sudden exanthematic disorder associated with systemic symptoms. It includes high fever, lymph node enlargement, hemolytic anemia, lymphocytic atypia and jaundice with increased canalicular enzymes and transaminases. This article aims at reporting a clinical case of SS. CASE DESCRIPTION: T.R.O.S., female, 26 years-old, northeastern brazilian, diagnosed with leprosy, who initiated multidrug therapy (Dapsone and Clofazimine) with an expected span of 6 months. She presented malaise in the first day after the beginning of the treatment, with spontaneous recovery and maintenance of the scheme. In the third week, she presented emesis, asthenia, vertigo and fever for 10 days, evolving with exfoliative dermatitis of the extremities, more accentuated in the upper limbs in the hypothenar region, lowering of the level of consciousness, expressive ponderal loss, jaundice, myalgia, submandibular lymphadenomegaly and epigastralgia. She denied other comorbidities and did not make continuous use of any other medication. Laboratory tests demonstrated moderate anemia, elevated bilirubin and liver enzymes. Corticotherapy with Prednisone 40mg/day was initiated during 15 days and definitive suspension of the DDS. The patient evolved with significant improvement in general condition and was treated for leprosy with Clofazimine alone, without complications. CONCLUSION: SS is a rare pathology that affects all ages, with no predilection for gender and clinical diagnosis. Its mortality is about 13 to $15 \%$. The clarification of its etiopathogenesis and the knowledge of its management have great value for the improvement of the medical assistance and the reduction of morbid and fatal outcomes related to the population affected by it.

\section{MESENTERIC SCISSOR IN PEDIATRIC PATIENT: A CASE REPORT}

Letícia Weba Couto Rocha; Anna Marieny Silva de Sousa; Anna Beatriz Trindade Lopes; Rafael Lopes Carvalhal; Átila Bezerra Atta Centro Universitário do Maranhão (CEUMA)

INTRODUCTION: Mesenteric Cyst (CM) is defined as a cystic lesion, that is, a benign tumor with a liquid, semi-solid or pasty content, which has different pathological origins. It is located between the two layers of the mesentery, originating anywhere in the gastrointestinal tract. Mesenteric cysts are rare lesions, incidence $1 / 100,000$ in adults, predominate in the female gender with age range for diagnosis of 30.48 years; in pediatric patients has an incidence of approximately $1 / 20,000$, affecting more children and the average age of $4 / 9$ years. The cases may be asymptomatic or not the first being more recurrent. The clinical picture is characterized by nonspecific pain, abdominal mass and distension, with a mean duration of 2 to 6 months. In children, this clinical picture may start more acutely and, depending on the size of the $\mathrm{CM}$, it can simulate ascites. Description of the Case: G.0. A 12-year-old female, from Viturino Freire, Brazil, presented with intense pain when walking and abdominal distension, associated with abscess, palpable mass above the umbilical scar. She sought medical care in a hospital in the city of Bacabal in August 2017 for diagnostic investigation. She was then admitted to the same hospital, where the diagnosis was confirmed through clinical examination and imaging (Total Abdomen Ultrasonography and Abdomen Computed Tomography Total). A cystic lesion measuring approximately $19.0 \times 10.0 \mathrm{~cm}$ was observed in the images, affecting almost all the left hemiabdome, extending to the pelvis. Conclusion: $\mathrm{CM}$ are rare intra-abdominal lesions in children. The case in question was a cystic, expansive formation. ogo, in order to rule out differential diagnoses, imaging and surgery are essential to promote a favorable diagnosis and prognosis, respectively.

\section{EPIDEMIOLOGICAL PROFILE OF SYPHILIS IN ARAGUAINA PREGNANT WOMEN FROM 2015 TO 2018}

Cecilia Jácome Carvalho; Danyelle Pimentel Do Rosário; Rosângela Do Socorro Pereira Ribeiro

CENTRO UNIVERSITÁRIO TOCANTINENSE PRESIDENTE ANTÔNIO CARLOS

INTRODUCTION: Syphilis is a bacterial infection caused by Treponema pallidum and transmitted sexually, vertically or hematogenously during any period of pregnancy. The occurrence of syphilis in pregnancy has been presenting great frequency and great repercussions in the maternal-fetal morbidity, increasing the rates of congenital infection and perinatal mortality. The aim of this paper is to describe the clinical and epidemiological profile of cases of congenital syphilis in the city of Araguaína-TO. METHODS: A retrospective and descriptive study of the confirmed cases of syphilis in pregnant women in the city of Araguaina TO, from 2015 to 2018, was performed using SINAN records. After data collection, they were analyzed and tabulated in the Microsoft Excel and Epi Info programs. RESULTS: There were 1614 cases of pregnant patients diagnosed with syphilis during the period from 2015 to 2018 . Of these, $4.46 \%$ were in the age group of $15-19$ years. Still being the highest incidence in the age group from 20 to 39 years old with $11.33 \%$. Regarding the diagnosis, $15.17 \%$ of pregnant women were diagnosed prenatally. The prevalent clinical classification at diagnosis was the primary stage of the disease with $9.3 \%$, followed by tertiary syphilis with $2.1 \%$, latent syphilis $1.9 \%$ and finally secondary with $1.6 \%$. Notifications were made from 48 municipalities in the state of Tocantins and $16.6 \%$ of cases in the city of Araguaina. CONCLUSION: 
Thus, it was observed that there was a $320 \%$ increase in diagnosed cases of gestational syphilis in the period from 2015 to 2018 in the city of Araguaína-TO and discrepant to $250 \%$ in the state of Tocantins. Given the data obtained, it is valid to articulate ways to improve public policies regarding the decrease in the prevalence of congenital syphilis in the mother-child binomial and its complications.

\section{ACUPUNCTURE AS THERAPY IN PATIENT WITH POST SURGERY PAIN:} CASE REPORT

Daniel Victor Viana Rodrigues Nunes; José Estevam Ribeiro Júnior; Elizabeth Teixeira Noguera Servin; Lyvia Maria Rodrigues de Sousa Gomes; João Batista Santos Carcia; Thiago Alves Rodrigues; Rayanne Luiza Tajra Mualem de Araujo

Universidade Federal do Maranhão (UFMA), Hospital Universitário da Universidade Federal do Maranhão (HUUFMA)

INTRODUCTION: The low back pain is one of the main causes of absence from work in industrialized countries. It can be caused by several factors such as osteoarthritis, herniated disc, spinal surgery, bone tumors, among others. Presently there is the conservative pharmacological treatment with anticonvulsants, tricyclic antidepressants, whether or not associated with opioids. For non-pharmacological treatment there is physical therapy and acupuncture by stimulating a point that has direct access to the central nervous system. CASE DESCRIPTION: Male patient, 47 years old, in treatment at the Chronic Pain Service of the UFMA's University Hospital for 2 years, refers burning pain located in the lower back, did not attend physiotherapy, reported non-restorative sleep and was taking anticonvulsants and tricyclic antidepressants for pain, reporting pain improvement. He was referred to acupuncture due to reports of slight improvement with pharmacological treatment. Were performed 10 acupuncture sessions with needling of ashi points VB34, Ig4, B25, B23, B67, B60, R3, and R7. Patient reported slight improvement with acupuncture after 10 sessions, but during the 10 sessions showed infidelity to pharmacological treatment. He kept his behavior after the 1oth session and the patient is still undergoing treatment. CONCLUSION: Although there are literary reports in favor of supporting acupuncture for the adjuvant treatment of low back pain due to the fact that acupoints trigger conductive fibers of high speed painful stimuli, which generates opioid release, this patient did not show significant improvements with pharmacological and non-pharmacological treatment, noting that the patient did not adhere to the pharmacological treatment due to its cost.

99.

\section{ASHTMA HOSPITALIZATIONS IN MARANHAO UNDER 5 YEARS IN THE LAST 10 YEARS}

Amanda Patrícia Vasconcelos Matos; Sérgio Antônio de Melo e Silva Borges; Gustavo Emanuel Lima Pinheiro; Andresa Alves de Lima Galvão; Nathaly Vitória Portela Santos

Universidade Federal do Maranhão (UFMA)

INTRODUCTION: Asthma is composed of hyperresponsiveness and airway and inflammation that are responsible for airflow, which regresses spontaneously with treatment. This is a public health issue throughout Brazil, due to high morbidity and mortality rates. In Maranhão, the disease is a cause of a significant number of hospitalizations in children. METHODS This is a descriptive study on the number of hospitalizations for asthma in children under 05 years, between 2009 and 2018, in the municipalities of Maranhão (MA), based on secondary data obtained from the Hospital Information System (SIH / DATASUS). RESULTS: The number of hospitalizations for asthma in MA in children under 05 years increased progressively in the first three years (2009-2011), ranging from 3425 to 3932 cases, and was unstable but declining in subsequent years. Among the municipalities, the largest numbers recorded in the research period were recorded for Grajaú with 1164, approximately triple the number of hospitalizations in the capital Sao Luis with 382 cases in the same 10-year interval. CONCLUSION: Increased levels of pollution, access to medicines, and lack of information about disease programs may explain the number of hospitalizations and behavior in the states of MA. Early diagnosis of asthma in children is important for treatment. From 2011 there was a decrease in the number of hospitalizations, even if irregularly, it can be explained by the implementation of specific health programs to control other public issues, which are not directly related to asthma, but which have a positive impact on the reduction of hospitalizations. in view of the increased intervention of health professionals in the community.

\section{HEART AND KIDNEY SYNDROME FROM EXOGENOUS PESTICIDE} POISONING

Maria Ana Salviano de Sousa; Bruno Cerqueira Lima; Francisca Ceysa da Silva Costa

Centro Universitário Tocantinense Presidente Antônio Carlos - UNITPAC. Hospital Regional de Araguaína - HRA.

INTRODUCTION: Acute kidney injury (AKI) is a complex and potentially serious clinical entity characterized by a rapid decline in kidney function within hours to days, with loss of ability to regulate hydroelectrolytic and acidbase balance and accumulation of nitrogen degradation products. Abrupt deterioration of kidney function may cause acute cardiac disorder, characterizing type 3 heart and kidney syndrome. CASE REPORT: Patient, male, 76 years old, hypertensive, farmer, smoker and long-term alcoholic, presented dyspnea after use of cypermethrin pesticide / chlorpyrifos on 7/18/2019. After 15 days, she developed dyspnea, associated with oliguria, fever $\left(38^{\circ} \mathrm{C}\right)$, vomiting and abdominal pain; sought the Emergency Care Unit (UPA), where was identified Ur: 116; $\mathrm{Cr}$ : 1.68; Troponin negative, being referred to the Araguaína Regional Hospital after 2 days. On admission patient reports dyspnea, asthenia, hyporexia, nausea, and has been anuric for 12 hours, with Ur: $167, \mathrm{Cr}: 3.6, \mathrm{~K}: 7.1$ and metabolic acidosis, ECG with high response atrial fibrillation, Echocardiogram with EF: $39 \%$ and moderategrade pericardial effusion, USG: bilateral pleural effusion, small ascites and kidneys of normal size and well-defined contours. The patient was referred to the ICU and started correction of hydroelectrolytic and acid-base disorders, remaining for 4 days. Patient presented good evolution, with return of diuresis, improvement of uremic condition, without need for renal replacement therapy, presenting Ur: 124; $\mathrm{Cr}: 1.8 ; \mathrm{K}: 3.5, \mathrm{pH}: 7.39, \mathrm{HCO} 3: 23$. $\mathrm{He}$ was transferred to the medical ward for continued treatment. CONCLUSION: Nephrotoxic AKI is an important cause of morbidity and mortality. The case described reinforces the importance of adequate clinical management in pathologies involving heart and kidney physiological connection.

\section{CAUSES OF DETH IN WOMEN IN A PUBLIC HOSPITAL OF SÃO LUÍS-MA BETWEEN 2015-2018}

Vitoria Coutinho dos Santos; Paulo Gabriel Sacramento da Silva; Mirella Alencar Moreira; Wildney Leite Lima; Rodrigo Matheus Santos Alves; Daniel Ewerton Herculano; Santiago Cirilo Noguera Servin

HOSPITAL MUNICIPAL DJALMA MARQUES (HMDM)

INTRODUCTION: Women are a sigficant part of of the general populatiton in Brazil, estimated at $51.5 \%$ of Brazil's population in 2016. The high mortality rate among women is still a public health problem. Analysis of the causes of deaath in women is necessary in order to monitor public health as well as to plan and evaluate health care. In 2016 there were 1,309,774 deaths in Brazil, of which $572,459(43.6 \%)$ were female. Therefore, this study presents the epidemiological profile and causes of death in women admitted to the Djalma Marques Hospital (HDMD) of São Luís - MA from 2015 to 2018. METHODS: Retrospective study of women deaths from 2015 to 2018, through medical records analysis from HMDM. Data were saved and analyzed by Microsoft excel 2016 program. RESULTS: Over the study period 5,586 deaths were recorded in HMDM, which $2134(38 \%)$ were women. Most deaths are in the age group above 70 years, with almost half of the cases $(46.15 \%)$. The lowest part is under 20 years with 76 cases. Among the main causes of death, cerebrovascular diseases stand out, as they were constituted by a total of $374(18 \%)$ deaths. Second, with $331(16 \%)$ cases is sepsis, which are those of pulmonary focus and urinary tract. Another important cause was pneumonia envolving with acute respitaroty failure, causing 205 (10\%) deaths. The others most frequent were neoplasms-related complications with $66(3 \%)$ cases, head trauma with $59(2.7 \%)$ and $196(9 \%)$ women dod not have their cause of death clarified. CONCLUSIONS: In the study, deaths were mainly due to diseases of the circulatory system and in the age group above 70 years, which fits the current statistics of female mortality in Brazil, considering that according to ministry of health, the main causes of mortality in brazilian women are circulatory diseases, neoplasms and the external causes.

\section{SLEEVE GASTRECTOMY EFFECTS ON PLASMA GHRELIN LEVELS}

Giovanna Maria Pacheco Barroso Maia; Leticia Weba Couto Rocha; Ceraldo José Coelho Granja Filho; Hilquyson Delon Cunha Ferreira; Camilla Lima Lindoso; Ozimo Pereira Gama Filho

Centro Universitário do Maranhão (CEUMA), Universidade Federal do Maranhão (UFMA) 
INTRODUCTION: Different changes of plasma ghrelin levels have been reported following gastric banding, Roux-en- $Y$ gastric bypass, and biliopancreatic diversion. METHODS: This prospective study evaluates plasma ghrelin levels and weight loss following laparoscopic sleeve gastrectomy (LSC) in 25 patients. RESULTS: Patients who underwent LSC $(n=25)$ showed a significant decrease of plasma ghrelin at day 1 compared to preoperative values $(41+/-15 \mathrm{fmol} / \mathrm{ml}$ vs $112+/-45 \mathrm{fmol} / \mathrm{ml}, \mathrm{P}=0.005)$. Plasma ghrelin remained low and stable at 1 and 6 months postoperatively. Mean excess weight loss was $27 \pm 18 \%$ on 1 month and 6 months $(45 \pm 29 \%$ $\mathrm{P}=0.001)$ compared with initial weight. CONCLUSIONS: As a consequence of resection of the gastric fundus, the predominant area of human ghrelin production, ghrelin is significantly reduced after LSG. This reduction remains stable at follow-up 6 months postoperatively.

\section{EVALUATION AND AWARENESS ABOUT PRENATAL OF PREGNANT WOMEN} IN SAO LUIS-MA HEALTH CENTER

Cláudio Ávila Duailibe Mendonça; Gabriela Coutinho Amorim Carneiro; Raissa Thaynana Torres Vale; Raphael Paiva Braga; Lucas Hewitson Fróes Santos; Priscila Bonfim de Sousa; Camila Furtado Rodrigues

Centro de Ensino Universitário do Maranhão (CEUMA)

INTRODUCION: Despite technological advances, underdeveloped countries still report many deaths of women and children due to pregnancy complications, most of which are preventable by adequate prenatal care. According to recommendations, care should start early, have universal coverage and be performed periodically, and this premise is a major concern within the health area, thus observing the need for clarification and strengthening of the importance of its proper practice. METHODS: A prospective and quantitative cohort analytical study was performed to identify the main failures in prenatal care. The study was conducted with all pregnant women belonging to micro area 09 attended by the Liberdade Health Center from October 2014 to January 2015. A questionnaire consisting of closed questions and multiple choices about the information that pregnant women should know about quality prenatal care. RESULTS: Analyzing the answers of the questionnaires, it was found that the pregnant women who started follow-up after the second trimester were young, single and had no interest in assuming pregnancy. Another failure was related to attendance, where the structure of the service makes it difficult for the patient to return if she misses the date of the appointment, being rescheduled up to 30 days after the ideal date. Thus, the script for the lecture was set up, targeting the main deficits found, enabling an analysis of the knowledge about the relevance of prenatal care for pregnant women. CONCLUSION: Prenatal care should meet the needs of pregnant women through the use of appropriate knowledge and resources for each case. In addition, it is of utmost importance that health actions are geared to the entire target population within the scope of the health unit, ensuring continuity in the treatment, monitoring and evaluation of these actions.

\section{FRANTZ'S TUMOR: CASE REPORT}

Andre Ricardo Lauande Carvalho Costa; Thalita Martins Bezerra Centro Universitário do Maranhão (CEUMA), Instituto Maranhense de Oncologia Aldenora Bello (IMOAB).

INTRODUCTION: Frantz's tumor, initially described in 1959, is defined as a pseudopapillary solid pancreatic neoplasm, which, although malignant, usually evolves with benign, slow and asymptomatic evolution. This pathology has a rare prevalence, comprising $0.3-2.7 \%$ of all pancreatic neoplasms, and mostly affects the body-caudal region of the pancreas. CASE DESCRIPTION: MSFS, a 27-year-old, housewife from Santa Luzia do Paruá was admitted to the Aldenora Belo Hospital complaining of abdominal pain for a year. Brought abdomen ultrasound (US), performed in another service, showing expansive abdominal mass to clarify. Magnetic nuclear resonance (MRI) showed solid cystic lesion in the pancreas, measuring about $6.0 \times 7.0$ $X 5.5 \mathrm{~cm}$, suggestive of Frantz tumor. Patient underwent exploratory laparotomy, which underwent central pancreatectomy with Roux-en-Y terminus-lateral jejunal pancreatic anastomosis, cholecystectomy and retroperitoneal lymphadenectomy without complications. In the fifth POD (Postoperative Day) he presented with jejunal-oriented fistula, and no new surgical approach was required. CONCLUSION: The case shows a young patient who developed the disease over a year, with no signs of weight loss or visible increase in abdominal mass, confirming, among other signs, the benign aspect of the tumor. Central pancreatectomy and Roux-en-Y jejunal shunt were effective in eradicating Frantz's tumor.

105. EPIDEMIOLOGICAL PROFILE OF AIDS CASES REPORTED IN BRAZIL IN 2017 Natalia Vicente de Souza Silva; Jennifer Branco Graça; Jane Augusto Guimarães Conçalves

Instituto Tocantinense Presidente Antônio Carlos (UNITPAC)

INTRODUCTION: Acquired Human Immunodeficiency Syndrome (AIDS) was first reported in 1981 and has since become an epidemic worldwide. In Brazil, AIDS has presented a dynamic and unstable distribution pattern. In absolute numbers, from 1980 to June 2018, 982,129 cases of AIDS were detected in the country. The epidemiological study of this disease is directly related and impaired by underreporting. METHODS: This is a descriptive epidemiological study, elaborated by means of consultation with the Information System for Notifiable Diseases and the Death Information System, available at the Department of Informatics of the Unified Health System. RESULTS: In 2017, 37,791 new cases of AIDS and 11,463 deaths from the disease were recorded. Between 2012 and 2017, there was a 15.7\% reduction in the syndrome detection rate, especially after 2014 with the recommendation of "treatment for all", which also interfered in the mortality rate, which suffered a decrease of $15.8 \%$ in the same period. The gender ratio was 22 cases in men for every 10 cases in women and remained stable between 2016 and 2017. For the first time in the last decade, the category of homo/bisexual exposure exceeded the cases of heterosexual exposure in men. Regarding age, the age group between 25 and 39 years had the highest number of reported cases. In patients under 13 years of age, exposure was through vertical transmission in $93.2 \%$ of cases and in those over 13 years of age through sexual intercourse in more than $95 \%$ of cases in both men and women. CONCLUSION: The high incidence of Human Immunodeficiency Virus (HIV) infection in young individuals is still a reality that calls attention. Prevention, with public health policies, must be built based on the epidemiological profile and directed to each risk group. Young men are the group most at risk of infection and represent the greatest challenge when it comes to HIV and AIDS prevention.

\section{SLENDER ANGIODYSPLASIA AS A CAUSE OF ENTERORRHAGE IN A} PATIENT WITH HIV: CASE REPORT.

Natalia Vicente de Souza Silva; Jennifer Branco Graça; Jane Augusto Guimarães Gonçalves

Instituto Tocantinense Presidente Antônio Carlos (UNITPAC)

INTRODUCTION: Patients with Human Immunodeficiency Virus (HIV) have a 3.640 times higher risk of acquiring Kaposi's sarcoma, which may manifest with low digestive hemorrhage (HDB). However, in the presence of a patient with acute enterorrhagia, it is important to highlight other diagnoses that may present with hypovolemic shock quickly. Among them, we have angiodysplasia. Small bowel angiodysplasia causes $6 \%$ of HDB and translates into poor blood vessel formation. CASE DESCRIPTION: A 38-year-old HIVpositive male patient on regular antiretroviral therapy is admitted to the emergency department with hypovolemic shock due to massive enterorrhagia. After hemodynamic stabilization, the origin of the bleeding was investigated. Physical examination was performed with data collection on current history. Subsequently, upper digestive endoscopy (EAD) and colonoscopy were performed, both without changes. The main diagnostic hypothesis was recurrence of Kaposi's sarcoma (KS), since a patient had been previously diagnosed with this cancer in 2015 , when he was treated with chemotherapy. He was transferred to an air intensive care unit in São Paulo, where he underwent an endoscopic capsule (EC) examination, which revealed a lesion in elevated jejunum topography with venous pattern hemorrhage, compatible with angiodysplasia. After a new episode of enterorrhagia, the patient underwent arteriography that could not find a bleeding focus. He was discharged with medical advice for return during rebleeding. CONCLUSION: The investigation of enterorrhagia in a patient with HIV should be initiated by the most commonly found causes, such as KS. After this diagnosis is ruled out, research for other etiologies is mandatory. Despite being little considered, the diagnosis of angiodysplasia should be taken into account, as it is the second cause of HDB in adults and the elderly.

107. BILATERAL ADRENAL HEMORRHAGE: A RARE POSTOPERATIVE COMPLICATION 
Luís Eduardo de França Barros Menezes; Natan Albuquerque Alves; Felipe Scipião Moura; Vanielle Carvalho Machado Centro Universitário UNINOVAFAP

INTRODUCTION: Bilateral adrenal hemorrhage (BAH) is a rare but potentially fatal condition. It may occur in the context of sepsis, trauma, coagulopathies, postoperatively or even spontaneously. The exact pathophysiological mechanism is not yet defined; however, the increase in arterial blood flow that occurs when serum ACTH levels are elevated in response to organic stress associated with insufficient venous drainage of the adrenals may explain this condition. In this sense, we present a case report of a previously healthy patient who developed BAH after rectosigmoidectomy after acute diverticulitis. CASE REPORT: E.M.V.J, male, 43 years old, previously obese and hypertensive, hospitalized with abdominal pain, fever and vomiting. He was diagnosed with acute diverticulitis (Hinchey I). Seven days after clinical treatment, the patien developed septic shock from the perforating acute abdomen. He underwent rectosigmoidectomy and remained in the intensive care unit for 13 days, requiring the use of vasoactive drugs. After clinical improvement and weaning medication, the patient presented persistent nausea and vomiting. A new abdominal CT scan was performed, which showed bilateral acute enlargement of the adrenal glands. Laboratory tests confirmed the diagnosis of primary adrenal insufficiency (cortisol $3.5 \mu \mathrm{g} / \mathrm{dL}$ - RV: 1.8 to 6.5; ACTH $60.1 \mathrm{pg} / \mathrm{dL}$; RV <46.0), $\mathrm{Na}+139.0 \mathrm{mmol} / \mathrm{L}$ and $\mathrm{K}+3.6 \mathrm{mmol} / \mathrm{L}$ ) and treatment with crystalloid and corticotherapy was started. CONCLUSION: Bilateral adrenal gland hemorrhage should be investigated in patients with postoperative nausea, vomiting and hypotension. The diagnosis is suggested by bilateral enlargement of the adrenal glands, as well as by the presence of elevated attenuation on CT scan. Early diagnosis and treatment are key to reducing mortality from this condition.

\section{OCCURRENCE OF CONTAMINATION BY PARASITES AND BACTERIA: SÃO} MARCOS BEACH

Maria Vitorya Lima Almeida; Ingrid Albuquerque Araújo Comes; Danielle do Nascimento Lopes; Neuriane Silva Lima; Gabriela Coutinho Amorim Carneiro; wellyson da Cunha Firmino Araújo Firmino; Maria Raimunda Chagas Silva Centro Universitário do Maranhão (CEUMA)

INTRODUCTION: Nowadays, the presence of parasites and bacteria in coastal regions is a topic of debate in the health area. Studies conducted on beaches in Brazil have considered the quality of sand for contamination by total and fecal coliforms, human and animal parasites. The population attending these areas is vulnerable to infection by microorganisms. OBIECTIVES: To perform a bacteriological and parasitological analysis of the sand of São Marcos beach, São Luís coastal region. METHODS: The collection was carried out at 3 defined points along the coastal zone, in March 2019. For microbiological analysis, the method of presence or absence using Colitest Kit, Indol test and Escherichia coli colony count by EMB culture medium and for the identification of helminth using the Hoffman method. RESULTS: The bacteriological analyzes of the beach sand presented values $14000 \mathrm{CFU} / 100 \mathrm{~g}$ higher than those acceptable by CONAMA 2000 legislation. The presence of $E$. coli has been used as an indicator of fecal contamination on beaches. The parasites found were Trichuris trichiura and eggs of Ascaris lumbricoides. CONCLUSION: It is noted that there is contamination by bacteria and parasites that may favor infection in humans, therefore, it is necessary to understand the causes of this contamination and warm beach goers about the risk of infection by these microorganisms.

\section{EQUISETUM POTENTIAL AGAINST DAMAGE AFTER ACUTE MYOCARDIAL} INFARCTION IN RATS

Matheus Fagundes da Silva; Marcos Vinícius Araújo Brito; Gabrie Gomes Oliveira; Vitor Paixão Cruz; Rachel Melo Ribeiro; Vinícius Santos Mendes

Universidade Federal Do Maranhão (UFMA)

INTRODUCTION: Cardiovascular diseases (CVDs) are one of the leading causes of death, especially from acute myocardial infarction, which occur by scarce supplying the bloodstream with oxygen and metabolism for long periods of time to cardiomocytes. In this study, the cardioprotective effect of the plan species Equisetum arvense (horsetail) on isoproterenol-induced myocardial injury (ISO) was evaluated. METHODS: E. arvense aerial parts were added to distilled water (1:6) and the technique subjected to decoction. Then, the lyophilized extract of $\mathrm{E}$. arvense (EEA) was extracted. Adult male Rattus novergicus rats were randomly divided into groups: healthy control $(0.05 \mathrm{~m}$ / $100 \mathrm{~g}$ water, v.0); isoproterenol (0.05 ml / $100 \mathrm{~g}$ water, v.0); atenolol (50 $\mathrm{mg} / \mathrm{kg} /$ day, v.0) and EEA (50 mg / kg / day, v.0). After 30 days of treatment, the three year-end groups received the subcutaneous ISO, $85 \mathrm{mg}$ / kg, s.c, for two consecutive days, except for the control group, which received the same route of administration. Blood samples were taken for analysis of cardiac enzymes biomarkers of myocardial injury. RESULTS: The results show that EEA $50 \mathrm{mg} / \mathrm{kg} /$ day was able to reduce the serum levels of the enzymes CK-MB (Creatinophosphokinase), LDH (Lactate Dehydrogenase) and AST (Aspartate Aminotransferase), compared with the ISO group. These enzymes are the main biochemical indicators of AMI. Since, in plasma, their values increase in proportion to the damage in cardiac tissue, and remains for days after myocardial injury. CONCLUSION: In conclusion, E. arvense had a potential cardiopreventive effect against ISOinduced myocardial injury, maintaining cardiac enzyme levels. Further studies will be needed to clarify the mechanisms of action on the cardiac functionality of this plant species.

\section{RIBEIRINHAS HEALTH: TRIZIDELA`S COMMUNITY SOCIAL AND} ENVIRONMENTAL CONDITIONS

Nádia Cristina Diniz de Carvalho; Amanda de carvalho Nogueira Karine Carneiro Fonseca; Laura Sousa Dias Carneiro; Talita Coelho Rabelo da Costa; Sandra de Castilho Bandeira; Maria Raimunda Chagas Silva Centro Universitário do Maranhão (CEUMA)

Environment is a collection of external conditions that influence the life in human behavior and society itself in all respects. In this sense, environmental health encompasses all aspects of human health, including quality of life, that are determined by physical, chemical, biological, social and psychosocial factors. Environmental factors affecting human health. Their understanding of the challenges lies in the complex matrix of elements that determine and integrate health. Thus, the purpose of this Article the health conditions of the population of the community Trizidela, the municipality was to characterize Monsoon - MA, the River Pindaré. This is a study of qualitative and quantitative approach, carried out from February to April 2018, in which 50 people representing their families were interviewed. On the assessment of health status, half of the respondents considered having a state of fair health (50\%). This reflection is related to the physical, physiological, psychological, social factors, among others reality. However, all mankind should reflect on environmental health, since this is not an isolated problem, but a social nature, requiring interdisciplinary and creative for discussion on the subject shares.

\section{EPIDEMIOLOGICAL PROFILE OF BREAST DISORDERS IN MARANHÃO, MAY} 2015 TO MAY 2019

Lidmar Costa Lima Junior; Ana Rita da Silva Nunes: Larissa Zanona Luís Augusto Silva Batista; Maria Luiza Vieira dos Santos; Naraja Menezes de Souza

Universidade Federal do Maranhão - UFMA. Hospital Universitário Presidente Dutra (HUPD)

INTRODUCTION: Breast disorders can be non cancerous (benign) or cancerous (malignant). The non cancerous can be breast pain, cysts, fibrocystic breast disease, fibroadenoma, breast secretion and infections. This epidemiological profile study aims to evaluate the morbidity of breast disorders in the state of Maranhão from May of 2015 to May of 2019. METHODS: A quantitative and descriptive epidemiological study based on DATASUS data regarding patients with breast disorders from May of 2015 to May of 2019 in the state of Maranhão. It analyzes the gender, race, age range, locality and type of care, elective or emergency. RESULTS: There were 3034 patients and 3 deaths from breast disorders during the study period. Predominance of the female sex $(90,07 \%)$, qualifying women as the most affected. Most of the races were not informed $(52,14 \%)$, but "parda" was the most quoted $(37,27 \%)$, followed by the other colors/races $(10,56 \%)$. Most of the cases happened with people with 15 to 49 years old corresponding to $86,47 \%$. Concerning to the type of care, most were elective care $(54,38 \%)$. The capital of the state, São Luís, registered the highest number of patients, $1325(43,67 \%)$, most of them are from the University Hospital Presidente Dutra (HUPD) with 737 cases. CONCLUSION: The study concerning to breast disorders shows that, in the state of Maranhão from May of 2015 and May of 2019, most affected are women, age range between 15 and 49 years old, race/color not informed and most of the cases were registered in the city of São Luís and more than a half of them in the HUPD. 


\section{CHEMOEMBOLIZATION OF HEPATOCELLULAR CARCINOMA}

Lidmar Costa Lima Junior; Vanisse Portela Ramos; Érico Murilo Monteiro Cutrim; Larissa Ferracini Andrade Souza; José Alberto Moraes Neto; Raphael Costa; Ana Beatriz Santos Cantanhede Universidade Federal do Maranhão - UFMA

INTRODUCTION: Patients with liver cirrhosis (LC) of any cause are at serious risk of developing hepatocellular carcinoma (HCC). $90 \%$ of HCC cases occur in patients with $\mathrm{LC}$, and among those with $\mathrm{LC}$, the risk of $\mathrm{HCC}$ is up to $30 \%$ in five years. Therapy will depend on the patient's general condition, comorbidities, Child-Pugh staging liver transplantation perspective, amon others. Liver Artery Chemoembolization (LAC) is an important therapeutic method, both as a palliative method in patients with no prospect of transplantation and as a bridge to definitive therapy. CASE DESCRIPTION: $55-$ year-old male patient with diabetes, carrier of virus C (genotype 3), with liver cirrhosis Child $A$, in clinical follow-up. CT scan of upper abdomen revealed a nodule with exophytic component, with heterogeneous

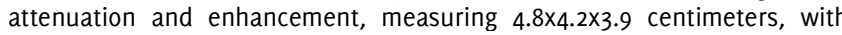
intense arterial enhancement, compatible with HCC, in segment II. LAC was proposed. Retrograde puncture of the left radial artery was performed with superselective catheterization of the tumor nourishing branches with doxorubicin and lipiodol; control angiography revealed satisfactory occlusion of the nodules with preservation of non-target arterial branches. Patient was released uneventfully. CONCLUSION: The only potentially curative treatment for hepatocarcinomas is surgical resection and only $15 \%$ of these tumors are operable. In this sense, LAC is one of the most promising modalities of minimally invasive treatment of these tumors. The principle of this locoregional technique is to enhance the therapeutic effect by injecting antineoplastic drugs into the target lesion, associated with subsequent embolotherapy to interrupt the nutritional contribution of these lesions. This therapy is at the forefront of treatments with good results and few adverse effects, as well as proven evidence in increasing patient survival time.

\section{ANGIOSARCOMA OF THE SCALP: CASE REPORT}

Bruno Ribeiro Alencar; Isabela de Angelles Floro Alonso; Ricardo Tadeu Villa; Beatriz Morais Costa; Cláudio Vinicius Araujo Pinheiro; Roseline Braga de Carvalho; Júlia Resende Rodrigues Universidade Federal do Maranhão (UFMA)

INTRODUCTION: Angiosarcoma are rare tumors and aggressive, focus more often on men, in the elderly and the scalp. 1 The diagnosis is confirmed by biopsy and histopathologic study with immunohistochemical tissue research.2 There are three types of treatment: the surgical removal of the tumor, radiation and adjuvant chemotherapy. The current consensus is to use a combined treatment, including excision of the disease with negative margins, if possible, more radiation associated or not to chemotherapy. The Paclitaxel used to be a drug of first line without treatment do angiosarcoma of the scalp because it is better tolerated by elderly patients.3 Despite the proposed treatments, prognosis of angiosarcoma is reserved and most patients die as a result of pulmonary metastases, cardiac or cerebral. CASE DESCRIPTION: White patient of 65 years old with a history of scalp injury just over 6 months. Initially, he was treated in another service for seborrheic dermatitis, but his clinical condition worsened. At the outpatient clinic of University Hospital of the Federal University of Maranhão (HUUFMA), hair shaving was suggested for a better appreciation of the clinical picture, revealing an erythematous plaque over $15 \mathrm{~cm}$ in the largest diameter, protrusions, recesses and compressible edema. Histopathological examination of the lesion revealed an aspect compatible with angiosarcoma and, given the impossibility of surgical resection, we opted for treatment with chemotherapy (Paclitaxel) and radiotherapy. Partial remission has been obtained. However, 2 years after clinical improvement, the patient had pulmonary metastasis and, upon starting the chemotherapy protocol, evolved to sepsis and death. CONCLUSION: Angiosarcomas are aggressive tumors that need early diagnosis so that the patient may have a greater chance of a favorable outcome. For this purpose it is necessary that dermatologists listen for the possibility of that diagnosis during outpatient consultations.
Alana De Oliveira Castro; Ricardo Henrique Viana dos Santos; Viviane Melo e Silva Figueiredo; Bruna Costa de Albuquerque Bogéa; Marcos Roberto Dias Machado Júnior; José Aparecido Valadão Universidade Federal do Maranhão UFMA; Liga Acadêmica de Gastroenterologia e Cirurgia do Aparelho Digestivo LAGECAD; Grupo PróCirúrgico.

INTRODUCTION: Bariatric surgery has become an important alternative in the fight against obesity. Even in referral centers, patients have complications. An early recognition allows a better patient approach, reduces treatment costs, length of in-hospital stay (LOS), morbidity and mortality. This study aimed to determine the prevalence of early complications associated with bariatric surgery. METHODS: This was an observational, descriptive, retrospective study that evaluated early complications in patients undergoing bariatric surgery at a São Luís-MA hospital in 2018. The procedures performed were Roux-en-Y Gastric Bypass and Vertical Gastrectomy. The early complications considered were those that occurred up to 30 days after surgery. RESULTS: There were 477 patients participating in the study, among these, $341(71.5 \%)$ women. The average age was 39.5 years, body mass index of $38.5 \mathrm{~kg} / \mathrm{m}^{2}$ and LOS of 52 hours. The main associated comorbidity was diabetes mellitus ( $22 \%$ ). The prevalence of early complications was $1.68 \%$ (eight cases). Considering only patients undergoing bypass, the value found was $1.83 \%$ and $1.54 \%$ for the sleeve. There were four bleeds (one upper and three intra-abdominal bleeding), two intestinal obstructions (enteroenteroanastomosis elbow and incarcerated incisional hernia) and two digestive fistulas (gastroenteroanastomosis and post-sleeve Hiss angle). Five (1\%) patients with complications went to the Intensive Care Unit. Rehospitalization within 30 days occurred in $0.42 \%$ (two cases) due to gastric fistula after sleeve and pneumonia after bypass. Six $(1.25 \%)$ patients were reoperated: two due to digestive fistula, two due to obstruction and two due to bleeding. There was no conversion to open surgery or death. CONCLUSION: The prevalence of early complications of bariatric surgery in this study was $1.68 \%$. Bleeding, digestive fistula, intestinal obstruction and pneumonia were the complications found.

\section{ANALYSIS OF SLEEPINESS LEVEL IN ELDERLY PRACTICES OF FORCE TRAINING}

Isabela Mendonça Rodrigues dos Santos; Rebeca da Rocha Comes; Nivia Barros da Silva; Igor Luís Ferreira Machado; Diogo Matheus Barros da Silva

Universidade Federal do Maranhão (UFMA), Centro Universitário do Maranhão (CEUMA)

INTRODUCTION: Strength training involves participation of physiological, physical and motor. Moreover, when done properly, it provides the most effective aging. healthy. Since this process of senescence can be influenced by aspects of biopsychosocial, environmental and genetic factors and influence on sleep patterns, including: increased latency, night waking, circadian phase advance, sleep fragmentation and daytime sleepiness. OBJECTIVE: To identify the degree of drowsiness in the elderly. strength training practitioners. METHODS: The study followed resolution recommendations $466 / 12$ of the National Health Council. Sample integrated, for convenience, with 08 female strength training practitioners. Presenting average age of $65.6 \pm 4.1$ years old, height $1.58 \pm 0.6 \mathrm{~cm}$, weight $62 \pm 9 \mathrm{~kg}$, body mass index $25 \pm 2.2 \mathrm{Kg} / \mathrm{m}^{2}$ of $(63 \%)$ eutrophic and (37\%) overweight. The degree of sleepiness was measured by the Epworth Sleepiness (ESE-BR) validated by Bertolazi et al. (2009), integrated by 08 (eight) questions of daily tasks of the individual. BioEstat 5.3 software was used for the statistical treatment, performing a descriptive analysis followed by the application of the tests Kolmogorov-Smirnov. RESULTS: Observed homogeneity between the variables. The sum drowsiness score was 78 , mean score $9.8 \pm 8.1$, the sample was classified as: $(61 \%)$ had normal values, $(13 \%)$ had mild daytime sleepiness, (13\%) moderate drowsiness and $(13 \%)$ severe drowsiness. CONCLUSION: There was a predominance of normality among the elderly. However, it is noteworthy, it is necessary to elaborate strategies aimed at sleep hygiene of practitioners, in order to benefit the class minority who presented drowsiness from mild to severe, thus avoiding possible disorders respiratory disorders, for example, obstructive sleep apnea syndrome.
114. EARLY COMPLICATIONS ASSOCIATED WITH BARIATRIC SURGERY IN A HOSPITAL IN SÃO LUÍS-MA
SUBJECTIVE ANALYSIS OF SLEEP QUALITY IN ELDERLY TRAININC PRACTICES FORCE 
Isabela Mendonça Rodrigues dos Santos; Rebeca da Rocha Comes; Nivia Barros da Silva; Igor Luís Ferreira Machado; Diogo Matheus Barros da Silva

Universidade Federal do Maranhão (UFMA), Centro Universitário do Maranhão (CEUMA)

INTRODUCTION: Strength training involves the participation of force transfe systems. aerobic as well as anaerobic energy, as well as physical and motor capacities. It is emphasized that the optimization of its benefits can be influenced by sleep. subdivision into two phases: REM sleep (fast waves) and N-REM sleep (slow waves). Considered reparative mechanism with active and passive principles of neurophysiological, physical and behavioral behavior in the elderly, changes in normality occur. Objective: To measure the subjective quality of sleep in elderly women practicing force. MATERIALS AND METHODS: The study followed the recommendations of resolution $466 / 12$ of The National Health Council. Participated in the study 08 elderly practitioners of the training of strength, for convenience, with a mean age of $65.6 \pm 4.1$ years, height $1.58 \pm 0.6 \mathrm{~cm}$, weight $62 \pm 9 \mathrm{~kg}$, body mass index $25 \pm 2.2 \mathrm{Kg} / \mathrm{m}^{2}$ of $(63 \%)$ eutrophic and (37\%) overweight. THE subjective sleep quality was measured by the Pittsburgh Sleep Quality Index (PSQI-BR) validated by Bertolazi et al. (2011). Statistical treatment occurred by BioEstat 5.3 software, followed by descriptive analysis using KolmogorovSmirnov tests. RESULTS: The elderly (100\%) had poor sleep quality, with total score 76 , average score $9.5 \pm 3.1$. CONCLUSION: The elderly women were identified with poor sleep. Therefore, sleep hygiene is necessary to improve its quality and quantity.

\section{MITROFANOFF DERIVATION IN THE TREATMENT OF URETHRAL STENOSIS:} A CASE REPORT

Thalita Martins Bezerra

Centro Universitário do Maranhão (CEUMA); Instituto Maranhense de Oncologia Aldenora Bello.

INTRODUCTION: The Mitrofanoff principle is based on the construction of an intermittently catheterized conduit between the bladder and the umbilical scar to promote emptying and bladder continence in patients who are physiologically unable - such as complex urethral injuries, for example. Mitrofanoff made through the cecal appendix has the lowest complication rate, but is not yet uneventful - which will be reported here. CASE DESCRIPTION: FPS, male, 69-years-old, retired, born in Altos / PI and resident in Potion de Pedras / MA, reports severe voiding dysfunction, associated with loss of libido and erectile dysfunction for 5 months after transurethral prostate resection. He sought medical help in his hometown and was referred to São Luís, where unsuccessful internal uterotomy was performed for complete proximal urethral stenosis. It was decided to perform a urinary Mitrofanoff shunt - from an appendectomy with preservation of the appendicular artery, the distal appendix was implanted in the bladder and the proximal portion in the umbilical scar to favor a clean and effective intermittent bladder catheterization. During hospitalization, the patien developed recurrent complaints of emesis, pain and wound infection, suture dehiscence, cough, pain in the inguinal region and evisceration - in addition to difficulty in Mitrofanoff catheterization. After changes in antibiotic therapy and intervention procedures, the patient evolved with resolution of complications and discharge at 6oth IHL. CONCLUSION: Mitrofanoff urinary shunt, performed through the use of the cecal appendix, has the least chance of complications and has the highest number of effective cases.2 Despite the rare postoperative complications, it can be state that choosing to do Mitrofanoff improved patient quality of life by providing autonomy and decreasing the chances of possible infections with SVD.

\section{MULTI-ARTERIAL COMMITMENT IN PATIENT YOUNG LOW RISK} CARDIOVASCULAR PATIENTS

Petra Samantha Martins Cutrim; Tácio Danilo Araújo Pavão Annanda Carolina De Araújo Martins; Thais Oliveira Nunes Da Silva Vitor Ferreira Cerude; Illana Catharine De Araújo Martins

Centro Universitário do Maranhão (CEUMA); Hospital Universitário da Universidade Federal do Maranhão (HUUFMA); Clínica Cardio Check up

INTRODUCTION: Coronary artery disease is still the leading cause of mortality in developed and developing countries; and the largest cause of health care spending in Brazil. There are some risk factors directly related to the progression and complications of atherosclerotic injury. The greater the number of risk factors present, the greater the chance of presenting a cardiovascular event. CASE DESCRIPTION: KFLA, 38 years old, male, white, married, physician, with a history of atypical precordial pain of recent onset. Dyslipidemic, denies high blood pressure and diabetes. Regular physical activity, balanced diet, non-smoker, social drinker. LDL 139; triglycerides 373; HDL33, other normal laboratory tests. Negative exercise test for ischemia, good functional capacity, effective. Normal transthoracic Doppler echocardiogram. She started using Somalgin 10omg, Rosuvastatin $20 \mathrm{mg}$ and Bisoprolol 5mg. Coronary angiotomography shows anterior descending artery (ADA) with severe lesion (LS) in proximal third (PX), myocardia bypass in middle third; diagonal with LS in third PX; circumflex artery with distal LS; right coronary artery with moderate lesion; posterior descending LS; calcium score 10. Coronary angiography confirmed the findings of CT angiography. Magnetic resonance imaging of the heart demonstrated Septal Ischemia. Patient underwent successful coronary angioplasty with 1 stent implantation in ADA. At the patient's request, six months later, she underwent negative myocardial scintigraphy for ischemia. It follows no cardiovascular complaints and optimal treatment for coronary artery disease. CONCLUSION: Even patients at low risk for the development of cardiovascular events may have severe coronary involvement.

\section{DIAGNOSTIC RESEARCH OF BRONCHIUM CANCER: CASE REPORT}

Rafael Gomes de Lucena; Amanda Sakaguthi Figueiredo; Jane Aparecida Augusto Guimaraes UNITPAC

INTRODUCTION: Bronchial as well as lung cancer is closely associated with smoking, being most often diagnosed at an advanced stage and with a reduced survival rate after diagnosis. Bronchoscopic examination assists in diagnostic elucidation by visualizing the lesion and performing a biopsy. CASE DESCRIPTION: PGG, male, 75 years old, farmer, hypertensive, diabetic with progressive dyspnea onset 4 months ago onset of major exertion, progressing to dyspnea on exertion, accompanied by chest breathing pain and sputum cough haemoptoids. On examination, patient in severe general condition, inconscious and disoriented, hemodynamically stable, presenting dyspnea on exertion, tachypneic, vesicular murmur abolished in right hemithorax from middle third, no adventitious noises, palpable liver $7 \mathrm{~cm}$ from right costal margin, with abdomen diffusely painful, with no signs of peritoneal irritation. Patient denied alcohol and smoking habits. Admitted for diagnostic investigation of neoplasia, were performed tomography of the skull, chest and total abdomen, which showed pleural effusion and lesion in the right hemithorax, were not observed other lesions suggestive of metastases, proceeding after bronchoscopic examination, which was infiltrative lesion in the intermediate bronchus, with biopsy in which a diagnosis of moderately differentiated acinar adenocarcinoma with papillary areas was confirmed. Being evaluated by oncology and radiotherapy, without indication of radiotherapy treatment, indicated palliative treatment. CONCLUSION: Respiratory cancer cases continue to be diagnosed late due to the absence of parameters that can be used as screening in this pathology, this disease is difficult to treat and has poor prognosis, and may affect individuals who do not have risk factors commonly found in these cases, like smoking.

\section{EFFECTS OF SLEEVE GASTRECTOMY IN CARDIOMETABOLIC RISK FACTORS PATIENTS WITH TYPE 2 DIABETES}

Hilquyson Delon Cunha Ferreira; Camilla Lima Lindoso; Giovanna Maria Pacheco Barroso Maia; Leticia Weba Couto Rocha; Luiza Brito Tomaz; 0zimo Pereira Gama Filho CEUMA, UFMA

OBJECTIVE: The aim of the study was to assess long-term metabolic effects of laparoscopic sleeve gastrectomy (LSC) in patients with type 2 diabetes (T2DM) and to identify predictive factors for long-term diabetes remission and relapse. METHODS: Outcomes of 100 patients with obesity with T2DM who underwent LSC at an academic center during 2007 to 2017 and had at least 2 years of follow-up were assessed. RESULTS: At a median postsurgical follow-up of 3 years (range: $3-6$ ), a mean body mass index loss of $-8.8 \pm$ $4.4 \mathrm{~kg} / \mathrm{m} 2$ (total weight loss: $19 \% \pm 8 \%$ ) was associated with a reduction in mean glycated hemoglobin ( $\mathrm{HbA} 1 \mathrm{C},-1.9 \pm 0.8 \%, \mathrm{P}<0.001$ ), fasting blood glucose $(-40 \pm 60 \mathrm{mg} / \mathrm{dL}, \mathrm{P}<0.001)$ and median number of diabetes medications $(-1, \mathrm{P}<0.001)$. Long-term glycemic control ( $\mathrm{HbA1C}<7 \%$ ) was seen in $70 \%$ of patients (vs $30 \%$ at baseline, $\mathrm{P}<0.001$ ), diabetes remission (HbA1C $<6.5 \%$ off medications) in $29 \%$, complete remission (HbA1C $<6 \%$ off medications) in $9 \%$, and continuous complete remission for .5 years was achieved in $2 \%$. Long-term relapse of T2DM after initial remission occurred in $40 \%$. Among patients with relapse, $70 \%$ maintained glycemic control 
( $\mathrm{HbA} 1 \mathrm{C}<7 \%$ ). On adjusted analysis, taking 2 or more diabetes medications at baseline predicted less long-term remission (odds ratio $0.2,95 \%$ confidence interval $0.05-0.75, \mathrm{P}=0.001$ ) and more relapse of T2DM (odds ratio $7.5,95 \%$ confidence interval: $0.40-5.20, P=0.02$ ). Significant improvement in triglycerides $(-60 \pm 120 \mathrm{mg} / \mathrm{dL}, \mathrm{P}<0.001)$, high-density lipoprotein $(9.1 \pm 14 \mathrm{mg} / \mathrm{dL}, \mathrm{P}<0.001)$, systolic $(-9 \pm 21 \mathrm{mmHg}, \mathrm{P}<0.001)$ and diastolic blood pressure $(-3.2 \pm 16 \mathrm{mmHg}, \mathrm{P}=0.04)$, and cardiovascular risk ( $20 \%$ relative reduction, $\mathrm{P}<0.001$ ) was observed. CONCLUSIONS: LSG can significantly improve cardiometabolic risk factors including glycemic status in T2DM. Long-term complete remission and "cure" of T2DM, however, occur infrequently.

\section{LAPAROSCOPIC SLEEVE GASTRECTOMY FOR DIABETES TREATMENT Matheus Lurine Guimarães Leitão CEUMA , PROGRASTRO}

OBJECTIVE: Although the laparoscopic sleeve gastrectomy (SG) is increasingly performed for morbid obesity, gastric bypass is still considered by many to be the gold standard procedure for obese diabetic patients. The aim of this study was to assess the long-term results of SC in morbidly obese patients with type 2 diabetes. METHODS: Diabetic patients who underwent SC at a single center between 2007 and 2013 were included. Outcomes assessed included postoperative complications, weight loss, and resolution or improvement in co-morbidities with an emphasis on diabetes, including glycated hemoglobin $\left(\mathrm{HbA}_{1} \mathrm{C}\right)$ and medication status. RESULTS: Fifty-five diabetic patients underwent SG, 47 females and 8 males, with a collective mean age of 44 years and a mean body mass index of $47 \mathrm{~kg} / \mathrm{m} 2$. On average, patients had had diabetes for $6 \pm 5$ years before surgery. Mean $\mathrm{HbA}_{1} \mathrm{C}$ and fasting glucose levels were $8.1 \pm 0.8 \%$ and $173 \pm 22 \mathrm{mg} / \mathrm{dL}$, respectively. Nine patients were insulin dependent at the time of surgery. Average body mass index at a mean follow-up of 5 years after surgery was $29 \pm 3 \mathrm{~kg} / \mathrm{m2}$, with an average $\mathrm{HbA}_{1} \mathrm{C}$ of $5 \pm 1 \%$ and an average fasting glucose of $119 \pm$ $40 \mathrm{mg} / \mathrm{dL}$. Only 3 patients remained insulin dependent. CONCLUSION: SC offers retainable weight loss results, accompanied by longstanding resolution or improvement of diabetes. Prospective, randomized controlled studies are warranted to better compare long-term outcomes between SC and gastric bypass.

\section{ACUPUNCTURE IN TREATMENT OF LOMBALGY IN A CHRONIC PAIN} CENTER IN SÃO LUIS-MARANHÃO

Denise Ailine Monteiro Lopes; Islanara Diogenes Urbano Sousa; Raynan Costa Santana; Thiago Alves Rodrigues; Elizabeth Teixeira Nogueira Servin; João Batista Santos Garcia; Rayanne Luiza Tajra Mualem de Araújo

Universidade Federal do Maranhão

INTRODUCTION: Acupuncture has been highlighted as an adjunctive measure in the treatment of low back pain (LB) providing in the short term clinically relevant improvements in pain intensity and functional aspects. LB refers to pain and discomfort in the lumbosacral region, with or without irradiation to the leg. It has a variety of alternatives to conventional therapy involving pharmacological, non-pharmacological and surgical treatment but no modality is superior or definitive, which stimulates the interest for alternative therapies to improve disease morbidity without adverse effects. CASE DESCRIPTION: A 49-year-old male patient out of work for 5 years, was seen at the Chronic Pain Outpatient Clinic of the UFMA University Hospital complaining of low back pain without continuous irradiation, strong intensity (EVN $=8)$, that worsened with physical effort and in standing or sitting position for a long time. His sleep was not restful. History of falling from a height of over $2 \mathrm{~m} 2$ years ago with constant pain since then. He referred pain on palpation with several trigger points in the cervical, dorsal and lumbar regions. Referred to the acupuncture service after little improvement in pharmacological treatment and epidural block intervention with corticosteroids. Ten sessions were performed with bilateral needlepoints: VB34, VB42, IG4, B23 and B25, as well as cervical, dorsal and lumbar ashi points. There was a marked improvement in pain intensity decreasing to mild (EVN $=3$ ) and episodic pain, functional aspects and psychological parameters, having better adherence to conventional treatment and desire to return to work. CONCLUSION: Acupuncture is widely used as a complementary therapy in LB, has greater efficacy than conventional treatment alone. Its mechanism of action affects the higher speed nerve fibers releasing endogenous opioids and acting on the myofascial pain components by inactivating the trigger points leading to an improvement in clinical parameters.

\section{CENTRAL PAIN TREATMENT IN PATIENTS WITH CHRONIC PAIN CENTER IN SÃO LUIS-MARANHÃO}

Denise Ailine Monteiro Lopes; José Estevam Ribeiro Júnior; Clarissa Monteiro Melo; Luiza Sousa Soares; João Batista Santos Garcia; Thiago Alves Rodrigues; Rayanne Luiza Tajra Mualem de Araújo Universidade Federal do Maranhão

INTRODUCTION: Central pain syndrome is a chronic neuropathic pain disorder caused by a central nervous system injury. It is one of the most complex painful syndromes, frustrating obscure and difficult treatment. Therefore, the aim of this study was to investigate the response to multimodal pharmacological strategy associated with non-pharmacological therapies of patients treated at the Chronic Pain Outpatient Clinic of the University Hospital of UFMA. METHOD: Cross-sectional study based on the analysis of medical records of patients diagnosed with central pain assisted at the Chronic Pain Service of the UFMA University Hospital, São Luís-MA, from 2010 to 2017. The following variables were evaluated: cause of pain, pharmacological and non-pharmacological treatment and improvement index. RESULTS: The sample consisted of 12 patients. Among the causes of central pain, stroke accounted for $75 \%$ of cases; $8.33 \%$ had as cause myelopathy; $8.33 \%$, brachial plexus avulsion; $8.33 \%$, not clarified. All patients underwent pharmacological treatment; Non-pharmacological therapy was associated with $75 \%$ of cases. The most used drugs as the first treatment option were gabapentin (58\%) and pregabalin (33\%). Amitriptyline was associated with $33.3 \%$ of therapeutic approaches. Tramadol $25 \%$. The main forms of non-pharmacological therapy were: physical therapy (50\%) and acupuncture (16.6). The treatment adherence rate was $66.7 \%$, and the lack of return to the outpatient clinic was the main reason. CONCLUSION: The multimodal strategy was very effective in the treatment of central pain. Anticonvulsants are the cornerstones of drug therapy, usually associated with a tricyclic antidepressant. Nonpharmacological therapy, mainly involving physiotherapy, proved to be a great ally to the beneficial effects of the drugs. Despite the significant percentage of improvement, a higher adherence rate would reflect a better picture of these patients.

\section{DESCRIPTIVE ANALYSIS OF VISCERAL LEISHMANIASIS IN MARANHÃO}

Willyanna Ravanielly Oliveira de Carvalho; Richardson Chaves de Abreu; Sanny Pinheiro Oliveira; Laana Késia Ribeiro Muniz; Raquel Araújo Salvador; Catalina Ribeiro Gonçalves Santos Universidade Federal do Maranhão (UFMA)

INTRODUCTION: Visceral Leishmaniasis is a zoonosis caused by a protozoa of the species Leishmania chagasi, as it is a highly prevalent disease in Brazil. Thus, this epidemiological analytical work focuses on Maranhão (MA), being one of the states with the highest incidence of cases. METHODS: This is an observational descriptive study that analyzes the amount of diagnosis of visceral leishmaniasis in the state of MA, based on data obtained from DATASUS. Data were selected from 2007 to 2017. An analysis was also made regarding the age of people diagnosed, considering that in Brazil it is in children under 10 years old that $80 \%$ of the occurrences are reported, according to data from the Brazilian Society of Pediatrics (SBP). RESULTS: Regarding the total number of cases in MA there is a growth from 407 in 2007 to 793 in 2017 . In the period from 2007 to 2017 there is a prevalence of cases of children between 0 and 14 years old, accounting for 3,843 cases in a total of 6,112 , representing over $60 \%$ of the total in MA. Between 2015 and 2017 there was an increase of cases in the ages from 0 to 59 years, mainly in children under 4 years. The 1-4 year age group has always remained above 130 in the entire decade studied. CONCLUSION: From the data obtained it appears that, in addition to the natural conditions of high temperature and humidity of the state, the high contingent of people suffering from malnutrition is a factor that acts strongly as a protozoan reservoir, which justifies the increase of the amount. of cases as the years evolve. In addition, the fact that the percentage of affected children is high in the analyzed time strengthens the idea that poor quality of life is a characteristic factor of the disease. Therefore, the imbroglio with this disease is much more a matter of development policies and the public health than climatic conditions for the development of the parasite.

125. BILATERAL THALAMIC INTRACEREBRAL GLIOBLASTOMA: A CASE REPORT Lucas Felipe Albuquerque da Silva; Giuliana Maria Morais Gonzalez; Gabriela Coutinho Amorim Carneiro; Joelmistokles Luís da Silva 
Macedo Vale; Júlia Beatriz Borges Coelho Duarte Feitosa; Jessica Fernanda Comes Rolim; Braulio Galdino de Araújo Universidade CEUMA (Uniceuma)

INTRODUCTION: Thalamus is an important nerve center located in the brain, more specifically in one of the regions of the Diencephalon, and, among its main functions, are: transmission of sensory impulses and assistance in regulating the state of consciousness and autonomous activities. So, by suffering influence of alterations in the organism, such as brain tumors or even surgical lesions, its activities can be widely compromised, as much as the patient's quality of life, since it may present several symptoms, such as motor and cognitive dysfunctions and uncontrolled level of consciousness. Based on this, we can say that early identification of the pathology and its careful treatment are extremely relevant for a good management and treatment of the affected individual. CASE DESCRIPTION: The patient in question is 17 years old and started, six months ago, progressive headache disorder, evolving with left motor deficit. She sought medical care and performed MRI, which indicated a brain tumor compromising both thalamus. The lesion stretched to the cerebellar peduncle and protruated into the lateral ventricles. The patient evolved with hydrocephalus and worsened the clinical condition, requiring surgica intervention. In the first surgery, the DVE was performed with removal of tumor tissue from the right thalamus, aiming to decrease the lesions and sequelae from the manipulation of both in a single procedure. CONCLUSION The diagnosis of brain tumors, as well as thalamic tumors, is based on both the clinical presentation and the analysis of imaging exams. These signs and symptoms may occur due to direct action of the tumor, by compression of adjacent structures or even by hydrocephalus. Imaging exams are essential to assess the extent and severity of the lesion and its origin, in order to define the best conduct to be approached.

\section{ECTOPIC PREGNANCY WITH ATYPICAL SYMPTOMS: CASE REPORT}

Amanda Angelo Pinheiro; Matheus Rizzo de Oliveira; Gabriel Costa Ferreira Andrade; Ingrid Macedo Araújo Centro Universitário do Maranhão (CEUMA)

INTRODUCTION: Ectopic pregnancy (EG) is defined as the implantation and development of the egg outside the uterine cavity. It affects one in 1,800 women and is the leading cause of maternal death in the first trimester of pregnancy. The main risk factors include Inflammatory Pelvic Disease (PID) Trichomoniasis, use of intrauterine device (IUD), smoking, and previous abdominal surgery. This paper aims to report the case of a patient with an ectopic pregnancy with atypical symptoms after two years of tubal ligation surgery. CASE REPORT: A 34-year-old female patient, SHSC, sought basic care for the maintenance of PID treatment after trichomoniasis cervicitis, with mild abdominal pain that worsened after feeding and smelly yellowish colored leukorrhea without signs. of peritonitis on physical examination. After transvaginal ultrasound, DIP was concluded, but without correlation with the clinical picture. After 3 days, an intense pain occurred at home showing GE through new ultrasound. She underwent salpingectomy on the right, progressing satisfactorily. CONCLUSION: Ectopic pregnancy remains frequent disease in gynecology services and a problem for women's health during reproductive life. The knowledge of its etiopathogenesis and early diagnosis has great value for the adequacy of the care provided and the reduction of morbid and fatal outcomes related to the population affected by it.

\section{EPIDEMIOLOGICAL PROFILE OF LABIAL AND / OR PALATINE CRAFT} MORBITY IN MARANHÃO

Mateus Ribeiro Gonçalves Carvalho; Ana Rita Da Silva Nunes; Izabela Veloso Bandeira de Melo; Letícia Freitas de Aquino; Erick Augusto dos Santos Oliveira

Universidade Federal do Maranhão (UFMA)

INTRODUCTION: The cleft lip and palate currently represent $65 \%$ of head and neck anomalies and their prevalence varies according to geographic region, ethnicity and socioeconomic conditions. In Brazil, they have an estimated prevalence of 0.36 cases per 1000 live births. Such anomalies constitute an important public health problem, since they generate structural, functional and social consequences for the affected individual. METHODOLOGY: This is a quantitative and descriptive epidemiological study. Data referring to the state of Maranhão from 2015 to 2019 from the database provided by DATASUS were used. RESULTS: The total sample consisted of 328 patients. In this population, oral clefts were more prevalent in males $(57.87 \%$ ).
Regarding ethnicity, among those who presented such categorical information $(39.19 \%)$, brown children are the largest group (80\%), followed by yellows $(12 \%)$ and whites $(4.8 \%)$. As for age, it ranged from o to 69 years, and $40.54 \%$ were between 1 and 4 years. Children under 1 year corresponded to $22.56 \%$. From the age of 5 , there was a downward trend in the number of hospitalizations. Regarding the character of care, there was a prevalence of urgent care over the elective (70.42 versus $29.57 \%$ ) Regarding location, most occurred in the municipality of São Luís (60.67\%), while $28.65 \%$ were registered in Imperatriz. The Maranhão Maternal Infant Hospital Complex was the service with the largest number of hospitalizations, corresponding to $38.1 \%$. CONCLUSION: Among the patients with cleft lip and / or palate registered in the state of Maranhão during the study period, most are male, brown and aged between 1 and 4 years. There is a large concentration of care in the state capital and in the municipality of Imperatriz, which raises the question about the need for decentralization of care in these centers.

\section{TOTAL ATRIOVENTRICULAR SEPTAL DEFECT: CASE REPORT}

Maria Luiza Vieira dos Santos; Adriano Paiva Sousa; Ághata Gabriela Fonseca de Oliveira; Dara Maria Sá Rêgo; Francisca Luzia Soares Macieira de Araújo; Thiago Gonçalves Araújo e Silva Universidade Federal do Maranhão (UFMA)

INTRODUCTION: Total Atrioventricular Septal Defect (TAVSD) is a congenita heart disease that necessarily contains Interatrial Communication (IAC) and Interventricular Communication (IVC). It represents about 4 to $5 \%$ of congenital heart disease and about $50 \%$ of patients with this problem usually the septum, have Down Syndrome (DS). CASE REPORT: One year old patient, female sex, with DS and lactose intolerance. History of mild heart murmur from birth, tachypnea and low weight gain. On physical examination, she was in good general condition, with weight and height $(63 \mathrm{~cm} ; 6 \mathrm{~kg})$, hydrated, afebrile, eupneic, acyanotic and heart rate of $125 \mathrm{bpm}$. He had a visible and palpable ictus cordis, a low intensity systolic murmur in the mitral focus. Hyperphonetic heart sounds and constant unfolded second sound. The electrocardiogram showed sinus rhythm, with signs of right ventricular overload due to the presence of high voltage $R$ wave in leads $V_{1}$ and $V_{2}$. Echocardiography showed situs solitus, atrioventricular (AV) and ventriculoarterial agreement, volumetric overload of the right heart chambers, trunk and dilated pulmonary branches showing significant pulmonary arterial hypertension. Analysis of the AV septum revealed moderate $8 \mathrm{~mm}$ ostium primum IAC, $8.5 \mathrm{~mm}$ moderate in let type IVC and single AV valve with single valve orifice and multiple reflux points. The right ventricular systolic pressure was $73 \mathrm{mmHg}$. Patient is on the waiting list for surgical correction and close clinical follow-up with a cardiologist using caverdilol $1 \mathrm{mg}$, furosemide $5 \mathrm{mg}$, spironolactone $5 \mathrm{mg}$ and captopril 5mg. CONCLUSION: Drug treatment for symptoms of heart failure resulting from TAVSD is efficient, however in this case immediate surgical correction is necessary to prevent the development of pulmonary vascular disease, especially in DS.

\section{PRE-GAME HEMODYNAMIC PROFILE AND BODY ADIPOSITY INDEX IN} FUTSAL PLAYERS

Ester da Silva Caldas; Bruno Luiz Galvão de Miranda; Diogo Matheus Barros da Silva; Bianca Silva Frazão; Andressa Frazão Pereira; Antonio Coppi Navarro; Marlon Lemos de Araújo

Universidade Federal do Maranhão (UFMA), Centro Universitário Leonardo da Vinci (UNIASSELVI).

INTRODUCTION: The physiological responses in futsal to the internal stress loads resulting from the specificities of the sport modality, imply demands of the systems, especially the cardiovascular system that result in changes in the hemodynamic profile of practitioners, whether professional or leisure sports. In addition, excess body adiposity may further magnify such changes, which when not monitored become predictors of risk. The aim of the present study was to analyze the body adiposity index and the hemodynamic profile of futsal players in the pre-game moment. METHODS: The study is based on the recommendations of Resolution 466/12 of the National Health Council. All variables were collected pre-match. The body adiposity index $(\mathrm{ACl})$ was calculated and classified by the equation and referential values of its protocol. The hemodynamic profile measured by digital method, assessing heart rate (HR), double product (SD), systolic (SBP) and diastolic (DBP) blood pressure, classifying them according to reference values of the Brazilian Arterial Hypertension Directive. Descriptive statistics were performed using Bioestat 5.3 software. RESULTS: The average 
body mass index of $27.8 \pm 5.2 \mathrm{~cm} / \mathrm{m}$ of the players has a normalized classification. Heart rate averaged $89.5 \pm 15.8 \mathrm{bpm}$. Mean systolic blood pressure of $122.4 \pm 12.5 \mathrm{mmHg}$, mean diastolic blood pressure of $77.3 \pm 8.7$ $\mathrm{mmHg}$ were classified in the normal parameters and the double product of $10976.64 \pm 2469.6 \mathrm{mmHg} / \mathrm{bpm}$ considered. normal. CONCLUSION: The study concluded that the players underwent changes in hemodynamic behavior before the game, and may become a factor in sports performance, with the body adiposity index outside the risk values.

130. HEMODYNAMIC, GLYCEMIC ALTERATION AND HIDRIC CONSUMPTION AFTER SESSION OF FITNESS ZUMBA

Bruno Luiz Galvão De Miranda; Diogo Matheus Barros Da Silva; Ester Da Silva Caldas; Roger Medeiros Xavier; Diego Antonio De Jesus Macau; Raphael Furtado Marques; Marlon Lemos De Araújo

Centro Universitário Leonardo da Vinci (UNIASSELVI), Universidade Federal do Maranhão (UFMA)

INTRODUCTION: Zumba fitness is a music-related training modality, its exercises combine dance steps of different rhythms and origins, alternating between different intensities and volumes (short and long). Promoting changes in body composition (specific circumferences and total body mass), high glycemic consumption and caloric expenditure, postural and joint strengthening, and improvements in hemodynamic patterns, directly interfering with the anaerobic and aerobic conditioning of its audience. The objective of this study was to identify changes in dual product and blood glucose at two times (pre and immediately after) after a session of zumba and to correlate the values of both variables (immediately after) with total water consumption (during and immediately after session). METHODS: The sample consisted of 14 students, with aged ( $22.1 \pm 3.2$ years), height (159.3 $\pm 5.4 \mathrm{~cm})$ and total body mass $(55.2 \pm 13.6 \mathrm{~kg})$. The double product and glycemia were collected five minutes before and immediately after the session, with lasting of 50 minutes, in a room of the institution frequented by the sample, with controlled temperature $\left(21^{\circ} \mathrm{C}\right)$ and availability of hydration with water ad libitum. The statistics were performed by BioEstat 5.0 software, using the following tests: Kolmogorov-smirnov, paired student t-test and Pearson correlation. RESULTS: The session caused significant increases and decreases in double product $(p=0.0018)$ and glycemia $(p=0.0098)$ respectively, the average hidric consumption was $476 \mathrm{ml}$. Correlations with hidric consumption were negative, with two degrees respectively (strong and moderate) and without statistical significance ( $p>0.05$ ). CONCLUSION: Therefore, a session of fitness zumba promoted significant hemodynamic and glycemic alterations, although they did not directly affect the amount of hidric consumption in the sample.

\section{TYPE IB CHOLEDOCHAL CYST IN PRESCHOOLER: A CASE REPORT}

Amanda Sávio Correia Araújo; Carla Maria Da Silva Santos; Thales José Ribeiro Gonçalo De Sousa; Caroline Marques Do Nascimento; Juliana Lima Araújo; Cabriel Perlmutter Lago; Neide Cristina Nascimento Santos

Centro Universitário do Maranhão (CEUMA)

INTRODUCTION: Choledochal cysts are a rare bile duct anomalies characterized by disproportionate dilation of the bile duct system. Its incidence is estimated to be 1: 150,000 live births in the West and 1: 1000 in Asia. It has a higher prevalence in females (4:1) and a higher prevalence in the pediatric population $(60 \%)$. It was first described in 1723 by Vater and, in 1977, Todani et al. began to classify them into five types, including intrahepatic cystic dilations. With unknown etiology, it is estimated that the main cause is due to congenital anomalies. Its diagnosis should be advanced in view of the clinical picture, in which abdominal pain, jaundice and palpable abdominal mass make up its classic triad (present in up to $45 \%$ of patients). And, defined, in front of compatible imaging exams. The recommended treatment is surgical, with complete cyst removal, associated with bileodigestive anastomosis. This paper aims to report a case of choledochal cyst type IB, with characteristic evolution in pediatric population. CASE DESCRIPTION: We describe a case of preschooler, 4 years old, female, brown, with abdominal pain, started after food introduction, with mild evolution for 3 years. At 4 years of age, the patient developed severe right-sided abdominal pain in the right hypochondrium, associated with an episode of fever $\left(38^{\circ} \mathrm{C}\right)$, nausea and vomiting, jaundice $\left(++/ 4^{+}\right)$, fecal acolia and hematuria. She sought hospital care, where after performing abdominal tomography, was showed focal dilatation of distal choledoccus with solid nodular image without posterior attenuation inside, measuring $1.3 \mathrm{~cm}$, compatible with type IB choledochal cyst, according to the classification of Todani et al. CONCLUSION: Despite being a rare entity, choledochal cyst is an important cause of jaundice and abdominal pain in children and its early diagnosis and treatment favor the lower risk of later complications.

\section{SCHISTOSOMIASIS IN MARANHÃO: EPIDEMIOLOGICAL PORTRAIT OF THE} DISEASE BETWEEN 2013 AND 2017

Harrison Baldez Reis; Lara Bianca Cardoso Pereira; Beatriz Melo Ribeiro; Indira Odete Amorim de Matos Menezes; Renata Costa Cavalcante

Universidade Estadual do Maranhão (UEMA)

INTRODUCTION: Schistosomiasis is a parasitosis caused by the larvae of the Schistosoma mansoni helminth. The person gets the disease when it comes into contact with fresh water where there are snails infected by the worms that cause schistosomiasis. Thus, this study aims to demonstrate the Maranhão epidemiological survey on cases of schistosomiasis in the period from 2013 to 2017. METHODS: This is an exploratory-descriptive study with quantitative approach. Data collection was performed through data collection from the Information System of Notification Disorders - SINAN, made available by the Department of Informatics of the Unified Health System - DATASUS. RESULTS: Between 2013 and 2017, 132 cases of schistosomiasis were recorded in Maranhão, with the municipality of São Vicente Ferrer being the most affected, with $64(47.76 \%)$ cases, followed by the municipality of Centro do Guilherme, with 32 (24.24). \%) cases. The age group with the largest number of cases was 20 to 39 years old, with 45 (34.09\%). Regarding the gender of the diagnosed population, $98(74.24 \%)$ were male and $34(25.76 \%)$ were female. Regarding cases confirmed by area of residence, $65(49.24 \%)$ were from rural areas and $24(18.18 \%)$ were from urban areas. Regarding the outcome of the disease, it was found that 85 $(64.39 \%)$ patients had a cure and $2(1.51 \%)$ died. CONCLUSION: Therefore, it is noted that the municipality of São Vicente Ferrer was the one that obtained the most records. In addition, there was a predominance in male adults. Thus, it is necessary to improve investments in basic sanitation. This involves building networks and systems for proper collection, treatment and disposal of sewage and drinking water. In addition, educational actions in the control of schistosomiasis are important and should be valued in order to raise the awareness of the population in adopting attitudes that reduce the incidence of the disease.

\section{EPIDEMIOLOGICAL ANALYSIS OF LEPTOSPIROSIS IN MARANHÃO FROM} 2013 TO 2017

Harrison Baldez Reis; Lara Bianca Cardoso Pereira; Beatriz Melo Ribeiro; Renata Costa Cavalcante; Indira Odete Amorim de Matos Menezes; Sílvia Valéria Teixeira Cruz; Ana Carolina Silva de Souza Universidade Estadual do Maranhão (UEMA)

INTRODUCTION: Leptospirosis is an infectious disease transmitted to humans by rodent urine and other animals, especially when flooding occurs, by the bacterium Leptospira. The disease has a high incidence in certain areas, a high hospital cost and a high risk of lethality. Its occurrence is related to the poor conditions of sanitary infrastructure. Thus, this study aims to demonstrate the Maranhão epidemiological survey regarding cases of leptospirosis in the period from 2013 to 2017. METHODS: This is an exploratory-descriptive study with quantitative approach. Data collection was performed through data collection from the Notification Disease Information System - SINAN, made available by the Department of Informatics of the Unified Health System - DATASUS. RESULTS: Between 2013 and 2017, 108 cases of leptospirosis were recorded in Maranhão, with the most affected municipality of São Luís, with 86 (79.63\%) cases. The age group with the largest number of cases was 20 to 39 years old, with 43 $(39.81 \%)$. Regarding the gender of the diagnosed population, $85(78.70 \%)$ were male and $23(21.30 \%)$ were female. Regarding cases confirmed by area of residence, $77(71.30 \%)$ were from the urban area and $24(22.22 \%)$ were from the rural area. Regarding the outcome of the disease, it was found that $77(71.30 \%)$ patients had cure and $18(16.67 \%)$ died. CONCLUSION: Therefore, it is noted that the municipality of São Luís was the one that obtained the most records. In addition, there was a predominance in male adults. Thus, it is necessary to improve investments in basic sanitation. This involves building networks and systems for proper collection, treatment and disposal of sewage and drinking water. In addition, educational actions in the control of leptospirosis should be valued in order to increase the awareness of the population in adopting attitudes that reduce the incidence of the disease. 
134. CLINICAL AND SOCIODEMOGRAPHICAL PROFILE OF DIABETIC PREGNANT IN A SPECIALIZED PRENATAL

Mayllane Lays Barbosa; Cláudia Teresa Frias Rios

Universidade Federal do Maranhão (UFMA); Hospital Universitário Unidade Materno-Infantil (HUUFMA)

INTRODUCTION: Gestational Diabetes Mellitus is defined as a syndrome of metabolic changes resulting from the failure of insulin production and / or the inability of this hormone to act properly in the body, whose onset or detection occurs during pregnancy. This clinical condition is evolutionary and consists of one of the main obstetric complications that the pregnant woman may present due to changes in her hormonal balance. The aim of the study was to characterize women with gestational diabetes regarding their sociodemographic and clinical-obstetric profile. METHODS: Descriptive study with quantitative approach, performed in a University Hospital of São Luís / MA. Forty-six women diagnosed with gestational diabetes were interviewed using a semi-structured form. RESULTS: The analysis of the data showed the prevalence of pregnant women from 26 to 35 years old $(41 \%)$, self-declared brown $(50 \%)$, Ludovicenses $(65 \%)$, housewives $(52 \%)$, in consensual union $(44 \%)$, with complete high school $(43 \%)$ and monthly family income between 1 and 2 minimum wages (39\%). Secondary pregnancies predominated $(63 \%)$, with no history of abortion and previous obstetric complications, with gestational age between 27 and 36 weeks and who had already had 6 or more consultations. Of the total pregnant women in the study, $74 \%$ reported having started prenatal care in the first trimester of pregnancy, $78 \%$ had no regular physical activity and $61 \%$ had a family history of diabetes. CONCLUSION: Through the obtained results it was possible to identify the clinical and sociodemographic profile of the participants, from which it is observed the importance of a qualified assistance, covering not only the biological aspects of the woman, but also the cultural, psychological and family issues. Diabetic pregnant women need specialized prenatal care, since diabetes is an important factor in maternal and fetal morbidity and mortality and requires specific care.

\section{ASSOCIATION BETWEEN HEART RATE AND SUBJECTIVE SLEEP QUALITY IN}

\section{RUNNERS}

Diogo Matheus Barros da Silva; Isabela Mendonça Rodrigues dos Santos; Ester da Silva Caldas; Bruno Luiz Galvão de Miranda; Dayanne Leice Feitosa Barros Dias; Antonio Coppi Navarro; Marlon Lemos de Araújo

Universidade Federal do Maranhão (UFMA), Centro Universitário Leonardo da Vinci (UNIASSELVI), Faculdade Laboro (LABORO)

INTRODUCTION: In street racing, as with all sports, structured planning based on physiological parameters is necessary. Heart rate can be used as intensity parameters for practitioners of street running training programs. Allied to this, it is known that sleep regulates neurophysiological mechanisms influencing the quality of life and cardiovascular responses of the individual, showing importance in sports performance. OBJECTIVE: This study aims to correlate sleep quality with heart rate in high performance runners. METHODS: The study followed the recommendations of Resolution $466 / 12$ of the National Health Council. 12 male suit runners participated in the study, for convenience. Presenting an average age of $29.17 \pm 5.64$ years, height $1.71 \pm 4.6 \mathrm{~cm}$, weight $63 \pm 6.1 \mathrm{~kg}$, body mass index $21.6 \pm 1.2 \mathrm{Kg} / \mathrm{m}^{2}$ classified as normal weight. Heart rate was measured in a training situation using the digital method and subjective sleep quality using the Pittsburgh Sleep Quality Index (PSQI-BR) validated by Bertolazi et al. (2011). BioEstat 5.3 software was used, performing a descriptive analysis followed by the application of the Kolmogorov-Smirnov tests and Pearson correlation adopting $\mathrm{p}<0.05$. RESULTS: There was homogeneity between variables, a moderate negative correlation was observed between subjective sleep quality and heart rate $(R=-0.1520 ; P=0.6373)$, subjects had a mean heart rate of $61.8 \pm 5.3 \mathrm{bpm}$, poor sleep quality. with average score $9 \pm 2.5$, average sleep duration $5.5 \pm 0.8$ hours, which is lower than that proposed for adults. CONCLUSION: Runners have poor sleep quality, presenting a correlation between heart rate and subjective sleep quality. Thus, repair of inappropriate habits is one of the factors that help reduce future cardiovascular problems and sleep disorders.

136. SURGICAL TREATMENT OF PATIENT WITH SYNDACTILIA SINOSTOSIS IN TWO HANDS, AT THE 4th COMMISS

João Victor Carvalho da Paz
INTRODUCTION: Syndactyly is an extremely rare embryological malformation that affects the fingers. It consists of the fusion between two or more fingers or toes, and may occur either in soft tissues (cutaneous syndactyly) or in bones (synostosis). The first case occurs when the fusion occurs in soft parts of the fingers, of simpler surgical solution. The second is the bone fusion of the fingers as is the case presented. CASE DESCRIPTION: Patient has syndactyly synostosis in both hands, with 5 th and 4 th finger joint. A brunner "V" incision was made, plus incision for volar and dorsal commissure per plane. Followed by distal phalanx osteotomy to separate the distal phalanges, a right inguinal skin graft was performed. CONCLUSION: The technique employed proved to be very efficient in that it aims to preserve the functionality of the fingers, providing satisfactory results with low complication rates.

\section{MEMBRANOUS DYSMENORRHEA: CASE REPORT}

Luana Bogea Ribeiro; Luana Lara Farias de Jesus Neves; Rafaella Furtado Perlmutter Lago; Clara Albino de Alencar; Milena Dara Farias de Jesus Neves; Larissa Balby Costa; Fernanda Rachel Melo e Vidigal do ó

Centro Universitário do Maranhão (CEUMA)

INTRODUCTION: Membranous Dysmenorrhea (MD) is a subclassification of dysmenorrhea, being characterized by the elimination of the endometrium or other membrane, shaped like the uterine cavity. The pathology leads to moderate to severe colic pain in the pelvic pain associated with bleeding and elimination of elastic or membranous material. Among the findings in the literature, there are rare cases of the disease. REPORT: A 12-year-old child sought care at a gynecological emergency department, accompanied by acute pelvic pain, radiating to the lumbar region and lower limbs, colic type, VAS 9 . She was wearing an absorbent pad, soaked in a large amount of material. bloody, transvaginal elimination product, similar to placental membrane. She reported her fourth period and was on the first day of her current period. She claims to be a virgin. At ectoscopy: skin-pale pallor ++ 4, suffering facies, easy crying. Flabby abdomen, mild discomfort in hypogastrium and iliac fossae on palpation. Vulva presenting recent, bleeding rupture of the hymenal region. Referred material brought by the patient for histopathological examination. Conclusion of the analysis showed massive scaling of menstrual endometrium, confirming diagnosis of Membranous Dysmenorrhea. Pelvic USC laudated uterus and normal ovaries. The child was referred to an outpatient gynecology and psychology outpatient clinic. CONCLUSION: The seriousness of the disease mediates the clinical findings and their complications associated with the epidemiological profile, with low prevalence and incidence. Thus, it is proven that vaginal expulsion of organic tissue in a woman of childbearing age should be the subject of study. The etiology of endometrial detachment still remains unknown, some studies have related to the intake of hormonal drugs, which is in contrast to the case presented, since the menarche was recent, without the use of return hormonal contraceptives.

\section{EPIDEMIOLOGICAL PROFILE OF VIRAL HEPATITIS CASES IN TERESINA-PI} FROM 2013 TO 2018

Sílvia Valéria Teixeira Cruz; Isadora Feitosa Melo; João Antônio Magalhães Lima Siqueira; Irene Sousa da Silva

Universidade Estadual do Maranhão (UEMA)

INTRODUCTION: Viral hepatitis are diseases caused by different etiological agents, with primary liver tropism. In Brazil, the most common are those caused by viruses A, B and C. They can be transmitted by oral-fecal contagion and by blood contagion. Therefore, prophylaxis is based on personal hygiene and the adoption of specialized vaccines. Treatment occurs according to the type of hepatitis, ranging from rest and hydration to drug use. In Brazil, viral hepatitis is still notorious, making the disease a public health problem. Therefore, reporting and delineating the epidemiology of cases of viral hepatitis in Teresina-PI contributes to the planning and development of preventive actions. METHOD: Quantitative research was conducted through a retrospective epidemiological study from 2013 to 2018, using the Information System. Disclosures (SINAN) as a source of information. The following criteria were analyzed: gender, age group, etiological agent and source of infection. RESULTS: It was found that during the study period 552 new cases of viral hepatitis were reported. Of these, $332(60.1 \%)$ were male. The prevalent age group was 40-59 years old with 214 cases $(38.76 \%)$. Regarding the etiological agent, viruses B and C 
predominated, 233 from virus B $(42.21 \%), 256$ from virus C $(46.37 \%)$. The prevalent source of infection was sexual infection with 76 cases (13.7\%). CONCLUSION: In conclusion, the epidemiological design shows that adult males aged 40-59 years are the most affected and that the prevalent virus was $C$, whose prophylactic vaccine is nonexistent. Thus, it is observed that the prevalence of bad social habits, such as drug abuse and promiscuity, associated with the absence of vaccination are relevant factors in the study of hepatitis. Therefore, the analyzed data reiterate the relevance of the elaboration of educational measures focused on prevention, aiming to reduce the incidence of the disease.

139. THE USE OF INFORMAL SECTOR OF HEALTH CARE BY CHILDREN DISCHARGED FROM THE NEONATAL UNIT

Dina Stefany de Oliveira Moreira; Zeni Carvalho Lamy; Fernando Lamy Filho; Hortênsia Coutinho da Rocha; Marina Uchoa Lopes Ferreira; Lia Cardoso de Aguiar

Universidade Federal do Maranhão. Hospital Universitário Materno Infantil

INTRODUCTION: According to Hellman, health care systems comprise three interrelated sectors: professional, popular and informal. The informal sector encompasses care provided by the individual's family, community, and social networks and can influence professional care, including when it comes to children born preterm. This study aims to understand the influences for the use of the informal sector in the care of children discharged from the Neonatal Intensive Care Unit. METHODS: Qualitative exploratory research, conducted in the two largest public neonatal units in São Luís. Mothers and caregivers of children born between January 2014 and December 2015, residing in São Luís, were included. Those who were in homecare were excluded. The final sample number was determined by the technique of sense saturation. The collection technique was the semistructured interview. Content analysis was performed in the thematic modality. RESULTS: We conducted 14 interviews involving: 13 mothers, 4 grandparents, 1 great-grandmother and 1 aunt. For 9 respondents, the first choice of care was informal sector practices. Self-medication was the most common practice, followed by the use of home remedies. They sought advice from people they thought were more experienced and / or who had experienced similar situations, including other mothers and relatives, especially the grandparents of the children. The use of teas and home remedies was especially influenced by maternal grandmothers. Some also referred to the use of previous medical prescriptions and suggestions from pharmacy clerks. CONCLUSION: The search for informal sector practices was especially influenced by relatives and close relatives, demonstrating the need to involve other people besides father and mother in the child's discharge guidelines. The maternal grandmother should be invited to attend hospitalization and consultations so that she can support the mother.

140. EPIDEMIOLOGICAL PROFILE OF PATIENTS WHO SUFFERED BURNS IN MARANHÃO

Ana Rita da Silva Nunes; Thiago Dutra Mendonça; Naraja Menezes de Souza; Cláudio Henrique de Melo Pereira Filho; Adriano Paiva Sousa

Universidade Federal do Maranhão (UFMA)

INTRODUCTION: Because of the lack of researches about the theme, this study aims to characterize the epidemiological profile of the victims who suffered burns in the state of Maranhão, also to define the predominance of the type of care, urgency or elective care. METHODS: Retrospective, crosssectional, descriptive and quantitative epidemiological study. Based on DATASUS data regarding victims who suffered burns and corrosion from May of 2015 to May of 2019 in the state of Maranhão, totalizing 2106 patients. RESULTS: Predominance of the male sex, $1319(62,63 \%)$ pacientes. Children from 0 to 9 years old are the most affected, $985(46,77 \%)$ of the patients. The most affect color/race is "parda" with $596(28,30 \%)$ patients. The cases were most reported at the Hospital Municipal, in the city of Imperatriz, 727 (34,52\%). CONCLUSION: Therefore, more specific studies about the theme are necessary in order to detail the profile of the most affected group in the state of Maranhão, children, aiming to develop and implement burn prevention programs that would decrease the incidence of burns in this group.

141. THE EPIDEMIOLOGICAL PROFILE OF INTRACRANIAL LESION IN SÃO LUÍS - MA FROM 2015 TO MAY 2019
Ana Rita da Silva Nunes; Thiago Dutra Mendonça; Brenno Raniere da Silva Araújo

Universidade Federal do Maranhão (UFMA)

INTRODUCTION: Intracranial lesion can be defined as a type of Traumatic Brain Injury (TBI), of a non-degenerative or congenital character, that triggers anatomical lesions or functional impairment of the scalp, skull, meninges or encephalon. Thus, this study aimed to describe the epidemiological profile of hospitalized patients with an intracranial lesion in the city of São Luís, Maranhão, between May 2015 and May 2019. METHODS: The epidemiological profile traced is a documentary research with quantitative and retrospective analysis, based on data provided by the Department of Informatics (DATASUS) of Brazil's unified health system (Sistema Único de Saúde [SUS]). Age, sex and ethnicity were considered in the analysis, as well as information such as the main places of care and death rate. RESULTS: in the city of São Luís, there were 3,834 cases of hospitalization and 307 deaths ( $8 \%$ ) due to intracranial lesion between May 2015 and May 2019. Among the hospitalizations, the majority were people aged between 20 and 29 years (21.20\%), maintaining a higher ratio between males (75.74\%), sustaining a 3: 1 incidence in relation to females. Regarding ethnicity, DATASUS reports that $96.40 \%$ of the cases did not have this characteristic described, but in relation to the rest, most people were pardos $(3 \%)$. In addition, the main places of hospitalization of the victims were the Djalma Marques Municipal Hospital (Socorrão I), with $66.77 \%$ of cases and Socorrão II with $25.92 \%$. CONCLUSIONS: TBI represents the most important cause of morbidity and mortality in people under 45 years of age, with the main cause of motor vehicle accidents. Thus, to trace the epidemiological profile of the victims, it becomes an essential tool for the implementation of more effective intervention strategies for the locality with a view to the prevention and reduction of these lesions.

\section{SCHEMIC STROKE IN PEDIATRIC: THE IMPORTANCE OF EARLY DIAGNOSIS}

Rayssa Mayara Rodrigues de Souza; João Marcelo Garcez Alves; Larissa Balby Costa; Gabriela Coutinho Amorim; Thaiana Abas de Moraes Rego; Andreya Sousa Costa; Maria do Perpetuo Socorro de Azevedo Veras

Centro Universitário do Maranhão ( CEUMA)

INTRODUCTION: Stroke is caused by blood interruption in one or more brain areas due to arterial obstruction. This event affects about 2-13/100,000 children, and the ischemic form (Clots) accounts for $60-75 \%$ of cases. Pediatric stroke is known to be predominant in male children, although the reason is unknown. Predisposing factors are complex and diverse, since cardiac causes till maternal infertility. Its clinical presentation varies according to age, etiology and area of the affected parenchyma, with hemiparesis being the most common presentation. The objective of this report is to raise awareness about the importance of early diagnosis of the disease, corroborating with the decrease of sequelae and improving the quality of life of the patient. CASE DESCRIPTION: LCCP, male, 4 years old, brown, born in São Luís-MA, born at term, eutocic birth, APGAR: 7 / 9. At 10 days of life, a low fontanelle, right upper limb bruising and right hemiparesis appeared. Mother reports a history of infertility due to tubal obstruction secondary to endometriosis, thus initiating in vitro fertilization for 1 year. In addition, she reported incomplete prenatal care. The magnetic ressonance of the skull revealed stroke with involvement of the anterior and middle cerebral artery, without surgical indication, but the patient had motor impairment. Therefore, motor physiotherapy and occupational therapy with significant improvement after 6 months of treatment were recommended. CONCLUSION: This study describes a case of pediatric stroke showing close linkage with certain exposures in pregnancy. The diagnosis of neonatal and infant stroke is arduous because the symptoms are unspecific. Therefore, greater investment in preventive measures and training for pediatricians are essential for early recognition despite the variable spectrum of the clinic.

\section{PREGNANT WOMEN'S KNOWLEDGE ABOUT TERATOGENS IN A BASIC} HEALTH UNIT AT SÃO LUÍS - MA

Ana Paula de Castro Ahid; Carolina Almeida SIlva Balluz; Nubya Barros de Araújo Comes; Marcia Rodrigues Veras Batista; Monica Caldas de Oliveira

Universidade CEUMA (UNICEUMA); Centro de Saúde Dra. Maria Ayrecila da Silva Novochadlo. 
INTRODUCTION: Teratogens are substances, organisms, physical agents, or deficiency states that, during the intrauterine period, can cause congenital defects. According to the Pan American Health Organization, congenital defects affect 1:33 children, and it's the second cause of death in new-borns and children under five years-old in the Americas. This research was developed through an intervention project done at a basic health unit in São Luís-MA, between August and September 2018. The general objective was to amplify the knowledge about teratogens on the prevention of congenital defects amongst pregnant women as well as to health care professionals responsible for prenatal consultations. METHODS: The research's sample was compound by 38 pregnant women. Data collection occurred through socioeconomic and gestational questionnaires, pre and post-tests about pregnant women's knowledge over teratogens, in addition to consultation's forms filled by health care providers. RESULTS: The profile was of pregnant women between 18 and 27 years old, in stable unions, that completed high school, housewives, with familiar income until 1 minimal wage. Around $16.1 \%$ stopped alcohol use upon finding out about pregnancy, $6.4 \%$ ingested only once and $3.2 \%$ in addition to ingesting alcohol at least once a month, smoked 3 to 4 cigarettes per day. Amongst those pregnant women who used medications, most could not specify which. Among 30 pregnant women who answered the pre-test, $30 \%$ had a low performance, however in the post-test this variable reduced to $7 \%$. Twenty-one consultation's forms were collected, and of the 6 pregnant women who did not know the importance of folic acid, 5 did not participate in the project. CONCLUSION: These results show that educational actions with pregnant women and health professionals collaborate with the prevention of congenital defects related to the main known teratogens, and therefore, more actions like those are essential, especially in primary health care.

\section{RELAPSING BRONCOESOPHAGEAL FYSTULA: A CASE REPORT}

Adriano Stênio Cenaro; Paula Armada Firmino; Aldicléya Lima Luz; Melina Costa Sereno; Letícia Coretti Moura Neto; Maria de Jesus Mendes Oliveira; Járison Lopes da Silva Universidade Federal do Maranhão (UFMA)

INTRODUCTION: Bronchoesophageal fistula (BEF) are abnormal communications between the esophagus and the bronchial network. They are usually diagnosed in a neonatal period and are rare in adults. Among the most common causes are iatrogenesis, ingestion of chemicals substances, chronic processes and trauma. The case report is unique by describing an adult BEF, a foreign body report, that relapsed four years into a recurrence database. Patient agrees to one session of this case report. CASE PRESENTATION: JPR, male, 36 years. He complains of frequent choking and recurrent cough. Foreign body ingestion (coin) at age nine, retained for 20 years in the esophagus, being complicated by pleural empyema. He presented BEF with surgical treatment on 9/2014. Currently, the patient evolves with repeat patients and right chest expansion. Spirometry of $1 / 25 / 2019$ confirms marked obstructive ventilatory disorder, with reduced forced vital capacity, ranging from bronchodilator use, with no return to normal pulmonary function. Chest tomography on $6 / 6 / 19$ demonstrated esophageal dilatation in the upper thoracic region, with communication in the right pulmonary cavity, and volumetric fall in an important area of atelectasis, affecting the entire medial lobe, part of the right upper and lower lobe. He is not clinical condition for surgical correction of BEF, should be distancing from professional and academic activities. Follows presentation mild dyspnea in ventile environment and dysphagia. Current weight of $35 \mathrm{~kg}$. CONCLUSION: Patient remains in clinical treatment so far. After further examinations and consultation with the surgical team, there is a proposal for stent resolution surgery, which presents rare complication and recurrence rates, showing promising prospects for the case in question.

145. PROFILE OF THE USE OF PSYCHOACTIVE SUBSTANCES AMONG STUDENTS OF A PUBLIC UNIVERSITY

Cícera Natália da Silva Rodrigues; Eduardo da Silva Pereira; Jesimarcus Guerra de Oliveira; Alexsander Silva de Oliveira; Guilherme Alfredo Wilsen; Pedro Gustavo Moura de Sousa; Aldicleya Lima Luz

Universidade Federal do Maranhão (UFMA)

INTRODUCTION: The use of psychoactive substances (PAS) has increased significantly in recent years, with the beginning of use increasingly early, especially among college students. This paper aims to outline the profile of psychoactive substance use among academics at the Federal University of Maranhão (UFMA). METHODS: Descriptive, cross-sectional and quantitative study, conducted with 60 students from the medical, nursing, food engineering and law courses of UFMA, during 2018, requesting the participation of the guardian with prior consent (ICF). The variables were statistically analyzed using the software SPSS version 22. A survey was conducted on the subject, based on publications in the databases Scielo, Medline and Pubmed, using descriptors in psychoactive substance Decs. RESULTS: of the 60 respondents, $51.7 \%$ were male, with a mean age of 22.26 years; As for housing, $60 \%$ live with their families, with a monthly family income higher than 4 salaries $(43.3 \%)$. When asked which SPA used at least once in their lives $78.3 \%$ answered alcohol, $71.7 \%$ caffeine and $20 \%$ cannabis; In the last 12 months, $68.3 \%$ reported alcohol use, $60 \%$ caffeine and $13.3 \%$ marijuana; and in the last 30 days, $43.3 \%$ reported using alcohol, $55 \%$ caffeine and $5 \%$ cannabis. The average age in relation to the first time using SPA was 13.66 , with alcohol $75 \%$ of the time. Regarding alcohol, the most consumed drink is beer (77.27\%), and $69 \%$ drink up to 4 drinks, with a monthly frequency of $38 \%$. The favorite places are bars $(54.7 \%)$, in the company of friends $(85.7 \%)$, with entertainment $(86.05 \%)$ the reason for the consumption; $16.6 \%$ say they drive after use and $14.2 \%$ missed activities the next day. CONCLUSION: The consumption of PAS among university students is a worrying factor regarding the health of this population. Thus, changes in habits and awareness campaigns among university students are necessary.

\section{MICA-2: MEDICAL STUDENT'S ATTITUDE REGARDING MENTAL ILLNESS AND PSICHIATRY}

Maira Letícia Souza de Carvalho; Ricardo Tadeu Villa; André Felipe Carvalho Lobato; Paloma Larissa Arruda Lopes Universidade Federal do Maranhão

INTRODUCTION: During your graduation, medical students are instruct to care for their mental health and their patient's, through the study of subjects as Medical Psychology, Psychiatry and Medicine and Spirituality. Even though, they present high incidence of mental illness, such as anxiety, depression, Burnout Syndrome and suicidal ideas. The following study aims to analyze the stigmatization level among medical students and their attitude for learning and acting towards mental illness and the reality they live with. METHODS: Transversal study applied as an online form (Coogle Form) on classes from the first to the twelfth term of Medical School at Federal University of Maranhão - São Luís Campus. The translated questionnaire, Mental Illness - Clinician's Attitude Scale - MICA-2, presents sixteen affirmatives categorized in five groups of stigmatization of mental illness and the psychiatry field, totalizing um scale from 16 to 96 points. The total average, categorical and per cycle (basic, clinical and internship) were evaluated. RESULTS: 101 responses were registered (22,8\% from basic cycle, $43,6 \%$ from clinical and 33,6\% from internship). The total average was 39,24 points. In categorical analysis, a higher stigma were observed for "personal diagnosis disclosure" and "view of mental illness and Psychiatry". Small difference was noticed among the score presented among cycles (basic 40,78; clinical - 38,53; internship - 38,52). CONCLUSION: Despite of the scientific knowledge available, medical students presented a moderated stigma rate towards mental illness, evidenced, mostly, in their personal lives. The small difference observed among cycles demand further investigation to identify the reason for maintaining this behavior, allowing a curricular intervention that provide an attitude changing during academic training.

\section{THE FACILITATING INITIATIVES IN THE PEDIATRIC PALLIATIVE CARE}

Ághata Gabriela Fonseca de Oliveira; Jacqueline Dutra Nascimento Moreira; Hortência Coutinho da Rocha; Zeni Carvalho Lamy UNIVERSIDADE FEDERAL DO MARANHÃO (UFMA)

INTRODUCTION: The palliative care establishes an integral, active and holistic assistance aiming to improve the quality of life of patients and their families facing life threatening conditions. This type of care is still in progress in the pediatric area amid technological advances that allow the survival of children, once it was previously considered not possible. It is relevant to note that this progress is permeated by specific particularities of this age group and the health professionals have difficulty indicating the Pediatric Palliative Care (PPC). Given this panorama, this study aims to recognize aspects that facilitates the assistance of children in palliative care. METHODS: Qualitative exploratory study of phenomenological type. Developed in a university hospital in the state of Maranhão from March to May of 2018. The data were collected from focus groups, addressing matters related to the knowledge, perceptions and experiences regarding PPC of 
these professionals. The choice of group of study was intentional composed by 32 professionals from the sectors involved on the research. The speeches were analyzed using the Van Manen approach. RESULTS: the facilitating initiatives identified by speech analysis are: the pursuit for team integration; multiprofessional approach to family and child; permanent health education; and the conception and discussion of the PPC in the context of the Singular Therapeutic Plan (STP). CONCLUSION: Presently, it is observed the predominance of the biomedical model in care practice, resulting in care fragmentation. However, the professionals recognize interventions with the adoption of techniques designed from the perspective of soft-hard technology, as the STP, being able to strengthen and facilitate PPC practices. Furthermore, the patient protagonism, the integrated work and the recognition of the worker are also presented as components of this scenario.

\section{VAGINAL STENOSIS AS A MANIFESTATION OF STEVENS JOHNSON SYNDROME: A CASE REPORT}

Lara Eliza Sousa Leitao; José Estevam Ribeiro Júnior; Jordana Araújo da Silva; Luís Augusto Silva Batista; Rebeca Mousinho Pestana de Oliveira; Cláudio Vinicius Araújo Pinheiro

Universidade Federal do Maranhão (UFMA)

INTRODUCTION: Stevens Johnson Syndrome (SJS) is a delayed skin hypersensitivity reaction that affects both the skin and mucous membranes; Furthermore in adults is mainly associated with drugs and neoplasms. The clinical condition is characterized by nonspecific symptoms, such as fever, in addition to the aforementioned, and may also evolve with adhesions in the GIT, urinary incontinence or vaginal stenosis. The objective is so to report vaginal stenosis as part of SJS, which led to the diagnosis, along with transvaginal US. CASE DESCRIPTION: Female, 29 years old, CoPoAo (pregnancy, parity and abortion), LMP: 22.02.2017, menarche: 12 years, 28day and 5-day flow cycles, deny dysmenorrhea, victim of severe accident in 2014, with brain mass loss (half of Broca's Area) and with SJS due to use of lamotrigine. It refers to difficulty in sexual relations, with incomplete penetration due to mucosal resistance, live bleeding and clots in the cervix. Stenosis of $1 / 3$ of the proximal vagina (maintaining patency for menstrual flow) with worsening to the touch, establishing a blind bottom. Digital touch communication was performed, with moderate output of coagulated blood. The evaluations performed by transvaginal US, in addition to get such findings confirmed, showed a womb in avf, vol: $5.92 \times 3.8 \mathrm{~cm}$, right ovary: $4.8 \mathrm{~cm} 3$ and left ovary: $7.1 \mathrm{~cm} 3$. Advised on the surgical possibility and use of dilator, 12 after the initial consultation, the patient returns to the office for guidance on the use of dilators. Initiates use of ABSOLOO in purple color, with good evolution, decrease in bleeding after digital exploration and no resistance of the mucosa to be ruptured. CONCLUSION: SJS is a large condition and needs a holistic approach. In this report, besides vaginal stenosis, bleeding and resistance of the vaginal mucosa during sexual intercourse. The therapeutic proposal of the use of vaginal dilator proved satisfactory, significantly reducing the discomfort during intercourse.

\section{SIGNIFICANCE OF THE EFFECTIVE REMNANT LIVER VOLUME IN MAJOR} HEPATECTOMIES

Joama Marques Lobo Quariguasi; Águida Shelda Alencar Santos; Gustavo Weyber Pereira Alves; Isabela Coelho Simão; Ozimo Pereira Gama Filho

Universidade Federal do Maranhão (UFMA)

BACKGROUND: Liver resection of tumors may put patients at risk for postoperative liver failure. The magnitude of the risk depends mainly on the volume and function of the future remaining liver (FLR). The volume of FLR required to prevent postoperative liver failure depends on the patient, disease and anatomy. Rapid FLR expansion can be safely performed with portal venous embolization of contralateral hepatic segments. There is no agreement on the preoperative measurement of liver volumes and the safe minimum size of the liver remnant after enlarged hepatectomy. METHODS: In 10 patients with hepatobiliary malignancy and without underlying chronic liver disease, volumetric FLR measurements (segments 2, $3+/-1$ ) were obtained before extended right lobectomy. FLR proportions for total liver volume were calculated using a formula based on body surface area. In 3 patients, the response to preoperative right trisectoral portal vein embolization was evaluated. In 10 patients undergoing planned resection, preoperative volumes were correlated with biochemical and clinical parameters. RESULTS: Perioperative characteristics did not differ between patients with or without portal vein embolization: duration of surgery (541 min $\pm 67 \times 486$ min \pm 97 , respectively), estimated blood loss $(1097 \mathrm{~mL} \pm$ $567 \times 896 \mathrm{~mL} \pm 562)$, transfusions ( $2.5 \mathrm{u} \pm 1.5 \times 1.5 \mathrm{u} \pm 1.5$ ), length of stay ( 14 days $\pm 5 \times 12$ days \pm 8 ). There were no biliary or septic complications, no perioperative mortality or mortality within 3 months after resections. 2 patients had major complications (prolonged ileus and jaundice; ascites and wound separation). CONCLUSIONS: A simple measurement method provides an evaluation of the liver remnant prior to resection. It is useful in assessing portal vein embolization response and predicting outcome before extended liver resections.

\section{REPEAT HEPATIC RESECTION AS EFFECTIVE TREATMENT OF RECURRENT} COLORECTAL LIVER METASTASES

Joama Marques Lobo Quariguasi; Amanda Marques Muniz; Milena Vasconcelos Falcão; Ceraldo José Coelho Granja Filho; Isabelle Arruda Cavalcante Souza; Ozimo Pereira Gama Filho Universidade Federal do Maranhão (UFMA)

PURPOSE: Liver resection is calculated as a single curative treatment modality for colorectal liver metastasis. Two or more hepatectomies are applied to treat recurrent metastases. Available from the risk and viability of hepatectomy, such as the prognostic factors after surgery. METHODS: This is a retrospective study that examined a survival of patients with repeated liver resection for recurrent colorectal metastases. Records of 35 patients undergoing liver surgery were reviewed between January 2008 and December 2018. Recurrence promoted in 28 patients with a syndrome being confined to the liver in 19 patients. 12 were highlighted to resect the bruise and compose a study population. RESULTS: 12 patients (mean: 63 years) developed liver-confined recurrence within 14 months after a hepatectomy. In 3 patients, the cancer had an area close to the resection line and remote sites of the first liver resection site. In 8 patients, it was located at remote sites of the first liver resection. In 1 patient, it was located in the same area as the original liver resection. A morbidity was $20 \%$. 6 patients died of recurrent disease, with disease-free median survival of 9 months. Four patients had a second relapsed resection at 6,18 and 24 months, respectively, after liver resection. One of the 4 patients had a liver resection for liver recurrence and is still alive with no evidence of disease. 3 patients are alive, 1 without a history of disease, with an average follow-up of 18 months. CONCLUSION: A repeated hepatectomy is necessary, effective and safe for the treatment of recurrent colorectal liver metastasis. Mortality, morbidity and survival are children after initial resection.

\section{EVALUATION OF CHRONIC PAIN AND NEUROPSYCOLOGICAL COMORBIDITY IN HYPERTENSE INDIVIDUALS}

Thamires Sales Ribeiro; Emanuel Cabral Pereira; Mateus Ribeiro Conçalves Carvalho; Déborah Costa Alves; Andreia Coimbra Sousa; Lucas Leonardo Lavra Dias; Plínio Cunha Leal

Universidade Federal do Maranhão, Centro Universitário do Maranhão

INTRODUCTION: Recent studies have shown that systemic arteria hypertension may be related to both hypo and hyperalgesic pain. However, such studies did not make an association with other variables, such as emotional states and sleep quality, which influence the perception of pain in individuals. METHODS: Quantitative, observational, analytical, casecontrol study. The sample chosen was made up of 103 participants of both genders, ageds 18 years, divided into three groups: normotensive, diagnosed and undergoing hypertension, and undiagnosed and untreated hypertension. Scientifically validated questionnaires specific to each variable analyzed were used. RESULTS: Regarding the history of diseases, the medications in use and the diagnosis of headache, diabetes, dyslipidemia and the use of medications were more frequent among diagnosed and undergoing hypertension, as well as the most used classes of drugs (anti hypertensive, antidiabetic and others), while migraine was less frequent in this group. In the other variables analyzed (general health conditions, chronic pain levels, psychometric data and sleep quality), there were no statistically significant differences. CONCLUSION: There was an inversely proportional association between the diagnosis of migraine and the presence of hypertension under treatment. There was no association between levels of chronic pain, neuropsychological comorbidities and changes in systemic blood pressure.

\section{EPIDEMIOLOGICAL DESIGN OF TUBERCULOSIS CASES IN MARANHÃO} 2013 TO 2018 
Lara Bianca Cardoso Pereira; Harrison Baldez Reis; Ana Carolina Silva de Souza; Indira Odete Amorim de Matos Menezes; Beatriz Melo Ribeiro; Renata Costa Cavalcante; Sílvia Valéria Teixeira Cruz Universidade Estadual do Maranhão

INTRODUCTION: Tuberculosis is caused by Koch's Bacillus and It is transmitted by inhalation of aerosols from the airway, mainly affecting the lungs and affecting other organs. Common symptoms are dry or productive cough for more than three weeks, evening fever and night sweats. Diagnosis can be made by rapid testing and / or sputum analysis, and the main prophylaxis is vaccination. In Brazil, the disease is an important public health problem and it is compulsorily reported. The present work aims to epidemiologically delineate tuberculosis cases in Maranhão from 2013 to 2018. METHODS: The quantitative research was carried out through retrospective epidemiological study, using as confirmed information sources the notified cases of tuberculosis in the Reporting Disease Information System- SINAN. RESULTS: It was found that, during the study period, 14475 cases of tuberculosis were reported, of which $4745(32.7 \%)$ were residents of São Luís. The age range of 20-39 years and males were prevalent, with $6246(43,1 \%)$ and $9361(64.7 \%)$ cases, in that order. It was also observed that $7740(53.5 \%)$ patients did not perform the TB Rapid Test and another $4641(32.1 \%)$ had undefined data. In addition, $8981(62.5 \%)$ cases had no Directly Observed Treatment (DOT). As for the outcome, $9014(63.3 \%)$ were cured, $1522(10.5 \%)$ abandoned the treatment and $989(6.8 \%)$ died CONCLUSION: Therefore, the epidemiological design shows that the most affected are adult men, and targets for disease control should be returned to this public. The high cure rate shows the excellence of the treatment offered, however, the predominance of patients who did not undergo the TB Rapid Test and DOT ratify the need for constant discussion about actions in the Health System of Maranhão. In addition, the remarkable percentage of data in white disrupts the articulation of the latter, being essential to qualify professionals involved in the information process.

153. CONSUMPTION OF FOOD SUPPLEMENTS BY PEOPLE OF PHYSICAL ACTIVITY IN SAO LUÍS-MA

Ruthlene Correa Da Silva Paixão; Simone Cantanhede Martins; Waleria Sthephani Mendonça De Oliveira; Fabiana Viana Macie Rodrigues; Matheus Caíck Santos Brandão; Raphael Furtado Marques; Marcos Roberto Campos de Macêdo Faculdade Estácio São Luís

INTRODUCTION: In Brazil, the use of nutritional supplements has increased alarmingly in gyms and clubs where physical activities are performed. In this context, nutritional supplements are widely used by athletes, large scale consumers and an important target group for this multi-million dolla industry, but have also been courted by the public within gyms. In addition, the indication of supplements by unprofessional people characterizes a crime and irregular practice of the profession, as such individuals do not have technical knowledge which can cause serious harm to the consumer's health. Thus, the present study aimed to evaluate the consumption of dietary supplements by practitioners of physical activity in a gym in. METHODS: This is a descriptive, cross-sectional study with a quantitative approach, composed of 30 respondents. A socioeconomic profile questionnaire and a food consumption questionnaire consisting of 12 questions were applied to evaluate the use of dietary supplements. For data tabulation and analysis, the Microsoft Excel version 2010 program was used. RESULTS: The results showed that $23,0 \%(n=07)$ of the practitioners were using some type of dietary supplement and only $14,0 \%(n=01)$ of them used the advice of a nutritionist to choose and use supplements, which shows that $86,0 \%(n=06)$ used a simple indication of friends/family, gym instructo or other professionals to choose and use consume food supplements. CONCLUSION: Through this study it was found that most respondents do no consume dietary supplements. However, as for the individuals who declared to do some type of supplementation, it was observed that the main objective is the gain of muscle mass and that use is made without the guidance of the nutritionist.

154

INSTITUTIONAL ANALYSIS OF TUBERCULOSIS ON CEARÁ STATE FROM 2015 TO 2018

Nathaly Vitória Portela Santos; Jéssica Magalhães de Barros; Ítalan de lesus Portela Santos; Italo Constâncio de Oliveira

Universidade Federal do Cariri (UFCA) e Universidade Federal do Maranhão (UFMA)
INTRODUCTION: Tuberculosis (TB) is a infectious disease caused by bacterium Mycobacterium tuberculosis and is transmited through elimination of bacillus in the environment. In the last years, it has been in evidence because of the appear of multiresistant strains that reduce treatment efficiency. That is why, in 2016, The World Health Organization (OMS), recognized TB as the infectious disease that kills the most around the world. Therefore, our objective is to analyze data of its incidence in Ceará, observe the main social groups reached and evidence the need to reverse this situation. METHODOLOGY: It is a retrospective and quantitative study of notified tuberculosis cases in Ceará in the period from 2015 to 2018. Epidemiological collection was done with Notification of Harm Information System (SINAN). The variables of the study are: age, more affected gender and ending situation. The data were analyzed graphically using Microsoft Excel 2010. RESULTS: There were 16776 notified cases in the analyzed region and time set. As the entry type, it was verified $79,7 \%$ of new cases, $3,2 \%$ of transferences, $5,9 \%$ of relapse and regression after case abandonment was of $10,3 \%$. Between 2016 and 2018 , occurrence prevailed on male gender $(67 \%)$ and people of both sexes aged between 20 and $39(43,5 \%)$. As the ending cases sistuation, $53 \%$ reached cure, $8,6 \%$ were transfered, $12,4 \%$ abandonned the treatment and $2,8 \%$ died. CONCLUSION: New cases are in evidence, set an alarming situation e confirms the problematic of multiresistant strains. Furthermore, the high treatment abandon level denotes the persistence of inffection and transmission origins, promoting raise in mortality and relapse and favoring the development of multiresistant bacillus strains, hampering cure process and increasing time and cost of treatment.

\section{LEISHMANIASIS AND HIV CO-INFECTION: EPIDEMIOLOGY BY AGE BANDS} IN MARANHÃO

Julia Beatriz Borges Coelho Duarte Feitosa; Ada Cristina Mendes Freitas; Valéria Carvalho Ribeiro

Centro Universitário Do Estado Do Maranhão (UNICEUMA)

INTRODUCTION: Visceral leishmaniasis, also known as kalazar, is a protozoosis which has in its etiology the complex of flagellate protozoa Leishmania Donovani. Brazil is responsible for $90 \%$ of cases in Latin America. 0 The objective of this paper is to point out the cities that presented the largest number of cases in Maranhão, between 2015 and 2017 , as well as correlating the cases with the age groups and possible coinfections with the HIV virus. RESULTS: During the chosen range from 2015 to 2017,2122 cases of visceral leishmaniasis were found Maranhão and 221 cases of co-infection with HIV, equivalent to about $10 \%$ of the total of cases. In addition, in the data collected by IBGE microregion of residence the two microregions with the highest incidence were: São Luís with 78 cases and the Middle Mearim with 32 cases. Equality was observed among these microregions in the range with the highest number of cases, being between 20-39 years old, bringing $t$ ogether the equivalent of 43 cases in São Luís and 16 cases in the Middle Mearim. METHODOLOGY: Study epidemiological study of co-infection of visceral leishmaniasis with the HIV virus, according to age group, performed from the analysis of the database of the DATASUS for Maranhão in the triennium from 2015 to 2017. CONCLUSION: The analysis of These results show the high prevalence of HIV virus coinfection with Leishmaniasis In view of this, it is necessary to screen patients with Leishmania, given that they are more susceptible to immunology, they can be also carriers of the HIV virus. Leishmaniasis is a disease of great expression in the Maranhão epidemiology and cannot be neglected by public health.

This work is licensed under a Creative Commons Attribution 4.0 International License

ISSN 2076-6327

This journal is published by the University Library System, University of Pittsburgh as part of the Digital Publishing Program and is co-sponsored by the University of Pittsburgh Press. 